\title{
Instrument Validation Project
}

\author{
B. A. Reynolds \\ E. A. Daymo \\ J. G. H. Geeting \\ J. Zhang
}

June 1996

Prepared for

the U.S. Department of Energy

under Contract DE-AC06-76RLO 1830

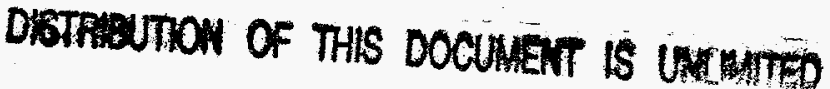

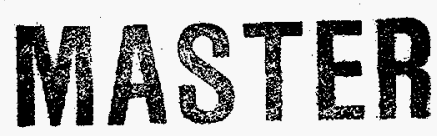

Pacific Northwest National Laboratory

Richland, Washington 99352 


\section{DISCLAIMER}

This report was prepared as an account of work sponsored by an agency of the United States Government. Neither the United States Government nor any agency thereof, nor any of their employees, make any warranty, express or implied, or assumes any legal liabiijty or responsibility for the accuracy, completeness, or usefulness of any information, apparatus, product, or process disclosed, or represents that its use would not infringe privately owned rights. Reference herein to any specilic commercial product, process, or service by trade name, trademark, manufacturer, or otherwise does not necessarily constitute or imply its endorsement, recommendation, or favoring by the United States Goverument or any agency thereof. The views and opinions of authors expressed herein do not necessarily state or reflect those of the United States Government or any agency thereof. 


\section{DISCLAIMER}

Portions of this document may be illegible electronic image products. Images are produced from the best available original document. 


\section{Summary}

Westinghouse Hanford Company Project W-211 is responsible for providing the system capabilities to remove radioactive waste from ten double-shell tanks used to store radioactive wastes on the Hanford Site in Richland, Washington. The project is also responsible for measuring tank waste slurry properties prior to injection into pipeline systems, including the Replacement of Cross-Site Transfer System (WHC Project W-058).

This report summarizes studies of the appropriateness of the instrumentation specified for use in Project W-211. The instruments were evaluated in a test loop with simulated slurries that covered the range of properties specified in the functional design criteria. The study also evaluated the design of the test loop itself against a less compact design (an "Ideal" loop) and the specified instruments were compared to several alternative pieces of instrumentation.

The results of the study indicate that the compact nature of the baseline Project W-211 loop does not result in reduced instrumental accuracy resulting from poor flow profile development. Of the baseline instrumentation, the Micromotion densimeter, the Moore Industries thermocouple, the Fischer \& Porter magnetic flow meter, and the Red Valve Pressure transducer meet the desired instrumental accuracy. An alternate magnetic flow meter (Yokagawa) gave nearly identical results as the baseline Fischer \& Porter. The Micromotion flow meter did not meet the desired instrument accuracy but could potentially be calibrated so that it would meet the criteria.

The Nametre on-line viscometer did not meet the desired instrumental accuracy and is not recommended as a quantitative instrument although it does provide qualitative information. Measuring the pressure drop over the test loop provides comparable data with comparable accuracies and directly measures one of the most important parameters in the operation of the cross site transfer line: pressure drop.

The recommended minimum set of instrumentation necessary to ensure the slurry meets the Project W-058 acceptance criteria is the Micromotion mass flow meter (measuring density, flow rate, and temperature) and delta pressure cells. The Moore Industries thermocouple is redundant. The Micromotion flow meter can substitute for the Yokagawa and Fisher \& Porter flow meters provided it is properly calibrated. 



\section{Acronyms and Abbreviations}

AC alternating current

cP centipoise

CRC Handbook of Chemistry and Physics

DC direct current

DP delta pressure

DSTs double-shell tanks

FBRM focussed beam reflectance method

FDC functional design criteria

HP horsepower

$\mathrm{Hz}$ hertz

ICFKH ICF Kaiser Hanford

IVF Instrument Validation Facility

P pressure

$\mathrm{Pa} \quad$ Pascal

PCA principle component analysis

PLC programmable logic controller

PLS partial least squares

PNNL Pacific Northwest National Laboratory

PSD particle size distribution 
RPM revolutions per minute

VIP variable importance in the projection

WHC Westinghouse Hanford Company 


\section{Contents}

Summary $\ldots \ldots \ldots \ldots \ldots \ldots \ldots \ldots \ldots \ldots \ldots \ldots \ldots \ldots \ldots \ldots \ldots \ldots \ldots \ldots \ldots$

Acronyms and Abbreviations $\ldots \ldots \ldots \ldots \ldots \ldots \ldots \ldots \ldots \ldots \ldots \ldots \ldots \ldots \ldots \ldots \ldots$

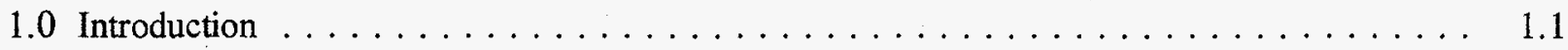

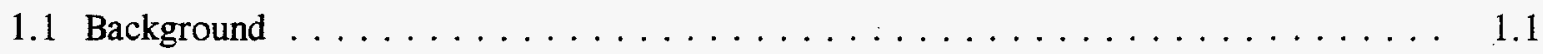

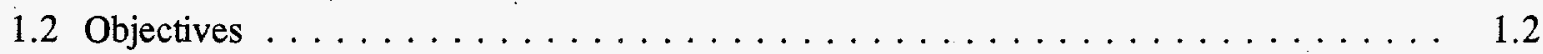

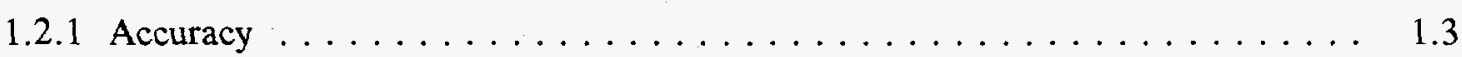

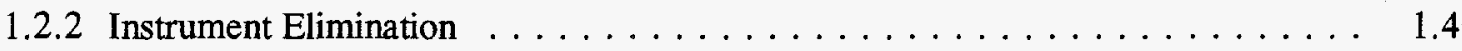

1.2.3 Instrument Loop Verification $\ldots \ldots \ldots \ldots \ldots \ldots \ldots \ldots \ldots$

1.2.4 Evaluate Alternate Instruments $\ldots \ldots \ldots \ldots \ldots \ldots \ldots \ldots \ldots$

1.3 Experimental Approach $\ldots \ldots \ldots \ldots \ldots \ldots \ldots \ldots \ldots \ldots \ldots \ldots \ldots$

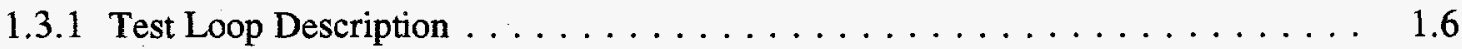

1.3.2 Test Loop Instrumentation $\ldots \ldots \ldots \ldots \ldots \ldots \ldots \ldots \ldots \ldots \ldots$

2.0 Experimental Instrumentation and Procedures $\ldots \ldots \ldots \ldots \ldots \ldots \ldots \ldots \ldots$

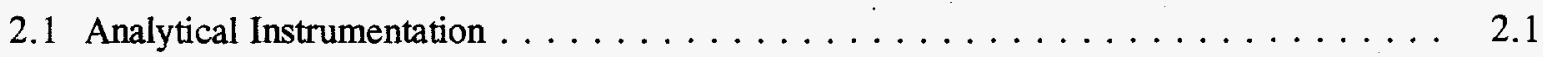

2.1 .1 Haake Rheometer $\ldots \ldots \ldots \ldots \ldots \ldots \ldots \ldots \ldots \ldots \ldots \ldots \ldots$

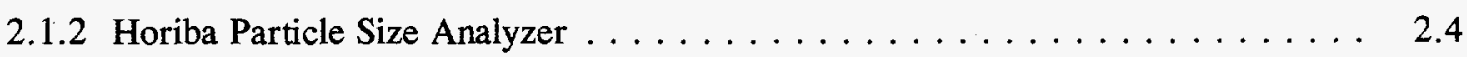

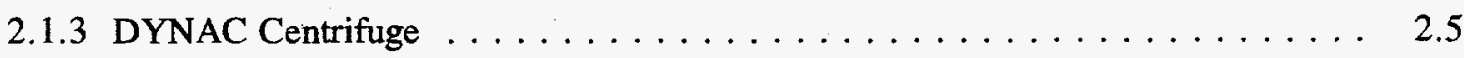

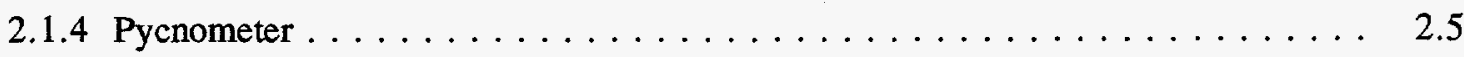

2.2 Experimental Procedure $\ldots \ldots \ldots \ldots \ldots \ldots \ldots \ldots \ldots \ldots \ldots \ldots \ldots \ldots \ldots$

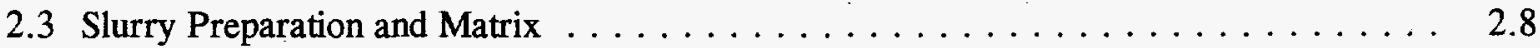

2.4 Experimental Text Matrix and Data $\ldots \ldots \ldots \ldots \ldots \ldots \ldots \ldots \ldots \ldots$

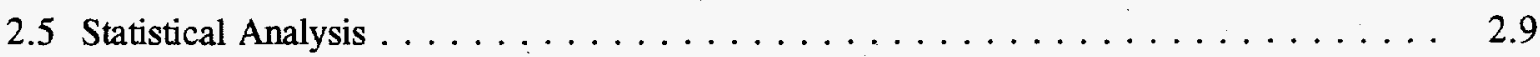


3.0 Results and Discussion

3.1 General Observations

3.1.1 Temperature

3.1.2 Vibration

3.2 W-211 vs. "Ideal" Loop

3.3 Instrument Validation

3.3.1 Pressure

3.3.2 Temperature

3.3.3 Density

3.3.4 Viscosity

3.3.5 Flow Rates

3.3.6 Particle Size Distribution Measurement

3.4 Instrument Elimination

3.4.1 Temperature

3.5 Multivariate Statistical Analysis Results

3.5.1 Viscosity Multivariate Analysis

3.5.2 Solids Concentration Multivariate Analysis

3.5.3 Particle Size Multivariate Analysis

3.5.4 Flow Rate Error Multivariate Analysis

4.0 Conclusions and Recommendations:

4.1 Instrument Validation Conclusions

4.2 Instrument Elimination Conclusions

4.3 Test Loop Design Conclusions

4.4 Evaluation of Alternate Instrumentation 
5.0 References

6.0 Appendices

6.1

Appendix A - Detailed Loop Designs

A. 1

Appendix B - Simulant Development

B. 1

Appendix C - Experimental Data

C. 1

Appendix D - Statistical Analysis Results

D. 1

Appendix E - Lasentec Calibration

E. 1 


\section{Figures}

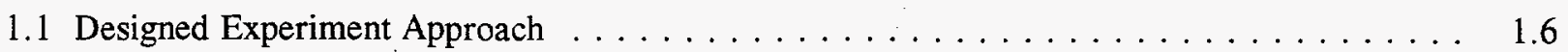

1.2 Test Loop Schematic $\ldots \ldots \ldots \ldots \ldots \ldots \ldots \ldots \ldots \ldots \ldots \ldots \ldots \ldots$

1.3 Nametre Preferred Installation Configuration $\ldots \ldots \ldots \ldots \ldots \ldots \ldots \ldots$

1.4 Lasentec Particle Size Measurement Method . . . . . . . . . . . . . . . . . . . 1.13

1.5 Lasentec Particle Size Distribution for Unknown Sample in Run 8C $\ldots \ldots \ldots \ldots$

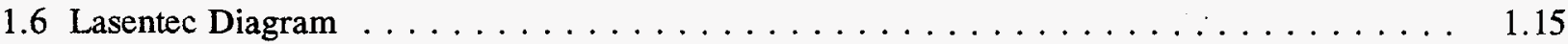

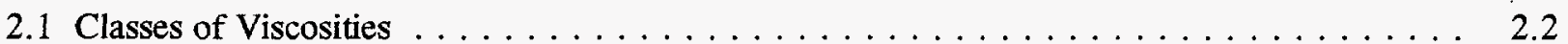

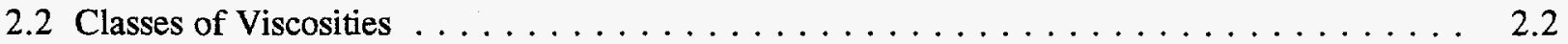

2.3 Typical Particle Size Distribution from Horiba $\ldots \ldots \ldots \ldots \ldots \ldots \ldots$

3.1 Rosemount vs. Red Valve Pressure $\ldots \ldots \ldots \ldots \ldots \ldots \ldots \ldots \ldots \ldots$

3.2 Thermocouple Comparison $\ldots \ldots \ldots \ldots \ldots \ldots \ldots \ldots \ldots \ldots \ldots$

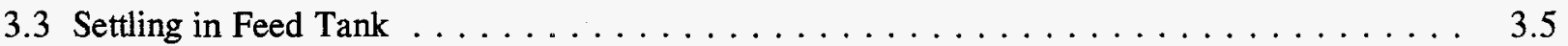

3.4 Test Loop Density vs. Feed Tank Density $\ldots \ldots \ldots \ldots \ldots \ldots \ldots \ldots \ldots$

3.5 Micromotion Density vs. Average S-3\& S-4 Density, Air Runs Included $\ldots \ldots \ldots \ldots$. . . 3.7

3.6 Micromotion Density vs. Average S-3 \& S-4 Density, Air Runs Excluded $\ldots \ldots \ldots \ldots$

3.7 Micromotion Density vs. Calibrated Vessel Density $\ldots \ldots \ldots \ldots \ldots \ldots$

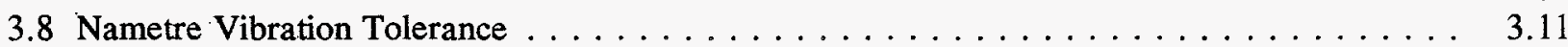

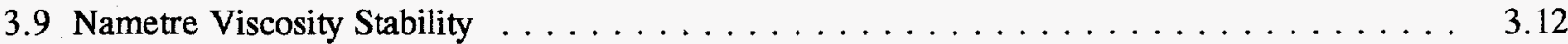

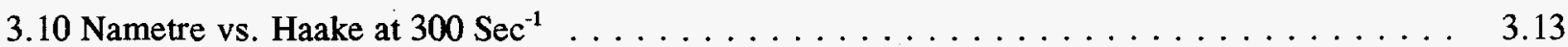

3.11 Nametre vs. Haake at $1000 \mathrm{Sec}^{-1} \ldots \ldots \ldots \ldots \ldots \ldots \ldots \ldots \ldots \ldots \ldots$ 
3.12 Nametre vs. Haake at $4084^{-1}$ Seconds

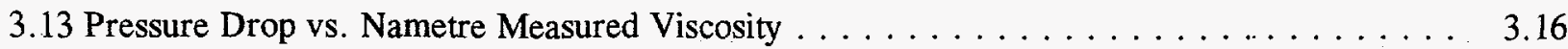

3.14 Haake Viscosity vs. Back Calculated Viscosity $\ldots \ldots \ldots \ldots \ldots \ldots \ldots \ldots$

3.15 Back Calculated vs. Laboratory Measured Consistency Parameters . . . . . . . . . . . 3.21

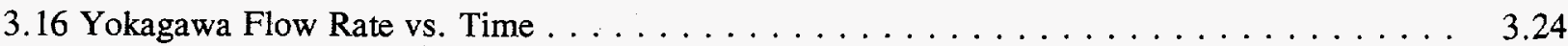

3.17 Yokagawa Instrument Volumetric Flow Rate $\ldots \ldots \ldots \ldots \ldots \ldots \ldots \ldots \ldots$

3.18 Fischer \& Porter Volumetric Flow Rate $\ldots \ldots \ldots \ldots \ldots \ldots \ldots \ldots \ldots$

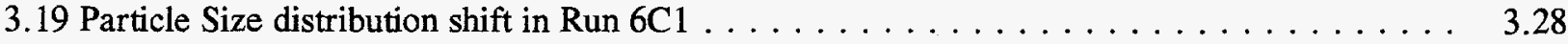

3.20 Lasentec Color Effects . . . . . . . . . . . . . . . . . . . . . . . . . . . . . . . . . 3.29

3.21 Impact of Bubbles on Measured Particle Sizes $\ldots \ldots \ldots \ldots \ldots \ldots \ldots$

3.22 Lasentec vs. Horiba Particle Size Distributions $\ldots \ldots \ldots \ldots \ldots \ldots \ldots \ldots$

3.23 Model Overview $\ldots \ldots \ldots \ldots \ldots \ldots \ldots \ldots \ldots \ldots \ldots \ldots \ldots \ldots \ldots$

3.24 VIP Plot of Haake to Measured Parameters $\ldots \ldots \ldots \ldots \ldots \ldots \ldots \ldots \ldots \ldots$

3.25 Predicted vs. Observed Viscosity $\ldots \ldots \ldots \ldots \ldots \ldots \ldots \ldots \ldots \ldots \ldots \ldots \ldots$

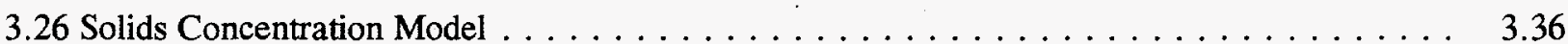

3.27 VIP Plot for Solids Concentration $\ldots \ldots \ldots \ldots \ldots \ldots \ldots \ldots \ldots \ldots$

3.28 Predicted Solids Loading vs. Observed Solids Loading $\ldots \ldots \ldots \ldots$. . . . . . . . . . 3.37

3.29 Particle Size Model . . . . . . . . . . . . . . . . . . . . . . . . . . 3.38 


\section{Tables}

1.1 Project $W-211$ Design Criteria $\ldots \ldots \ldots \ldots \ldots \ldots \ldots \ldots \ldots \ldots \ldots$

1.2 Acceptable Accuracies for Instrumentation $\ldots \ldots \ldots \ldots \ldots \ldots \ldots \ldots \ldots \ldots \ldots$

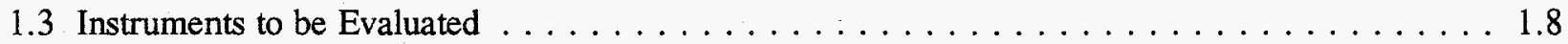

1.4 Instrument Cross-Check and Validation $\ldots \ldots \ldots \ldots \ldots \ldots \ldots \ldots$

3.1 Horiba PSD Instrument Repeatability with Run 4A "Ideal" Loop Sample . . . . . . . . . . . 3.30 


\subsection{Introduction}

Westinghouse Hanford Company (WHC) Project W-211 is responsible for providing the system capabilities to remove radioactive waste from ten of the Hanford Site's double-shell tanks (DSTs). The project is also responsible for measuring tank waste slurry properties prior to injection into pipeline systems, including the Replacement of Cross-Site Transfer System (WHC Project W-058).

WHC Project W-211 requested that Pacific Northwest National Laboratory (PNNL) construct and operate an Instrument Validation Facility (IVF) test loop to determine if the selected instruments and proposed instrument loop configuration function as intended to measure specific slurry characteristics and to recommend the minimum suite of instruments to provide reasonable assurance that the waste can be pumped.

\subsection{Background}

Project W-211 is designed to remove radioactive waste from ten DSTs used to store radioactive wastes on the Hanford Site and condition those wastes for transport via underground cross site transfer pipelines. The project is responsible for ensuring that wastes are suitably conditioned and meet the W-058 specification for transport. Project personnel will also install an instrument loop with selected instrumentation to measure the properties of importance for slurry transport and for use in process control of the conditioning of the waste feed.

The pertinent slurry characteristics for which Project W-211 is being designed (Table 1.1) have been set forth in the functional design criteria (FDC) for Project W-211, Initial Tank Retrieval Systems, (WHCSD-W-211-FDC-001, Rev. 2):

The Project W-211 Project specified the following instruments as part of the instrument loop:

- Micromotion Mass Flow Meter, Densimeter

- Nametre Viscometer

- Moore Thermocouple

- Red Valve Pressure

- Fischer \& Porter Flow Meter

- Moore Industries Thermocouple 
Table 1.1. Project W-211 Design Criteria

\begin{tabular}{|c|c|c|}
\hline Process Parameter & Nominal & Range \\
\hline Slurry Viscosity ${ }^{(a)}$ & $10 \mathrm{cP}$ & $1.0-30.0 \mathrm{cP}$ \\
\hline Solid Content $\mathrm{t}^{(\mathrm{b}, \mathrm{c})}$ & 20 vol $\%$ & 0.0 to 30.0 volume $\%$ \\
\hline Specific Gravity & 1.25 & $1.0-1.5$ \\
\hline Miller Number & $<100$ & \\
\hline Particle Size ${ }^{(d)}$ & 0.5 to 4000 microns & \\
\hline Minimum pH: & 11.0 & \\
\hline Design Velocity: ${ }^{(\mathrm{e})}$ & $6 \mathrm{ft} / \mathrm{sec}$ & $4.5-6 \mathrm{ft} / \mathrm{sec}$ \\
\hline Temperature (flushes) & $35^{\circ} \mathrm{F}$ to $200^{\circ} \mathrm{F}\left(2^{\circ} \mathrm{C}\right.$ to $\left.93^{\circ} \mathrm{C}\right)$ & \\
\hline Friction Factor & Newtonian Flow & \\
\hline \multicolumn{3}{|c|}{$\begin{array}{l}\text { (a) Ranges were taken from Rev. } 1 \text { of the FDC. } \\
\text { (b) } \mathrm{C}_{\mathrm{v}}=\left(1-\mathrm{M}_{\mathrm{l}} / \mathrm{V}_{\mathrm{t}} \rho_{\mathrm{l}}\right) \text { where, } \mathrm{C}_{\mathrm{v}}=\text { solids concentration by volume, } \mathrm{M}_{1}=\text { mass of liquid, } \\
\mathrm{V}_{\mathrm{t}}=\text { total sample volume } \rho_{1}=\text { liquid density. } \\
\text { (c) The } 30 \text { vol\% solids for the purposes of this project is defined as true volume percent } \\
\text { solids. The volume percent settled solids and the volume percent centrifuged solids } \\
\text { were measured for comparison to the settled solids volume fraction, which is the basis } \\
\text { for the Project W- } 058 \text { volume\% solids slurry acceptance criterion. } \\
\text { (d) Guidance on the particle size distributions are not specified in the Project } \mathrm{W}-211 \mathrm{FDC} \text {. } \\
\text { However, since some guidance was needed to prepare the slurries, the information was } \\
\text { taken from the } \mathrm{W}-058 \text { FDC. Specifically, } \leq 50 \text { micron particles will comprise } \\
\text { approximately } 95 \% \text { of the total, } 50-500 \text { micron particles will comprise }<5 \% \text { of the } \\
\text { total and } 500-4,000 \text { micron particles will comprise }<1 \% \text { of the total. } \\
\text { (e) } 4.5 \mathrm{ft} / \mathrm{sec} \text { is based on a slurry viscosity of } 30 \mathrm{cP} ; 6.0 \mathrm{ft} / \mathrm{sec} \text { is based on a slurry } \\
\text { viscosity of } 10 \mathrm{cP} \text {. }\end{array}$} \\
\hline
\end{tabular}

\subsection{Objectives}

The four main objectives of the IVF project were to

- determine the accuracy of the instruments

- eliminate unnecessary instruments 
- verify adequacy of instrument design and ability for process control

- evaluate alternate instruments.

Each of the four objectives will be discussed in the following subsections.

\subsubsection{Accuracy}

The first and principal goal of the IVF project was to determine whether the specific brands of instruments specified for the WHC Project W-211 instrument loop adequately measured the desired slurry properties over a broad range of physical properties. A corollary to this testing is that specific types of technologies were also evaluated. Alternate brands of instruments that use these technologies could potentially be substituted at a later date if needed.

Each instrument's accuracy was determined by the degree to which the measurement matched that of a "fundamental measurement" (i.e., a measurement that involves only length/volume, time, and mass) and/or a laboratory measurement. ICF Kaiser Hanford (ICF KH) and WHC staff provided guidance on the level of accuracy required for the instruments to be considered acceptable for use in the test loop (see Table 1.2).

A secondary goal was to determine the instrument and instrument loop performance at off-normal process conditions.

Table 1.2. Acceptable Accuracies for Instrumentation

\begin{tabular}{|l|l|l|l|}
\hline \multicolumn{1}{|c|}{ Instrument } & $\begin{array}{c}\text { Acceptable } \\
\text { Accuracy }\end{array}$ & \multicolumn{1}{|c|}{ Reference Standard } & \multicolumn{1}{|c|}{$\begin{array}{c}\text { Reference Standard } \\
\text { Accuracy }\end{array}$} \\
\hline Micromotion Density & $+/-5 \%$ & Laboratory Pycnometer & $\pm 0: 1 \%$ \\
\hline Micromotion Mass Flow Rate & $+/-5 \%$ & $\begin{array}{l}\text { Volumetric Calibration } \\
\text { Tank }\end{array}$ & $\pm 1.2 \%$ \\
\hline Pressure (Red Valve) & $+/-1 \%$ & Instrument Calibration & Not Applicable \\
\hline Temperature (Moore Industries) & $+1-1 \%$ & Instrument Calibration & Not Applicable \\
\hline Fischer \& Porter Volumetric Flow & $+/-1 \%$ & $\begin{array}{l}\text { Volumetric Calibration } \\
\text { Tank }\end{array}$ & $\pm 1.2 \%$ \\
\hline Yokagawa Volumetric Flow & $+/-2 \%$ & $\begin{array}{l}\text { Volumetric Calibration } \\
\text { Tank }\end{array}$ & $\pm 1.2 \%$ \\
\hline Viscosity (Nametre) & $+/-10 \%$ & $\begin{array}{l}\text { Haake Laboratory } \\
\text { Rheometer }\end{array}$ & $\pm 1.0 \%$ \\
\hline (a) See Section 3.3.5 for derivation of this value. & & \\
\hline
\end{tabular}


The final goal was to determine if the IVF operators and engineers could determine slurry characteristics on-line. This interpretive test used the knowledge generated in testing known, well quantified slurries to interpret the readings of an unknown slurry.

There were three primary components to the experimental work to evaluate the accuracy goals:

1. Rheological simulants were prepared to span the range of slurry properties specified in the Project W-211 FDC. The instruments were tested and the results compared to lab data and/or fundamental measurements.

2. The flow rate was varied and air bubbles were introduced to test off-normal conditions. (Note that bubbles are likely to always be present in tank wastes and may be normally present in the simulants as well.)

3. Blind interpretive tests were run to find out whether operators could determine slurry characteristics without prior knowledge of the feed with in-line instruments only. The blind test simulant, which may not meet the W-058 transport criteria but was made from the solids tested, was injected into the pipe loop. The test operator(s) and engineer(s) relied solely on the in-line instruments to measure the physical properties of the slurry and determined whether the feed was within the allowable transport specifications. After the blind tests were completed, the interpretive tests were treated like all of the other simulants and were used in the statistical analyses.

\subsubsection{Instrument Elimination}

The second objective was to determine if the number of instruments specified by ICF KH and WHC could be reduced. Instruments are expensive to service and replace in a radioactive environment and the fewer instruments installed, the greater the cost savings to the operation of the system. Reducing the number of instruments would reduce the space requirements in the tank farm valve pits, lower the operational cost of the facility, and lower the frequency of forced shutdowns due to instrument failure.

All the instruments were tested with a broad range of physical simulants and a multivariate analysis was used to search for relationships between important process variables (e.g., viscosity, density, flow rate, PSD, etc.) that might be difficult to find otherwise. Fewer instruments were recommended if strong correlations can be made. Redundant instruments were recommended for removal where possible.

\subsubsection{Instrument Loop Verification}

The third objective was to verify that the proposed instruments function adequately in the valve pit as designed. The instrument loop designed for WHC Project W-211 was believed to be adequate for measuring the desired slurry characteristics; however, instruments were placed in positions where it was suspected that the flow would probably not be fully developed. (This loop is replicated in the IVF facility and is called the Project W-211 loop. An alternate test loop was installed and called the "ideal" loop.) The 
proximity of instruments to elbows and other instruments may have resulted in inaccurate readings if fullydeveloped flow was not achieved. If the instruments adequately measured the slurry properties to the desired accuracy in the Project W-211 loop, the expense involved in designing and constructing a new instrument pit could be avoided.

The design of the instrument loop was evaluated by comparing the performance of each instrument in the "ideal" and Project W-211 loops to look for synergistic (or antagonistic) effects. This comparison helped separate poor performance resulting from an inadequate test-loop design from an inadequate instrument. It also established a best-case baseline against which informed decisions can be made about whether alternate instrument configurations in the Project W-211 test loop should be considered. Knowledge of this baseline could prevent unnecessary trial and error runs if the instrument performance is not adequate in the Project W-211 loop. The baseline was used to establish the best-case accuracy performance expected for the various instruments.

The experimental approach used for this objective was to compare the instrument performance in the Project W-211 loop to the performance in the best-case "ideal" loop. If poor performance was seen in the Project W-211 loop, it could be determined if the poor performance was caused by flow conditions or by instrument performance and if. "adequate" performance (see Table 1.2) can be attained in the "ideal" test loop.

\subsubsection{Evaluate Alternate Instruments}

The fourth objective was to evaluate selected alternate instruments. If the performance of any of the specified instrumentation is not adequate, additional and/or different instruments would be evaluated to measure the desired slurry characteristics.

A Fischer \& Porter DC-driven magnetic flowmeter was evaluated head to head against the Yokogawa Dual Frequency magnetic flowmeter to determine if it enhanced the performance of the test loop. DCdriven magnetic flowmeters are known for having low drift, whereas AC-driven magnetic flowmeters experience less noise when measuring slurry volumetric flowrate.

A Lasentec particle size distribution (PSD) analyzer was installed to determine if solids concentration or PSD could be determined. The Replacement of Cross-Site Transfer System (Project W-058) has delineated solids concentration and PSD limitations. Although no instruments specified for use in the Project W-211 design, directly measure the solids concentration or PSD, it was postulated that viscosity, density, mass flow rate, and perhaps other measured quantities could provide an adequate estimate for these two unknown parameters.

\subsection{Experimental Approach}

The slurry properties varied and tested were the slurry specific gravity, viscosity, and solids content. These properties were anticipated to be largely determined by the characteristics of the carrier 
liquid, the solids selected, and the particle sizes of the solids tested. Each of these three parameters was characterized by a low and a high specification limit. There were eight combinations of these three values and they can be thought of as the corners of a cube (see Figure 1.1). Simulants were developed to represent each combination of low and high values of these three parameters. The combination of high specific gravity and low solids content was not feasible. The initial low solids content, low specific gravity combination were modified during the course of a run by adding solids to test interior points in this cube. The interior line in Figure 1.1 represents the relationship between solids loading and slurry density. See Section 2.3 for a description of the experimental procedures.

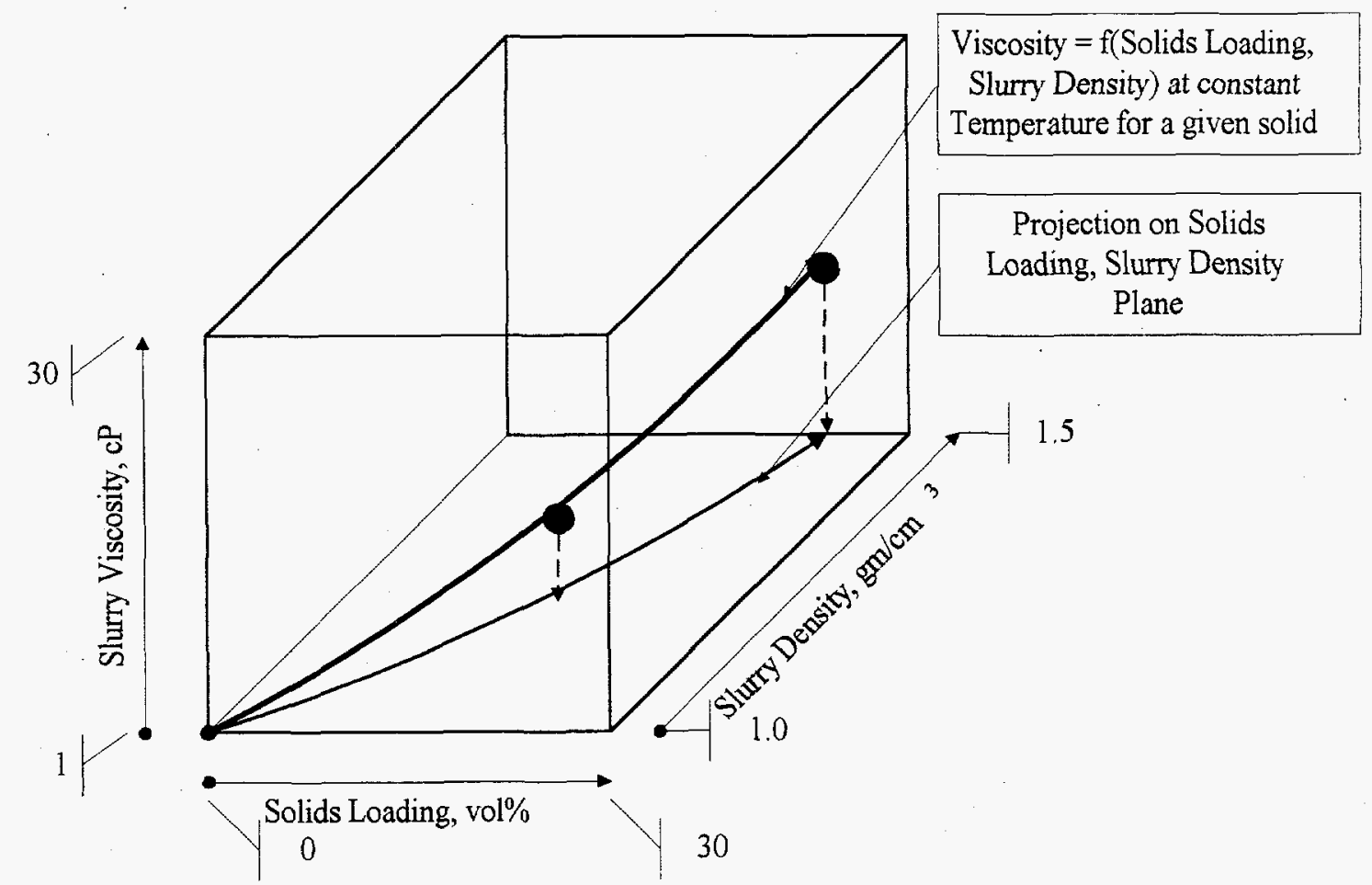

Figure 1.1. Designed Experiment Approach

\subsubsection{Test Loop Description}

The Instrument Validation Facility (IVF) is located on the mezzanine levels of the 336 Building. Detailed drawings of the IVF are found in Appendix A. The pump, feed tank, and calibration tank are located on the ground level and the instrumentation is located on the second and third mezzanine levels. The piping is 3 -inch schedule 40 stainless steel. The programmable logic controller and data acquisition system are located on the ground floor near a display panel for many of the instruments used in the test loop.

The IVF is a slurry test loop designed to evaluate various instruments at various slurry flow rates. Figure 1.2 shows a schematic of the IVF. It consists of a 250 gallon feed tank and a $225 \mathrm{gpm}$ centrifugal pump which can pump simulant to either one of two test loops with the instruments installed. The 


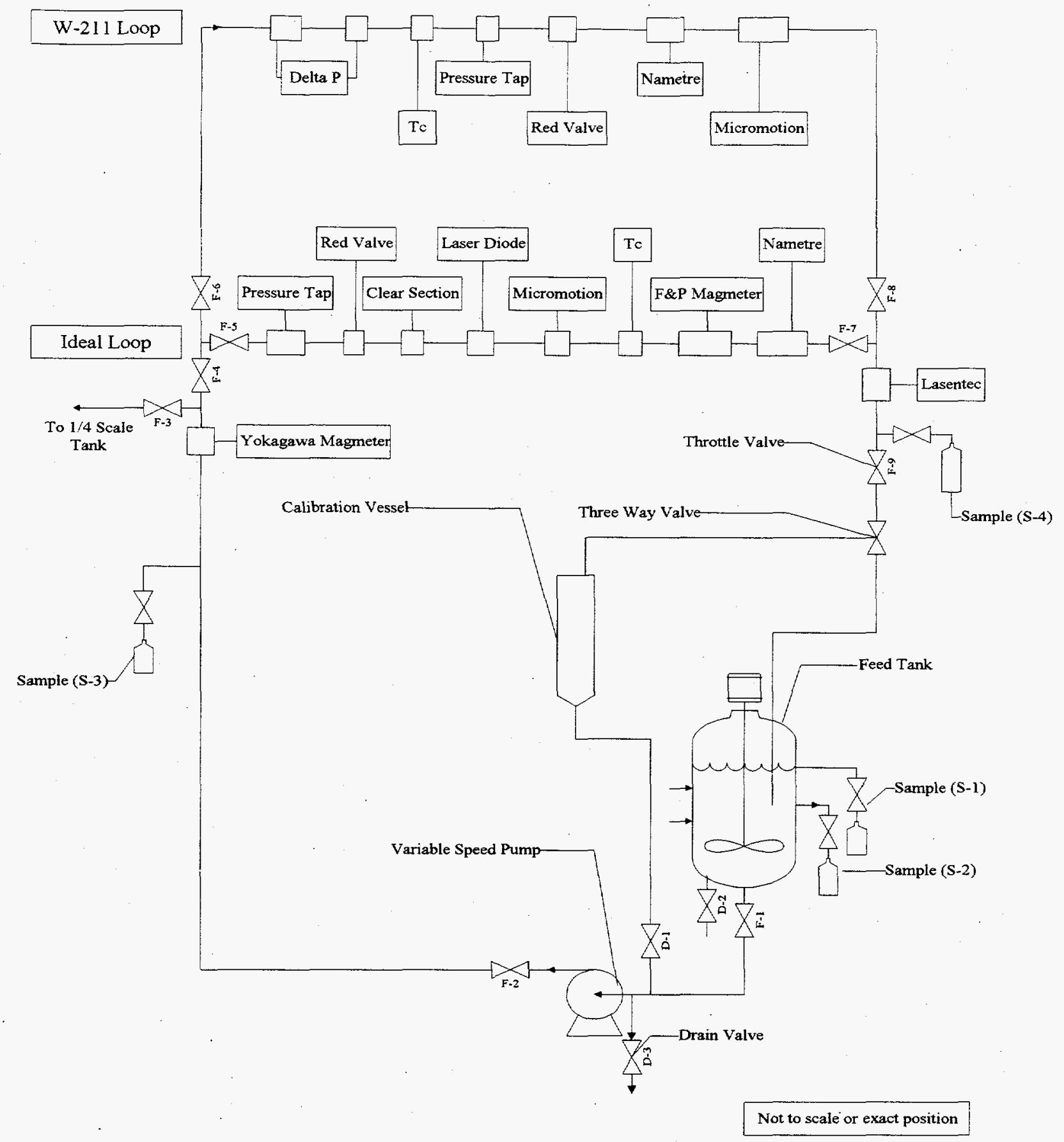

Figure 1.2. Test Loop Schematic

two test loops are teed off common up-flow and down-flow pipes. The Lasentec Particle Size Analyzer was mounted in the common down-flow leg of the two loops. The Yokagawa was mounted in the common up-flow leg of the two loops. 


\subsubsection{Project W-211 Loop}

The Project W-211 instrument loop is located on the third level, 42 feet above ground level. The pipe size, instrument configuration, and spacing matches that proposed in the Title I design of the upgraded valve pits for Project W-211.

\subsubsection{2 "Ideal" Loop}

The "ideal" flow instrument loop is located on the second level, approximately 33 feet above ground level. Instruments in this loop are spaced so that a more fully developed flow profile exists at each measuring point. (Completely developed flow profiles would require approximately 10 feet between instruments and this was not possible in any reasonable loop design.) Vibrational interference, between the Nametre in-line viscometer and the Micromotion mass flow meter were expected to be virtually eliminated because the instruments were adequately spaced.

\subsubsection{Test Loop Instrumentation}

The instrumentation evaluated is described in this section and shown in Table 1.3.

Table 1.3. Instruments to be Evaluated

\begin{tabular}{|c|c|c|}
\hline Property & Project W-211 Specified & PNNL Supplemental \\
\hline \multirow[t]{2}{*}{ Mass Flow Rate } & Micromotion mass flow meter & \\
\hline & $\begin{array}{l}\text { Fischer and Porter magnetic (DC) } \\
\text { flowmeter }\end{array}$ & Yokogawa magnetic (AC) flowmeter \\
\hline Pressure & Red Valve pressure sensor & \\
\hline Pressure Drop & & $\begin{array}{l}\text { Rosemount Differential Pressure } \\
\text { Transmitter with Remote Seal } \\
\text { Assembly }\end{array}$ \\
\hline \multirow[t]{2}{*}{ Temperature } & Moore Industries Thermocouple & \\
\hline & Micromotion Flow Meter & \\
\hline Viscosity & Nametre in-line vibrating ball viscometer & \\
\hline Density & Micromotion Flow Meter & \\
\hline $\begin{array}{l}\text { Particle Size } \\
\text { Distribution }\end{array}$ & & Lasentec PSD analyzer \\
\hline Solids Loading & & Lasentec PSD Analyzer \\
\hline
\end{tabular}


Table 1.4 lists the instruments evaluated and the planned method of cross checking and validating the evaluated instrument measurement.

Table 1.4. Instrument Cross-Check and Validation

\begin{tabular}{|c|c|}
\hline Instrument & Method of Measurement Cross-check and Validation \\
\hline \multirow[t]{2}{*}{ Micromotion Mass Flow Flowmeter } & 1. Divert system flow for set time to calibrated vessel and weigh. \\
\hline & 2. Compare to other flowrate instruments (i.e., volumetric) \\
\hline \multirow[t]{2}{*}{ Density } & 1. Divert system flow to calibrated vessel, weigh. \\
\hline & 2. Take grab sample, measure density in laboratory. \\
\hline Moore Industries & 1. System thermocouples. \\
\hline \multirow[t]{2}{*}{ Fischer \& Porter Flowmeter } & $\begin{array}{l}\text { 1. Divert system flow for set time to calibrated vessel and } \\
\text { weigh. }\end{array}$ \\
\hline & 2. Compare to other flowrate instruments. \\
\hline \multirow[t]{2}{*}{ Yokogawa Flowmeter } & $\begin{array}{l}\text { 1. Divert system flow for set time to calibrated vessel and } \\
\text { weigh. }\end{array}$ \\
\hline & 2. Compare to other flowrate instruments. \\
\hline Red Valve Pressure Sensor & 1. Compare to Pressure gauges in system. \\
\hline \multirow[t]{2}{*}{ Nametre Viscometer } & 1. Grab sample, measure viscosity in laboratory. \\
\hline & $\begin{array}{l}\text { 2. Measure } \Delta \mathrm{P} \text { across the Micromotion mass flowmeter. } \\
\text { Since the flowrate is known, the viscosity can be derived. }\end{array}$ \\
\hline \multirow[t]{2}{*}{ Lasentec PSD Analyzer } & 1. Knowledge of PSD in feed. \\
\hline & 2. Grab sample, measure PSD in laboratory. \\
\hline
\end{tabular}

\subsubsection{Nametre Viscoliner}

The Nametre Viscoliner operates using the torsion-oscillation principle which moves the sensor at resonance $(~-650 \mathrm{~Hz})$ at constant amplitude (1 micrometer). The manufacturer states that this method of operation gives the instrument excellent accuracy over a broad viscosity range. This, however, means that the Nametre measurement is affected by high-frequency, high-energy, mechanical vibrations translated by the process. When the viscosity changes, the Nametre Viscoliner varies the power input to maintain a constant oscillation amplitude. The power requirement is proportional to the viscosity. 
For mounting within a pipeline, Nametre recommends installing the viscometer in a piping tee with the flow impinging on the sensor as shown in Figure 1.3. Flexible piping ( 3 feet minimum) or vibration dampening baffles are recommended if mechanical noise dampening is required. These vibration dampening devices were not used because they would not fit in the Project W-211 test loop and because they would not stand up to the radiation environment.

A. This distance should be the minimum distance as dictated by the clearance needed to fasten the flange. This eliminates stagnant flow between the flange face and the outer edge of incoming flow.

B. First hand tighten all nuts; then stagger tighten to $40 \mathrm{ft} \mathrm{lbs}$. The viscometer flange must be flush mounted to process flange--no uneven torque.

C. Flexible piping ( $3 \mathrm{ft}$ minimum) or vibration dampening baffles.

D. Couple pipe section to a stable member such as a floor, wall or structural member of the building.

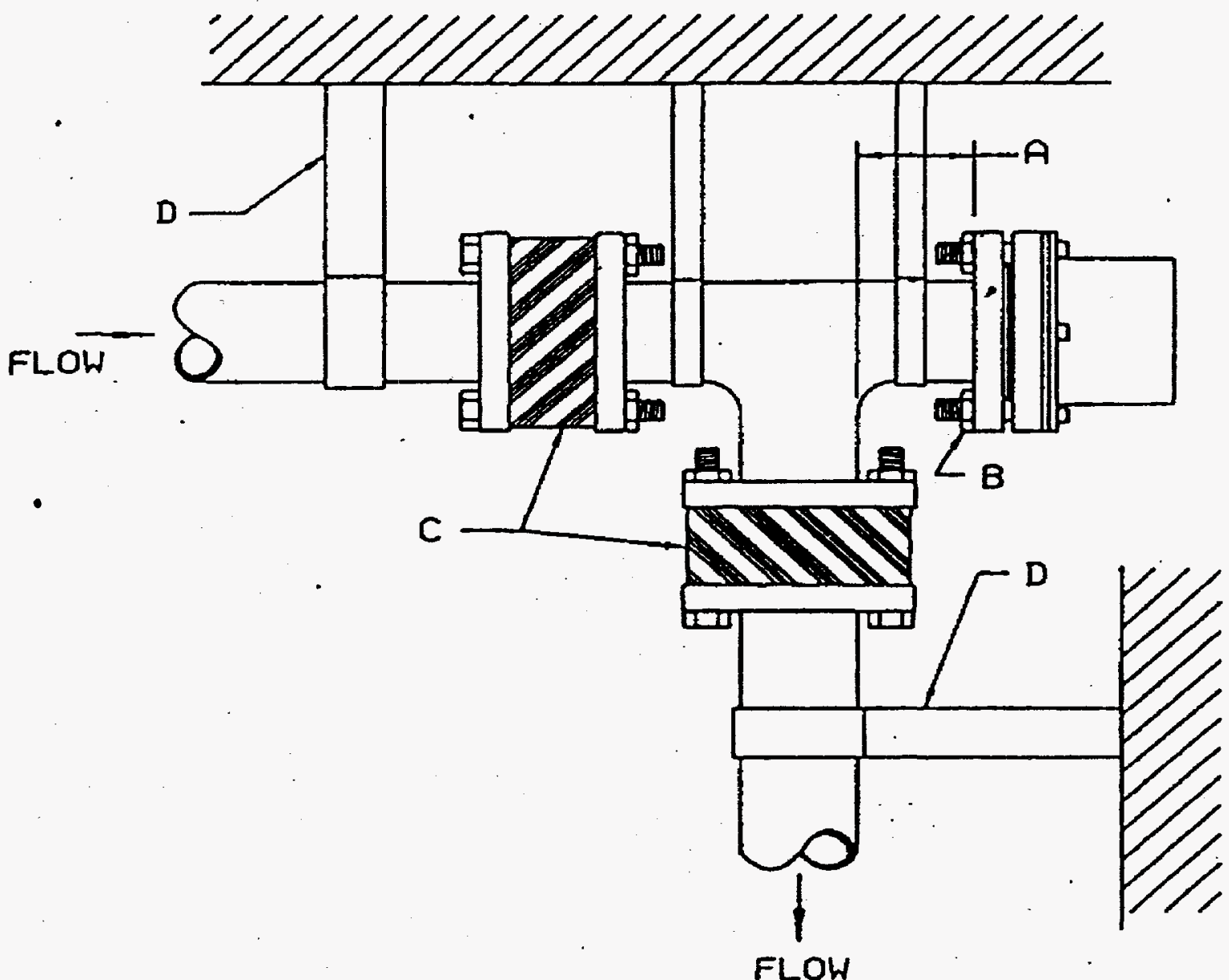

Figure 1.3. Nametre Preferred Installation Configuration 


\subsubsection{Fischer \& Porter "Minimag" Flow Meter}

Fischer \& Porter's Minimag flowmeter belongs to the general category of electromagnetic flowmeters, commonly referred to as magmeters. Magmeters measure the flowrate in electrically conductive liquids by applying Faraday's Law of Electromagnetic Induction. A voltage is induced as a conductive fluid moves through a magnetic field. The magnitude of this induced voltage, $\mathrm{E}$, is directly proportional to the velocity of the fluid, V, the strength of the magnetic field, B, and the conductor width (i.e, pipe diameter), D. Since the direction of flow and the magnetic field are at right angles to each other, Faraday's Law reduces to

$$
\mathrm{E}=\mathrm{kBDV}
$$

where $\mathrm{k}$ is a proportionality constant.

Magmeters can be used to measure the flow rate of fluids with a minimum conductivity of 5 microSiemens $/ \mathrm{cm}$ ( 5 micromhos $/ \mathrm{cm}$ ), making this instrument appropriate for most water-based applications. Magmeters are a popular choice for flowmeter applications since they are non-intrusive and the measurement is not influenced by the slurry density and viscosity. Like most popular magmeters, the Fischer \& Porter Minimag uses a pulsed-direct current (pulsed-DC) system to excite the magnetic coil. The pulsedDC system is popular since the electronics can be re-zeroed between the 7-Hz pulses. This stable zero feature makes the instrument less susceptible to the effects of coating of the electrode.

\subsubsection{Yokogawa Flow Meter}

As mentioned above, pulsed-DC magmeters can self-zero between each measurement. But for slurries, the lower sampling frequency can cause problems.

While an AC magmeter reverses polarity at 60 cycles per second, a DC system pulses at 4-7 Hz. At these low pulse frequencies, the instrument manufacturer claims that the instrument is sensitive to noise from electrochemical reactions, high viscosities, and/or low conductivity liquids. Traditionally, slurries have caused noise in these pulsed-DC magnetic flow meters.

Yokogawa has introduced an instrument which is capable of dual "frequency excitation," called the Admag. The instrument has a carrier frequency of $7 \mathrm{~Hz}$ with a low pass filter, and a $72-\mathrm{Hz}$ superimposed high-frequency waveform. The two waveforms are then combined. The result is an instrument claimed by the manufacturer to have all the benefits of zero correction of DC magmeters and the noise immunity of $\mathrm{AC}$ magmeters.

\subsubsection{Micromotion Coriolis Mass Flow Meter}

A coriolis mass flow meter measures mass flow rate by vibrating a sensing tube at its natural frequency. The flow of mass through the tube causes a twisting action due to the coriolis effect. The twist angle is measured by position sensors, which subsequently generate a voltage signal which is proportional 
to mass flow rate. Since the density of the fluid affects the natural frequency of the tube, measuring the driving frequency of the tube yields the density of the fluid along with the mass flow rate.

\subsubsection{Red Valve \& Rosemount Pressure Meters}

Two line pressure instruments were investigated: a Red Valve pressure transducer (Model 1151 Smart series 48 with hypalon sleeve and silicone oil sensor fluid) and a Rosemount direct tap sensor (Model 3051CG). The Red Valve pressure instrument was chosen for Project W-211 since the diaphragm is protected from the slurry process fluid. The Red Valve is certified to $+/-1 \%$ of full scale $(1.0 \mathrm{psig}$ on a 1-100 psig scale). Unlike the Rosemount direct pressure tap, where slurry travels through a 1/4-inch tube to act against a diaphragm, a silicone oil acts as an intermediate (transmitting) fluid so that the slurry never contacts the diaphragm. The principle behind the Red Valve pressure transducer suggests that plugging and fouling issues should be eliminated when this instrument is used. Both instruments use the same transmitter (Rosemount Model 3051CG), with a reported accuracy of $1.0 \%$ full scale (3.0 psig on a 1-300 psig scale).

\subsubsection{Moore Thermocouple}

The Moore Industries thermocouple assembly is a Type $\mathrm{J}$ thermocouple mounted in a 3/4-inch stainless steel thermocouple well. The thermocouple well is inserted into the slurry stream by means of flange mounting the assembly to the pipe loop. The signal from the thermocouple is sent to the TCX thermocouple transmitter which converts the signal to a 4-20 mA which is then read by the PLC. The transmitter has a zero and span adjustment to be used for calibration.

\subsubsection{Lasentec Particle Size Analyzer}

Only a few instrument manufacturers produce instruments that can measure PSD in-line. Lasentec's optical sensor is the only one which claims to measure in-line PSD in concentrated slurries ( $>35$ vol \%) that can change in composition (optically and chemically).

The Lasentec sensor uses a technique known as focused beam reflectance measurement (FBRM) to measure the chord length distribution of particles which pass by the instrument. A focused laser is reflected off of a rotating mirror resulting in a linear velocity of $6 \mathrm{ft} / \mathrm{sec}$. This system reflects light off particles as they pass. The time the laser light is reflected off a particular particle is recorded by the sensors electronics. Since the traverse velocity of the laser light ( $v$ ) is set at $6 \mathrm{ft} / \mathrm{sec}$ and the reflection time is known ( $t$ ), the size of the particle can' be estimated by

$$
\mathbf{s}=\mathbf{v} * \mathrm{t}
$$


Since both the orientation of the laser beam and particles are random, the chord length measured is also a random chord length as illustrated in Figure 1.4. The instrument will tend to measure larger chord lengths for larger particles, so there is a natural correlation between a chord length distribution and a PSD.

The Lasentec software prepares a chord length distribution (i.e., a PSD) (Figure 1.5). The software manipulates the chord lengths and prepares four different mean PSD values: average particle size

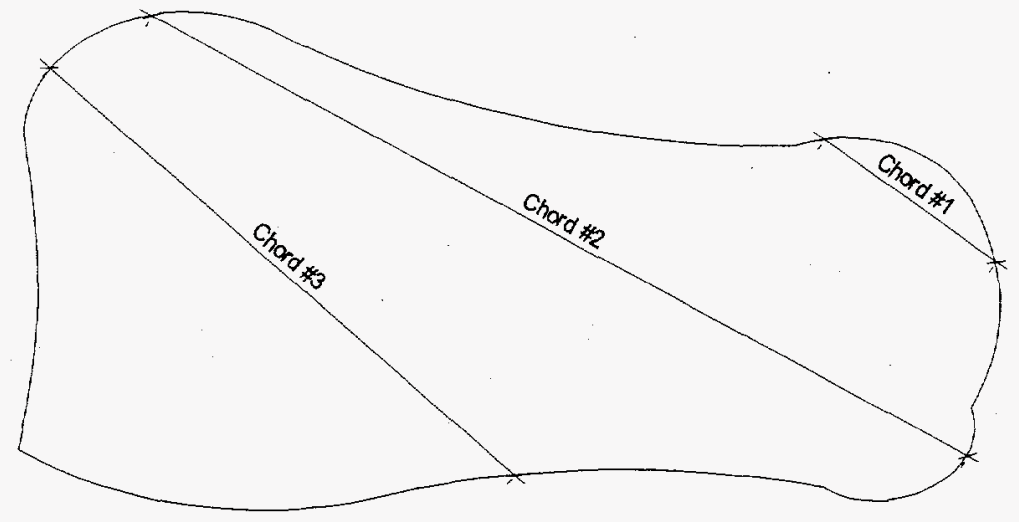

Figure 1.4. Lasentec Particle Size Measurement Method

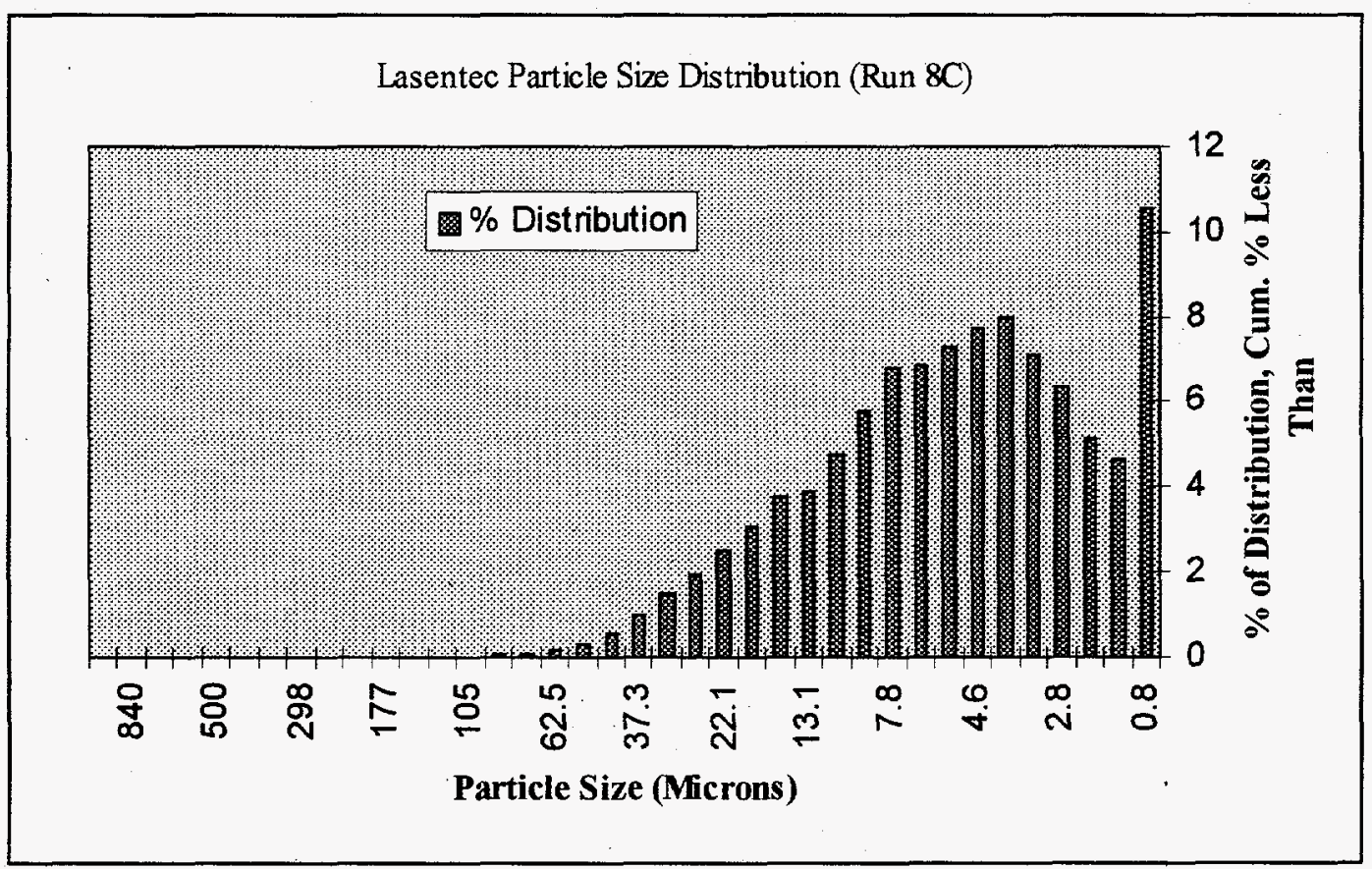

Figure 1.5. Lasentec Particle Size Distribution for Unknown Sample in Run 8C 
(number), length weighted average particle size, length squared weighted average particle size, and length cubed weighted average particle size. These length weighted averages accentuate the presence of the larger particles more than the simple number average particle size. Thus the presence of a few large particles, which would not shift the number of the average size, would dramatically change the weighted average. The length weighted average was used the most during the runs because it gave a good compromise of not weighting large particles heavily while still emphasizing the effect of deposition and resuspension of large particles on the average particle size.

The instrument was calibrated at the factory and again on-site by measuring the PSD of polyvinyl chloride/water slurry. The particle size measurement graphs were virtually identical (see Appendix F).

The Lasentec is not advertised as a solids concentration instrument, but it can be used to determine relative solids loading up to its saturation limit of 64,000 particles per scan. Since saturation was observed only once, relative solids loading information should be available for analysis.

The Lasentec does not correct for the velocity of the particles as they move by the sensor window. Increasing or decreasing the flow rate tends to shift the PSD slightly. Increasing the flow rate causes particles to move by the sensor faster, thereby decreasing the average time for which the laser reflects off of a particle. Thus faster flow rates result in slightly smaller measured particle sizes and vice versa for slower flow rates

The Lasentec M300 Sensor is diagramed in Figure 1.6. It is normally installed in a vertical upflow run with the sensor window pointed against the flow at a 45 degree angle. Since the laser has a linear velocity of $6 \mathrm{ft} / \mathrm{sec}$ (essentially the same as the flow rates tested), a pipe expansion spool piece was used to locally lower the flow rate to about $4.5 \mathrm{ft} / \mathrm{sec}$.

The probe is normally titanium, but other metals can be used for chemical compatibility. The window at the end of the probe tip is sapphire, which is claimed by the manufacturer to be chemically compatible with alkaline waste and radiation. (Recent Hanford experience with sapphire windows used in the velocity density temperature trees for 101-SY is poor. Field experience initially indicated that the sapphire window disintegrated; however, more detailed analysis showed that the bonding material between the sapphire window and the metal mounting bracket failed and allowed tank waste to penetrate behind the sapphire window.) The probe is positioned about 2 inches into the pipe and angled into the flow at a 45 degree angle so that it is self-cleaning. (Even after the graphite run, which coated the inside of the Yokogawa and Fischer \& Porter magnetic flow meters, the Lasentec sapphire window remained clean.)

Vertical upflow mounting is recommended to prevent segregation of particles. The Lasentec was actually installed in a downflow position in the common downflow leg based on process knowledge of settling behavior at the processing conditions. (The original design phase assumption was that the solids would be well mixed during both upflow and downflow. This assumption proved to be correct. See Section 3.3.3 for details.) 


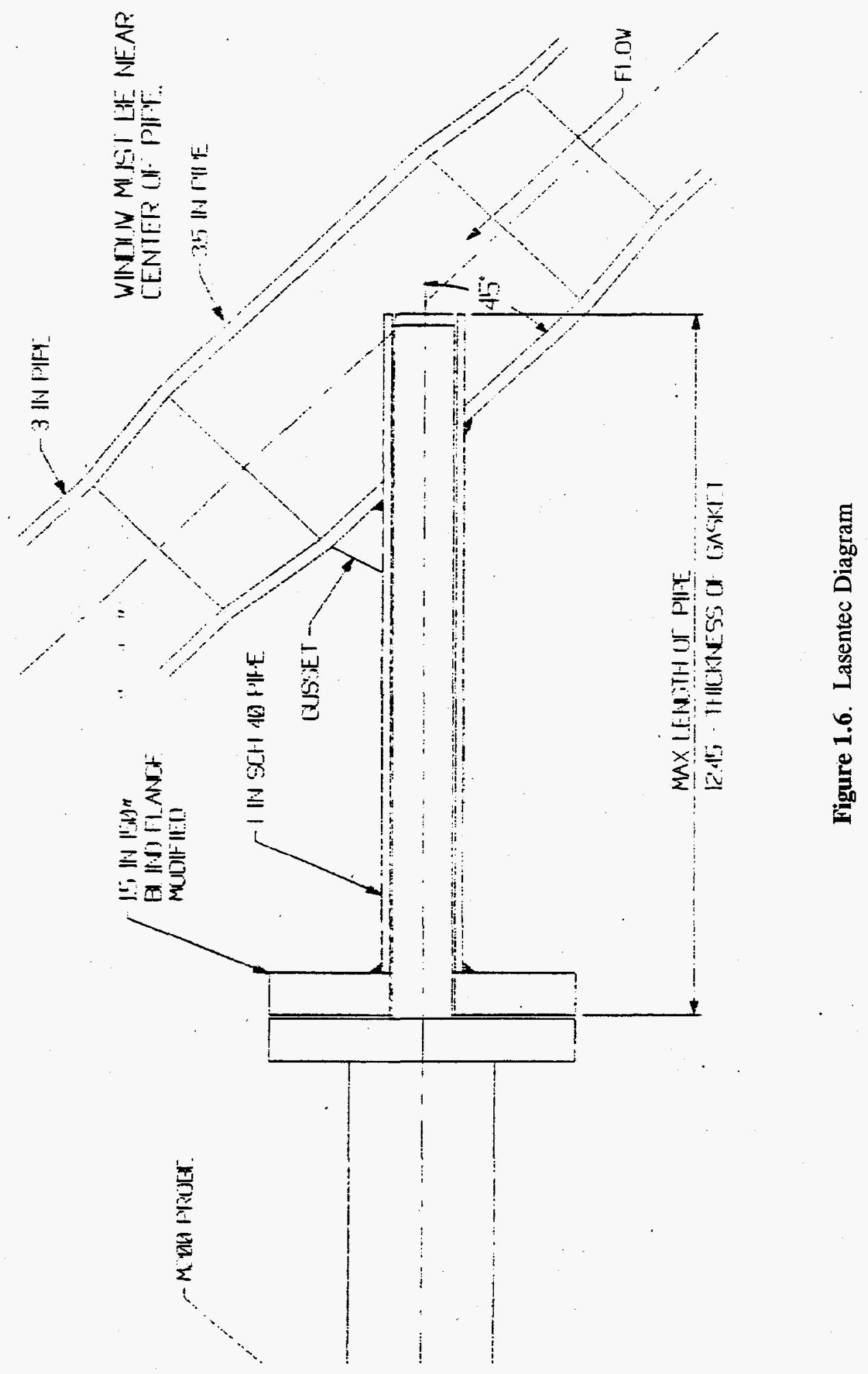


The entire instrument is claimed to be safe for use in a radiation area. The M300 has only one moving part: a bearing assembly which is used to rotate the laser light. This bearing assembly is rotated by $60 \mathrm{psi}$ instrument air. The electronics (including the diode laser) are located in a remote field unit connected by a fiber optic cable to the sensor. The field unit is normally located no more than 10 meters away from the probe, although this distance can be increased.

Lasentec recommends that the bearing assembly be replaced about once a year if the probe is continuously used. Normally the entire probe must be removed from the pipe in order to change the bearings, however the probe can be engineered to avoid this requirement.

\subsubsection{Pressure Drop}

The pipe loop flow differential pressure was measured with a Rosemount 3051CD transmitter with a remote seal assembly with a 0.25 inches of water accuracy. The transmitter was calibrated such that the 4-20 $\mathrm{mA}$ output signal was proportional to 0 to 25 inches of water pressure. The remote seal assembly consists of two flange mounted diaphragms connected to the transmitter via tubing which is filled with a seal fluid, thus preventing the slurry solids from plugging the impulse tubing or the transmitter. During operation, the isolating diaphragms and the fill fluid on the high and low sides transmit process pressure to the oil fill fluid. The fluid in turn transmits the process pressure to a sensing diaphragm in the center of the transmitter. The sensing diaphragm functions as a spring which deflects in response to differential pressure across it. Capacitor plates on both sides detect the position of the sensing diaphragm. The differential capacitance between the sensing diaphragm and the capacitor plates is converted to an output signal to the PLC. 


\subsection{Experimental Instrumentation and Procedures}

This section presents the instrumentation used in the analytical laboratories to compare the test loop measurements. Also included is a description of how the experimental slurries were derived.

\subsection{Analytical Instrumentation}

The analytical equipment used in the PNNL Slurry Processing Laboratory to measure the slurry simulants and the slurry samples is discussed in the following subsections.

\subsubsection{Haake Rheometer}

The Haake rheometer operates according to the Couette principle in which an outer cup rotates while the inner cylinder, which measures the torque, remains static. The outer cylinder is driven by an electronically controlled motor while the resistance of the sample to flow causes a very small movement in a torsion bar, mounted between the motor and the drive shaft. This movement is detected by an electronic transducer. Signals proportional to the speed and torque are transmitted to the control unit for processing and display.

The Haake rheometer has precise temperature control for the sensor system because the measured viscosity is sensitive to temperature change. The sensor system used in this test was Mooney-Ewart (ME) 45 .

The Haake rheometer measures the shear stress as a function of shear rate from 0 to $300 \mathrm{sec}^{-1}$ and can be used to analyze slurries that follow several types of rheological behaviors as illustrated in Figure 2.1. The viscometer is not well suited for large particles with high settling rates. Simulants that contained the large (500 micron) silica solids were difficult to measure and exhibited high levels of variability.

Figure 2.2 presents an illustrative rheology curve representing a typical rheogram measured with the Haake rheometer. (The experimentally measured rheograms have a much faster initial slope than is depicted in this figure.) The slurries evaluated in the instrument validation test loop (as well as actual tank wastes) all are categorized as shear thinning slurries or Bingham plastics. The figure shows that shear stress goes up as the shear rate is increased; however, the ratio of shear stress/shear rate goes down with increasing shear rate.

The test data can be regressed to determine structure coefficients, yield points, or viscosity temperature coefficients. Ten different models and an automatic evaluation of best fit are available.

The Nametre Viscoliner operates at a single shear rate of $4084 \mathrm{sec}^{-1}$. It is believed to report the slope of the line between 0 and $4084 \mathrm{sec}^{-1}$. Therefore, a strategy of extrapolating the Haake viscosity data based on the best fit to $4084 \mathrm{sec}^{-1}$ and plotting the two against each other was selected. This strategy was selected 


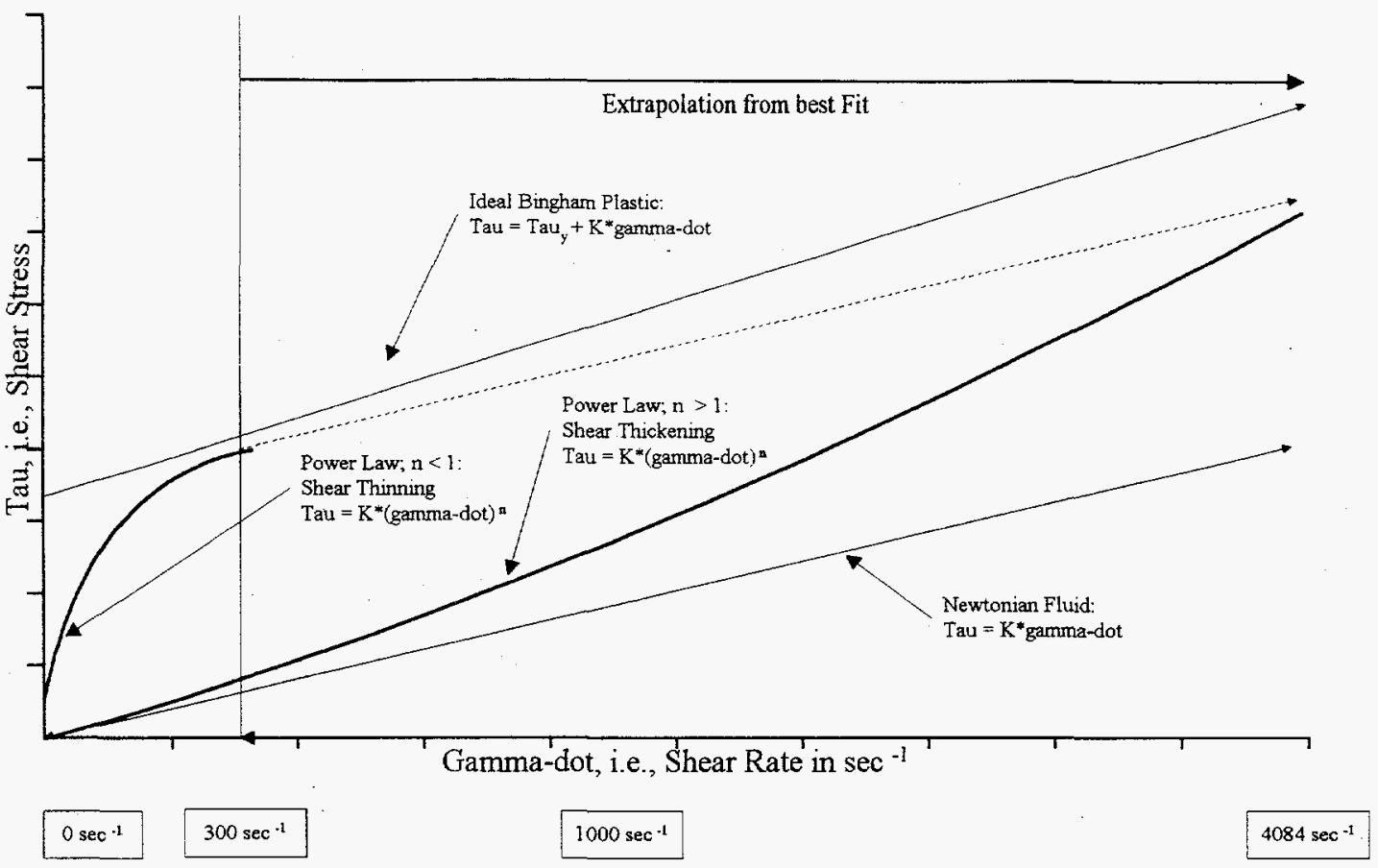

Figure 2.1. Classes of Viscosities

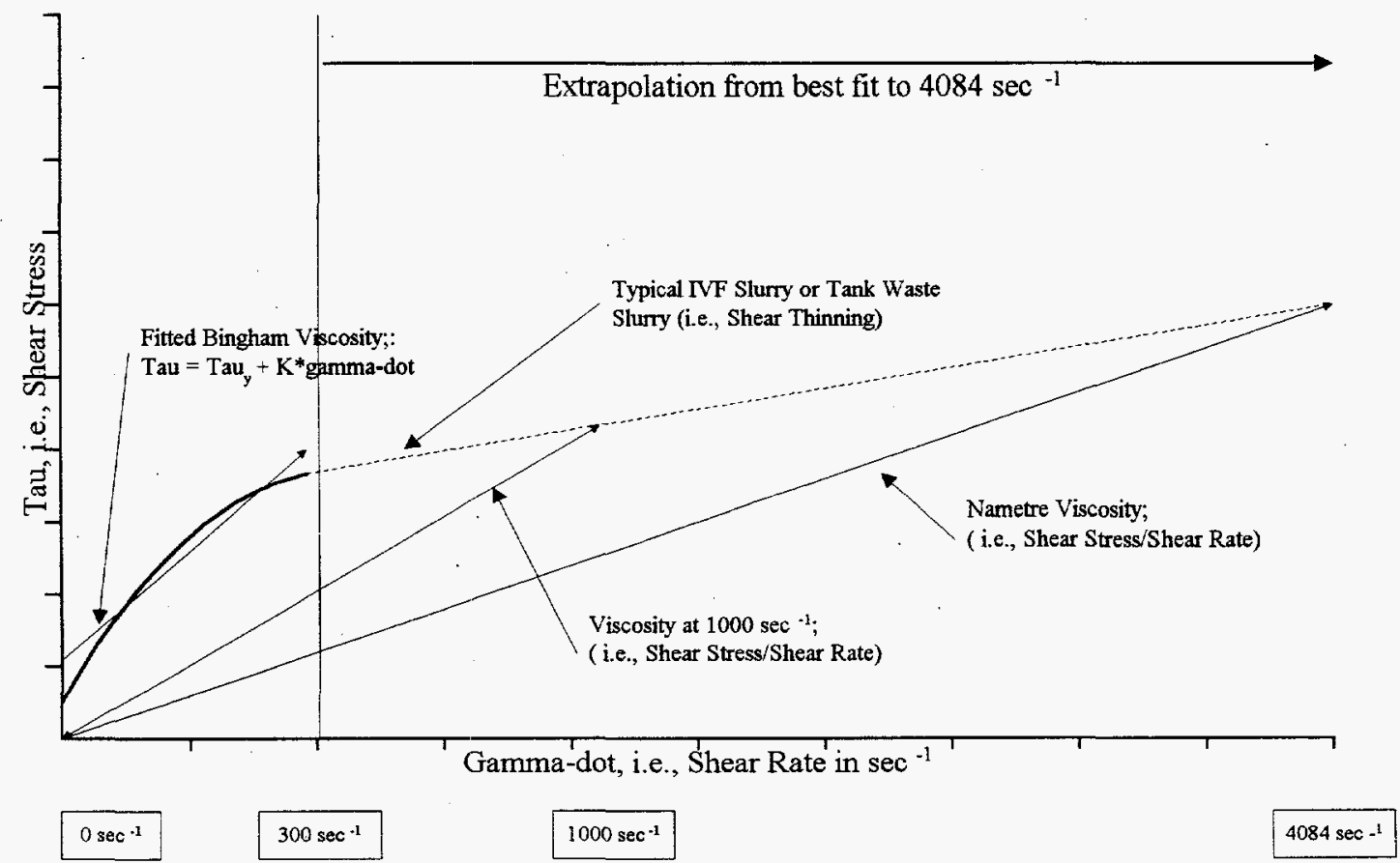

Figure 2.2. Classes of Viscosities 
despite the dangers of extrapolating an order of magnitude even for very good fits because any errors are magnified. This was the only known method to compare the laboratory based viscosities to the Nametre viscosity.

The WHC Project W-211 design criteria requires that the viscosity of the slurry be less than $30 \mathrm{cP}$ at a slurry velocity of $4.5 \mathrm{ft} / \mathrm{sec}$, or $10 \mathrm{cP}$ at a slurry viscosity of $6 \mathrm{ft} / \mathrm{sec}$. These viscosity limits were used to calculate a Reynolds number (and hence estimate the friction factor) when determining the pressure drop across the line. Viscosity is defined here as the shear stress/shear rate. Since the pressure drop measured in the pipe is due to the friction of the fluid at the wall, the shear stress at the wall, $\tau_{w}$, is directly proportional to the pressure drop:

$$
\tau_{w}=4 \Delta P \frac{D}{L}
$$

The shear rate at which the 10 or $30 \mathrm{cP}$ viscosity limit is measured at must therefore be the shear rate at the wall. Unfortunately, it is difficult to precisely measure the shear rate at the wall since the flow is turbulent and non-Newtonian. It is possible, however, to obtain an order-of-magnitude estimate of the shear rate of the wall by considering Newtonian turbulent flow. The purpose of estimating the shear rate at the wall is to demonstrate that the viscosity of a non-Newtonian (i.e., shear rate dependent) fluid measured by the Haake at $300 \mathrm{sec}^{-1}$ or by the Nametre at $4084 \mathrm{sec}^{-1}$ will probably not correlate to the shear rate of the fluid at the wall (i.e., the shear rate at which the Cross-Site Transfer System viscosity limit is imposed).

At the fluid velocities tested in the test loop ( $6 \mathrm{ft} / \mathrm{second})$, the expected shear rate is on the order of $1000 \mathrm{sec}^{-1}$ and a corresponding shear stress can vary between 1 and $100 \mathrm{~Pa}$ depending on the fluid.

The $1000 \mathrm{sec}^{-1}$ shear rate was determined from a rough approximation of the fluid velocity near the wall of the pipe. Bird et al. (1960) give the velocity profile of a turbulent Newtonian fluid to be

$$
v_{z}=v_{z, \max }\left(1-\frac{r}{R}\right)^{1 / 7}
$$

and $v_{z, \max }$ equal to

$$
\mathrm{v}_{\mathrm{z} \text { max }}=\frac{5}{4} \mathrm{v}_{\mathrm{B}}
$$

and $v_{B}$ the bulk velocity. 
It is further assumed that the turbulent core gives way to a boundary layer at a radius of $0.05 \mathrm{R}$ (Bird et al. 1960, Figure 5.1-1). This boundary layer is responsible for most of the fluid resistance, and hence the pressure drop. Thus, the fluid viscosity associated with the pressure drop is directly related to the shear rate at the wall. The shear rate at the wall is then approximated as the fluid velocity near the wall divided by the distance from the wall:

$$
\frac{\mathrm{v}_{\mathrm{z}}(0.05 \mathrm{R})}{0.05 \mathrm{R}}=1228 \mathrm{sec}^{-1} \approx 1000 \mathrm{sec}^{-1}
$$

Again, this estimate makes several assumptions which may not be rigorously correct for the slurries tested within the IVF. In particular, some rather large assumptions are made about the boundary layer resistance for a non-Newtonian fluid. However, for purposes of this report, this shear rate estimate will serve to illustrate why the 10 and $30 \mathrm{cP}$ limits may not be measured directly by either the Haake or Nametre viscometers.

\subsubsection{Horiba Particle Size Analyzer}

The Horiba CAPA 700 was used to measure the PSD of the slurry samples in the laboratory. It uses a non-contact measuring method based on liquid phase sedimentation and light transmission techniques. The slurry samples were extremely diluted to avoid saturation of the detector. In this method, Stokes' sedimentation equation is combined with the proportional relationship between the absorbency and particle concentration. A particle having diameter (D) and density ( $r)$ in a solvent of density $\left(r_{0}\right)$ and viscosity coefficient $\left(\mathrm{h}_{0}\right)$ will settle at a constant velocity according to the Stokes sedimentation law by the effect of gravity. Particles with a larger diameter settle faster than particles with a smaller diameter if all particles have the same density.

For centrifugal sedimentation (CS), the relation between particle size (D) and particle density ( $\rho$ ), solvent density $\left(\rho_{0}\right)$, solvent viscosity $\left(\eta_{0}\right)$, centrifugal rotational angular velocity $(\omega(t))$, distance between center of rotation and sedimentation plane $\left(\mathrm{X}_{1}\right)$, and distance between center of rotation and measuring plane $\left(\mathrm{X}_{2}\right)$ is given as follows:

$$
D=\left[\frac{18 \eta_{0} \ln \left(X_{2} / X_{1}\right)}{\left(\rho-\rho_{0}\right) \omega^{2}(t) t}\right]^{\frac{1}{2}}
$$

where $\omega(t), x_{1}$, and $x_{2}$ are constant instrument factors during the entire centrifugal sedimentation measurement. The sample characteristics are described by both solid and solvent physical properties. Water was used as the dispersion medium for all samples used in the data analysis. For a single component slurry system, particle size is a key factor affecting sedimentation velocity, which in turn influences the measured optical properties. However, for a multi-component slurry system, both density and particle size can control the particle sedimentation velocity. The equation for calculating the average density in a mixture of solid particles is 


$$
\bar{\rho}=\frac{W_{1}+W_{2}+\ldots}{\frac{W_{1}}{\rho_{1}}+\frac{W_{2}}{\rho_{2}}+\ldots}
$$

The optical transmission method measures the degree of particle sedimentation by measuring the amount of light transmitted. The intensity of the transmitted light is proportional to particle concentration and size. The relationship between measured optical property and particle size is given below:

$$
\log \left(\frac{I_{0}}{I_{i}}\right)=K \sum k\left(D_{i}\right) N_{i} D_{i}^{2}
$$

where $I_{0}$ is the incident light intensity, $I_{i}$ is the transmitted light intensity through particle $D_{i}, K$ is the optical coefficient of the cell and particle form, $k\left(D_{i}\right)$ is the absorptivity of particle $D_{i}, N_{i}$ is the number of particle $D_{i}$, and $D_{i}$ is the particle diameter.

Figure 2.3 shows a typical PSD taken during testing. The graph shows both an incremental and cumulative PSD, respectively, as a function of particle size in microns.

\subsubsection{DYNAC Centrifuge}

A DY'NAC Centrifuge (60 Hz, from Becton Dickinson \& Company, Model \# 420101) was used in the measurement of the slurry samples solid volume percentage. Each sample was centrifuged at 1350 RPM rotation (centrifugal radius of $16.3 \mathrm{~cm}$ ) for 5 minutes and resulted in a very good phase separation. The separated solids were dried in an oven at $60^{\circ} \mathrm{C}$ for 3 to 4 days. To ensure that no residual water remained in the solid, the samples were put back into the oven, and re-weighed the following day to see if there was any additional drying. The solids volume concentration was obtained by dividing the measured solids weight, its density, and the total volume and weight of the sample.

\subsubsection{Pycnometer}

The pycnometer is used to take fast measurements of the density of a slurry. It works by filling a container of a known volume, weighing the mass of the slurry, and dividing the mass by the known volume. These density data are taken within a few minutes of taking the samples and are measured essentially at the temperature of the slurry in the test loop.

\subsection{Experimental Procedure}

The location of the instruments can be seen in the test loop schematic shown in Figure 1.2 for the "ideal" and Project W-211 loops. A throttle valve controls the flowrate and a pneumatically operated 3-way valve directs the simulant either to the feed tank or to a 100 gallon (16-inch diameter schedule 


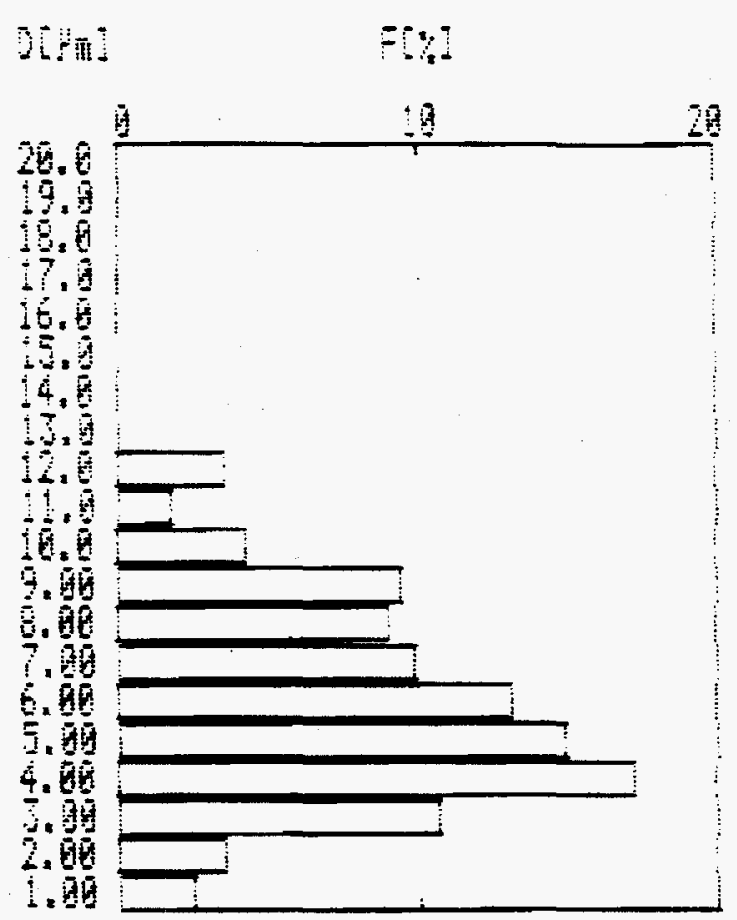

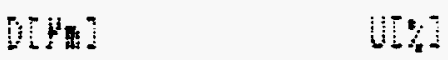

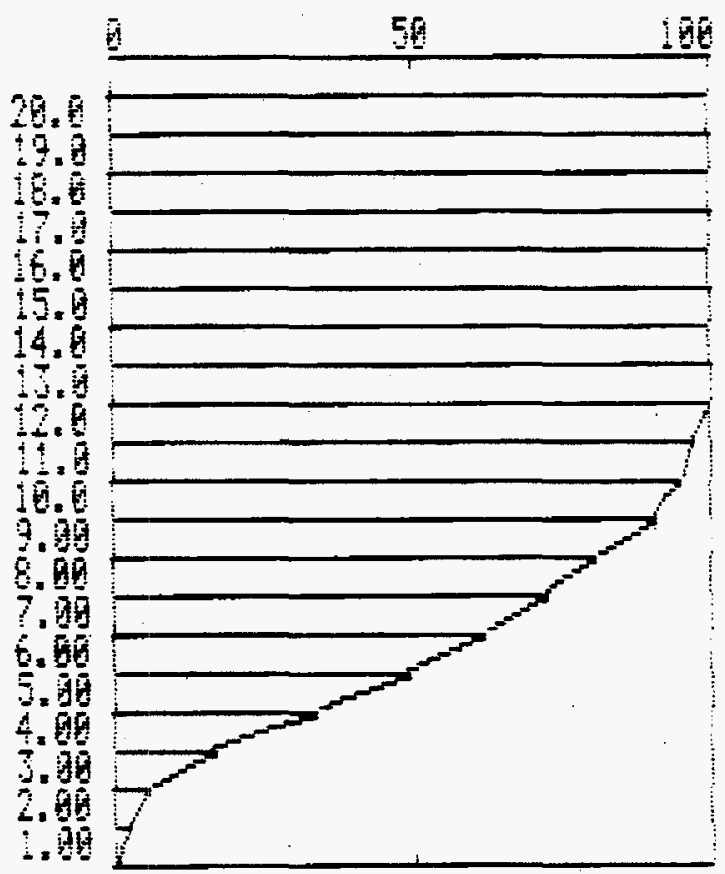

Figure 2.3. Typical Particle Size Distribution from Horiba (Run 5B0) 
30 pipe 10 feet high flow calibration tank). Control of the 3 -way valve is through the computer which measures the duration the flow is diverted to the flow calibration tank. The computer also integrates the signal from all the flowmeters during the diversion and displays the total flow for each flowmeter during the flow diversion. The level in the flow calibration tank corresponds to a volume and can easily be measured within $1 / 4$ inch or 0.75 liters. The flow calibration tank is mounted on load cells so that the mass of the slurry can be measured and the slurry density can be determined by dividing the mass by the volume. After the flow and density calibrations, the simulant is drained back to the feed tank. Bubbles can be introduced into the IVF just downstream of the pump through a 1/4-inch tubing connection.

Tests were generally carried out as follows. The simulant was prepared in the feed tank which has a 1.5 HP agitator to keep the solids suspended. The desired solids were weighed and added to a known quantity of water in the feed tank. After the solids were added to the feed tank, the pump was started directing flow from the feed tank to the desired loop ("ideal" or Project W-211) and back to the feed tank. The throttle valve was adjusted to achieve the desired flowrate. System parameters were then monitored until steady-state is reached, as determined by a stable density and PSD. Typically the system required from five to ten minutes to reach steady-state.

After steady state was achieved, three flow calibrations were conducted by diverting flow from the feed tank to the flow calibration tank for 20 to 30 seconds. Since the estimated error in reading the volume is 0.75 liters in the nominal 20 seconds diversion at 9 liters per second, the estimated percentage error in flow rate is $0.4 \%$. The error at the 6 liter per second conditions is also $0.4 \%$. The volume in the flow calibration tank was compared with the volume obtained from the computer (which integrated the instantaneous flow signals from the flowmeters). The mass and volume of the slurry in the flow calibration tank was used to determine the slurry density. This measured density is compared with the density reported by the Micromotion densimeter. The flow rate data from the Yokagawa, Micromotion, and Fischer \& Porter flow meters is expressed as a percent error from the calibrated vessel flow rate and not as volumetric flow per time. The reason for this is that the flow rate in the loop was not constant when the flow is diverted to the calibration tank.

After the flow calibrations, individual density measurements are taken from each of the four sample locations (S-1 through S-4) and recorded with the time and temperature. This information is used as a check and to ensure that the density at the top (sample S-1) and bottom (sample S-2) of the feed tank are similar (a large difference would indicate significant solids settling in the feed tank). Samples were also taken from the upflow sample locations (S-3) and downflow sample location (S-4) in the test loop for analytical laboratory testing (Haake viscosity, PSD, vol\% centrifuged solids).

The flowrate, density, Nametre viscosity, Moore Instrument temperature, and the Micromotion temperature are time averaged for ten seconds via the computer and stored electronically. The differential pressure measured over a ten-foot section of straight pipe was also recorded in the Project W-211 loop. These values were recorded manually at least three times during the run. 


\subsection{Slurry Preparation and Matrix}

Physical properties of approximately 35 solids were obtained through literature searches and product brochures and by personal communication with the manufacturer or manufacturer representatives. A subset of nine solids was selected for further analysis. Samples were obtained and tests were performed in the laboratory to verify the manufacturers claims of physical properties. Slurries of some of the solids that were interesting were prepared and viscosity measurements were performed in the laboratory. (Detailed information on the testing of these solids and slurries is available in the Project files but will not be presented in detail here.)

Based upon solids and slurry characterization work and on the hazards/toxicity of the solids, slurries were selected for use in the IVF. The process of selecting the exact simulant and combinations of simulants was intuitive but was guided by the designed experiment objective and the known properties of the simulants previously tested. Combinations of types of solids, concentrations, size distributions, and slurry viscosities were evaluated until a set of simulants were found that represented each corner of the design cube. Interior points were evaluated by adding solids to a low solids loading simulant or alternatively by adding water to a high solids loading simulant.

Simulants were specifically selected for the following:

1. Some simulants were selected to include a variety of solid densities which when combined with water in solids loading concentration of 0 to $30 \mathrm{vol} \%$ solids were constrained by the Project W-211 density specification of 1.0 and $1.5 \mathrm{gm} / \mathrm{cm}^{3}$. These simulants were made up from either plastic or silica powders to form the low $\left(1.0 \mathrm{gm} / \mathrm{cm}^{3}\right)$ and high $\left(1.5 \mathrm{gm} / \mathrm{cm}^{3}\right)$ density simulants. The tests with the neutrally buoyant plastic powders were designed to create a simulant where settling of the solids did not occur in the upflow and downflow portions of the test loop.

2. Some simulants were selected to include a variety of solids which when combined with water were constrained by the Project W-211 solids loading constraint of 0 to 30 vol\% solids and not the density. These simulants were primarily made up of Gibbsite.

3. Some simulants were selected to include a variety of solids which when combined with water were constrained by the Project W-211 viscosity constraint and not by either the solids loading or slurry density. These simulants were primarily made up of combination of solids with small particle sizes (i.e., Bentonite, Graphite, and Mica).

4. Some simulants were selected to give a variety of slurry PSDs, including some bi-modal distributions by having multiple solids with different PSDs. These simulants were primarily made up of small particle size silica and solids with a very small particle size (i.e., Bentonite or Graphite). The simulant used in Run $5 \mathrm{C} 1$ also contained the W-058 specification limit of 1 vol\% 500 micron particles (i.e., large silica powder). 
5. The simulants described above were also used to test effects of the shape of the solid particle. No simulants were prepared with the express explicit purpose of testing particle shapes. The original test plan called for the evaluation of particle shapes (i.e., spherical, irregular, rod-like, plate-like). All of these shapes are represented in the simulants with the exception of the rod-like particles. Suitable particles for this geometry could not be located.

Processing conditions were chosen to cover the range of operational parameters that were used to design the Project W-211 test loop.

The slurry simulant and processing conditions test matrix is shown in a table in Appendix B.

\subsection{Experimental Text Matrix and Data}

All the runs listed in the test matrix in Appendix B were executed with one exception. The exception was one of the unknown slurries to determine if the operator could tell the appropriate slurry characteristics based purely on the instrumentation. This condition (Run 8D) was designed to be a very viscous slurry that would challenge and potentially plug the test loop. During the switch over from Run $8 \mathrm{C}$ to $8 \mathrm{D}$, the operators observed tremendous increases in the reported viscosity (i.e., from a nominal $40 \mathrm{cP}$ to over $100 \mathrm{cP}$ ). The operators felt that this would plug the test loop and shut the run down. The experimental condition was not deleted on the test matrix, however. Appendix $\mathrm{C}$ shows the experimentally measured and laboratory based analytical data collected.

\subsection{Statistical Analysis}

Two types of statistical analyses are used in the analysis of the data. The first statistical test is a paired $\mathrm{t}$-test that compared two sets of values. It calculates the difference between the ordered sets of values and determines if the average difference is statistically different from zero at the $95 \%$ confidence level. These tests were used to determine if settling occurred in the feed vessel and if the laboratory measured analytical values are different from the values measured at the test loop.

Multivariate statistical analysis is the second type of analysis. This analysis was used to determine if the performance of any specified measured response is a function of any other or any other grouping of predictor variables. These analyses are used to help pinpoint where the sources of error in the flow rate measurements, $\Delta \mathrm{P}$, and viscosity measurements derived. A software package called SimcaP was chosen to analyze the project data.

Multivariate statistical methods are used since the amount of data is large and the process variables are interrelated. Software packages like SimcaP essentially reduce the number of independent variables by creating new variables which are nothing more than linear combinations of the original, measured variables and measured slurry properties. For example, the 13 measured variables from the IVF (Yokogawa flow rate; Moore Industries Temperature; Lasentec mean particle size; laboratory mean particle size; 
Nametre viscosity; Haake viscosities at 300, 1000, and $4084 \mathrm{sec}^{-1}$; line pressure; Lasentec small particle count; differential pressure, vol\% solids; and Micromotion density) were reduced to five statistically relevant independent variables by the SimcaP software.

SimcaP performs two types of multivariate analyses: principle component analysis (PCA) and partial least squares analysis (PLS). PCA is used to find outliers, recognize groups of data, and determine the general relationships between process variables. PLS, on the other hand, performs regression to relate input parameters to designated output parameters. For example, PLS can be used to find a quantitative relationship between viscosity and the rest of the measured variables. 


\subsection{Results and Discussion}

The results of the test loop testing are discussed in this section. The discussion is split into general

observations that were either associated with the startup of the test loop or cut across all runs. Specific discussion of the performance of the individual test loop instrumentation is presented in Sections 3.2 through 3.5 .

\subsection{General Observations}

General observations associated with the start-up and testing of the test loop and observations that occurred for all runs are discussed in Section 3.1.

\subsubsection{Temperature}

In every run, the temperature of the slurry increased from a nominal starting temperature of $10^{\circ} \mathrm{C}$ to $20^{\circ} \mathrm{C}$ and leveled out at about $40^{\circ} \mathrm{C}$ to $45^{\circ} \mathrm{C}$. While a temperature rise was considered in the preliminary design of the test loop, no temperature control system was installed. The magnitude of the temperature increase was not anticipated and led to a large increase in laboratory analytical work and in data analysis/ modeling work to determine the viscosity vs. temperature dependence of the slurry samples. If the slurries were shown to be temperature sensitive in laboratory tests, this correlation was then used to correct the observed viscosity data to the temperature at which the Nametre viscosities were recorded. The temperature corrections in the viscosity values are sources of small errors in the analysis.

Similarly, the Micromotion densities were recorded at a different temperature than the pycnometer samples. The Micromotion densities were either interpolated or extrapolated to the temperatures that the pycnometer samples were taken at. These interpolations or extrapolations were generally within a range of $5^{\circ} \mathrm{C}$ or less. The temperature corrections in the density values are also sources of small errors in the analysis.

\subsubsection{Vibration}

Viscosity standards were tested with the Nametre viscometer prior to installation to verify the viscometer worked properly. A static test stand site next to the Nametre was installed in the test pipe loop so that the Nametre could be merely unbolted and placed in the stand while conducting static tests. The Nametre provided steady viscosity values that were 1 to $2 \mathrm{cP}$ higher than the accepted standard. Because these tests were conducted in the 336 Building High Bay, which is unheated during December, the value was expected to be a little high as the viscosity standards cooled slightly during testing.

After the static tests, the viscometer was installed in the pipe loop in accordance with factory instructions. However, during shakedown testing the Nametre viscometer did not work properly with flow in the pipe loop regardless of flow rate, as the Nametre was subject to severe vibrations. For example, it rapidly 
fluctuated between 10 and $27 \mathrm{cP}$ while running a simulant which in the lab had a viscosity of $\sim 5 \mathrm{cP}$. The Nametre was again tested statically with viscosity standards and satisfactory results similar to the previous static tests were obtained. The Nametre was re-installed and various equipment was turned off that may be causing interference with no success (e.g., Micromotion mass flowmeter). The Nametre was sent back to the factory to check the system out. They reported the unit was operating properly, but the symptoms persisted.

The cause of the poor readings was determined to be vibrational interference. The vibration in the Project W-211 loop was measured and the vibrations present at various frequencies neared or exceeded the acceptable level defined by Nametre (see Figure 3.8). The pump was isolated with rubber expansion joints, causing a substantial decrease in the measured vibration in the Project W-211 loop, and the Nametre began operating properly.

Unfortunately, the Nametre could not be made to work in the "ideal" loop even with the pump isolation. Vibration measurement in the "ideal" loop showed it to be within the acceptable level as defined by Nametre. Nevertheless, despite all efforts, the unit did not function properly in the "ideal" loop and was not used.

\subsection{Project W-211 vs. "Ideal" Loop}

One of the lesser objectives of this project was to determine if the design of the Project W-211 test loop was satisfactory as compared to the "ideal" test loop where the instruments were spaced out and flow was allowed to more fully develop. To test this, the pycnometer densities, Micromotion densimeter, and the Micromotion flow meter in the two loops were compared against the laboratory data. This comparison used a paired t-test previously described with one added feature. All data collected in both loops were used in the analysis and data was segregated by "Groups" (i.e., Project W-211 or "ideal") and then the paired t-tests were run. The results showed the following:

1. The average of the upflow density (S-3) and downflow density (S-4) measured with the pycnometer (labeled S-3/S-4 in subsequent graphs) compared to the lower feed tank density (S-2) (measured with a pycnometer) were not statistically different. (See Grouped t-Tests in Appendix D-3).

2. The Micromotion densimeter performance compared to the average of the upflow (S-3) and downflow (S-4) density (measured with a pycnometer) were not statistically significantly different. (See Grouped t-Tests in Appendix D-4).

3. The Micromotion density performance compared to the density from the calibrated feed vessel was not statistically significantly different. (See Grouped t-Tests in Appendix D-5).

4. The Yokagawa and Micromotion flow rate meters are statistically different from each other and are also statistically significantly different in each loop. In the Project W-211 loop, the Micromotion flow meter measured 5.9\% less flow than the Yokagawa flow meter. In the "ideal" loop, the Micromotion flow meter measured $7.9 \%$ less flow than the Yokagawa flow meter. These regressions were poor 
Appendix D-7.) Since the Yokagawa is in a common location for the testing in both loops, the test loop must have affected the Micromotion flow rate. The relevance of this observed difference is discounted because the grouped $t$-Tests on the Micromotion density did not differ between the two loops and because the temperature reported by the Mcromotion thermocuple consistently agreed with the Moore Industries thermocouple.

The only grouped $t$-Test analysis that showed that there was a difference between the two test loops is item 4 above and it had relatively poor correlations with wider confidence limits. Since the other five had very good regressions with tight confidence limits and showed no difference between the test loops, it is not felt that there is a difference between the two flow loops. Therefore, the data analyses in all of the following sections will be on the full data set comprised of both loops.

\subsection{Instrument Validation}

The following sub-sections describe the results of each instrument being evaluated separately.

\subsubsection{Pressure}

The Rosemount and Red Valve instruments functioned consistently well and gave measurements that were consistently within about one psi of each other (Figure 3.1). Typical operating line pressures were $60-90$ psig.

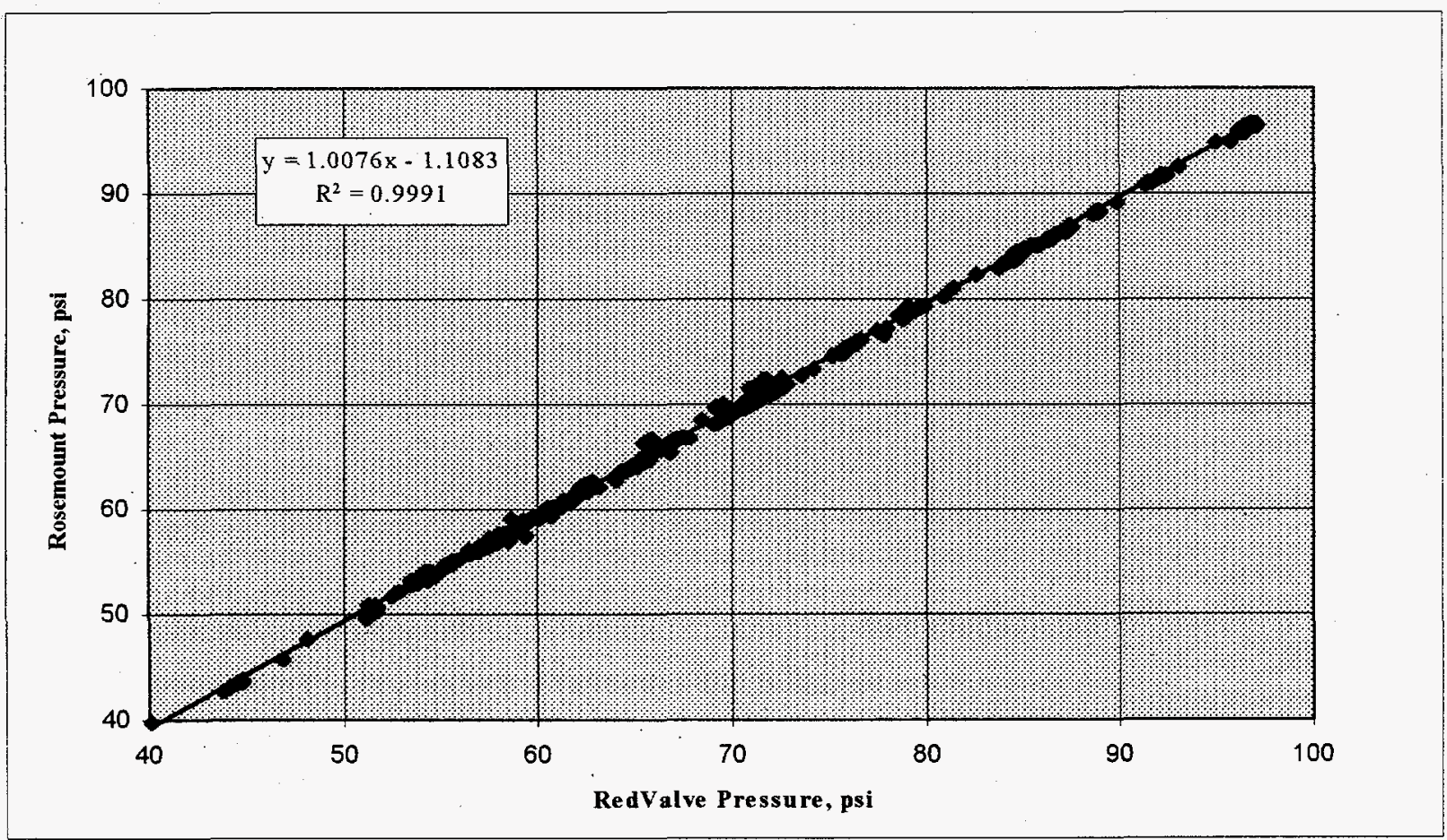

Figure 3.1. Rosemount vs. Red Valve Pressure 


\subsubsection{Temperature}

Two thermocouples were installed in the slurry pipe test loop: the Moore Industries thermocouple (as specified in the Project W-211 FDC) and the Micromotion thermocouple. The Moore Industries thermocouple was recorded by the data acquisition system. The Micromotion transmitter only allows two 4-20 mA signals to be sent to the PLC, consequently the thermocouple reading is only available as a readout from the rack mounted display panel and is not logged to the PLC data acquisition system. Micromotion temperatures were manually recorded whenever samples were taken for density measurements and just before flow calibration tests.

The Micromotion thermocouples measured temperatures consistently between 0.2 and 0.9 degrees higher than the Moore Industries thermocouple (Figure 3.2). The Micromotion thermocouple has a reported accuracy of $\pm 1^{\circ} \mathrm{C}$ (CMF 300 Product Brochure), and the Moore Industries thermocouple has a reported accuracy of $0.1 \%$ of full scale (full scale $=200^{\circ} \mathrm{C}$ ), or $\pm 2{ }^{\circ} \mathrm{C}$. Thus, the nominal error for the two thermocouples overlaps the reported difference between the temperature measurements. No other independent measurement of temperature was made.

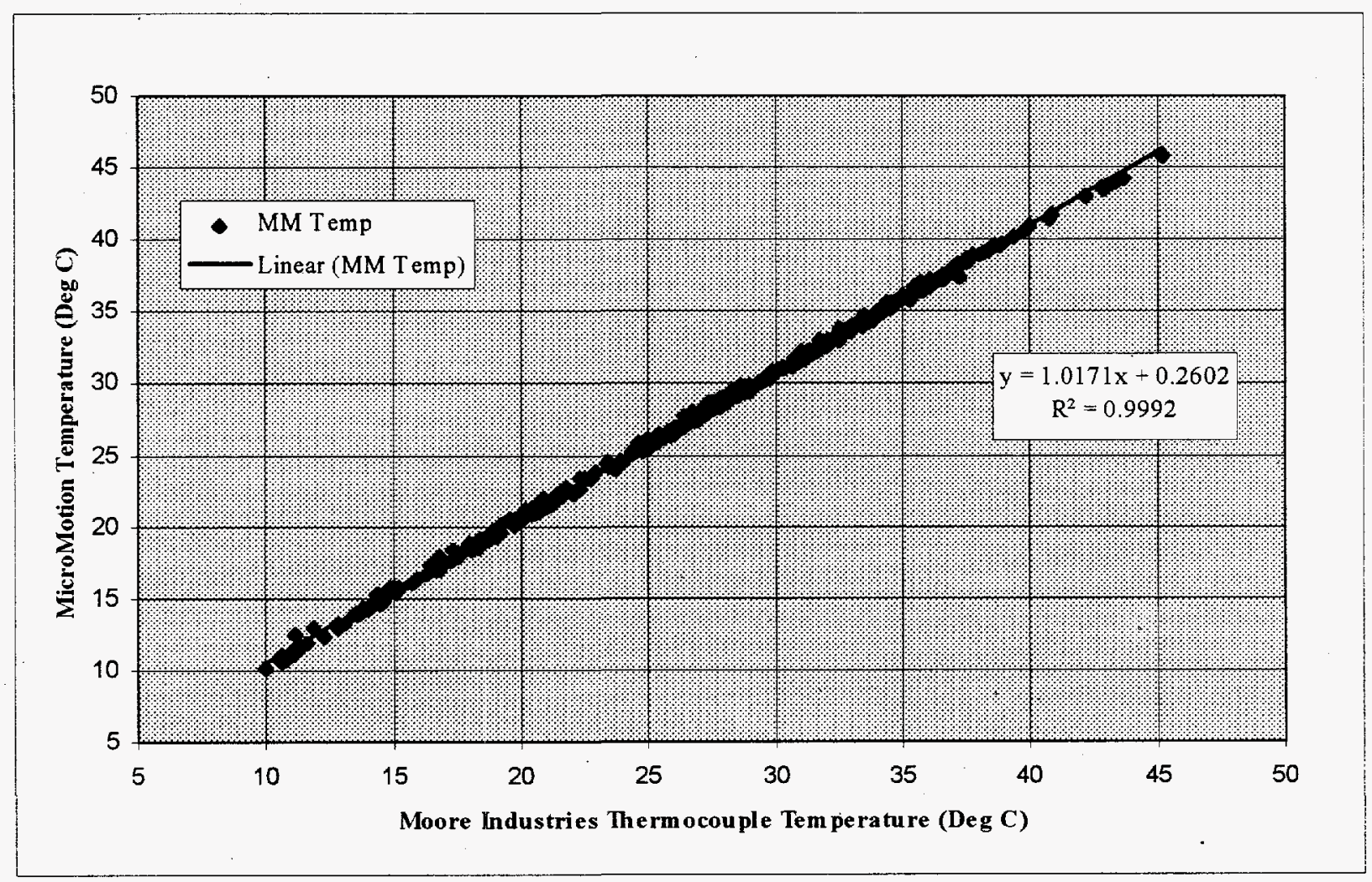

Figure 3.2. Thermocouple Comparison 


\subsubsection{Density}

The results of the density analyses showed that settling did not occur in the feed tank or in the test loop itself. The Micromotion densities agree very well with the reference densities and to the densities derived from the feed tank volumetric calibration tests.

\subsubsection{Settling in Feed Tank}

Two sample ports were installed into the feed tank to determine if solids settled during the course of a run. Samples from the upper (S-1) and lower (S-2) sample ports were taken during each run. The samples were analyzed in the field with a pycnometer and in the laboratory. If the solids settled, the solids concentration or density of sample S-2 should be greater than in S-1.

Analysis of the laboratory based density as measured with a pycnometer is shown in Figure 3.3. The largest percentage increase observed in the density of the S-2 sample was less than $1 \%$ and the average was calculated to be $0.03 \%$ with a standard deviation of $0.24 \%$. A paired $t-T e s t$ showed that the difference between the S-1 density and S-2 density was not statistically significantly different from 0 (see

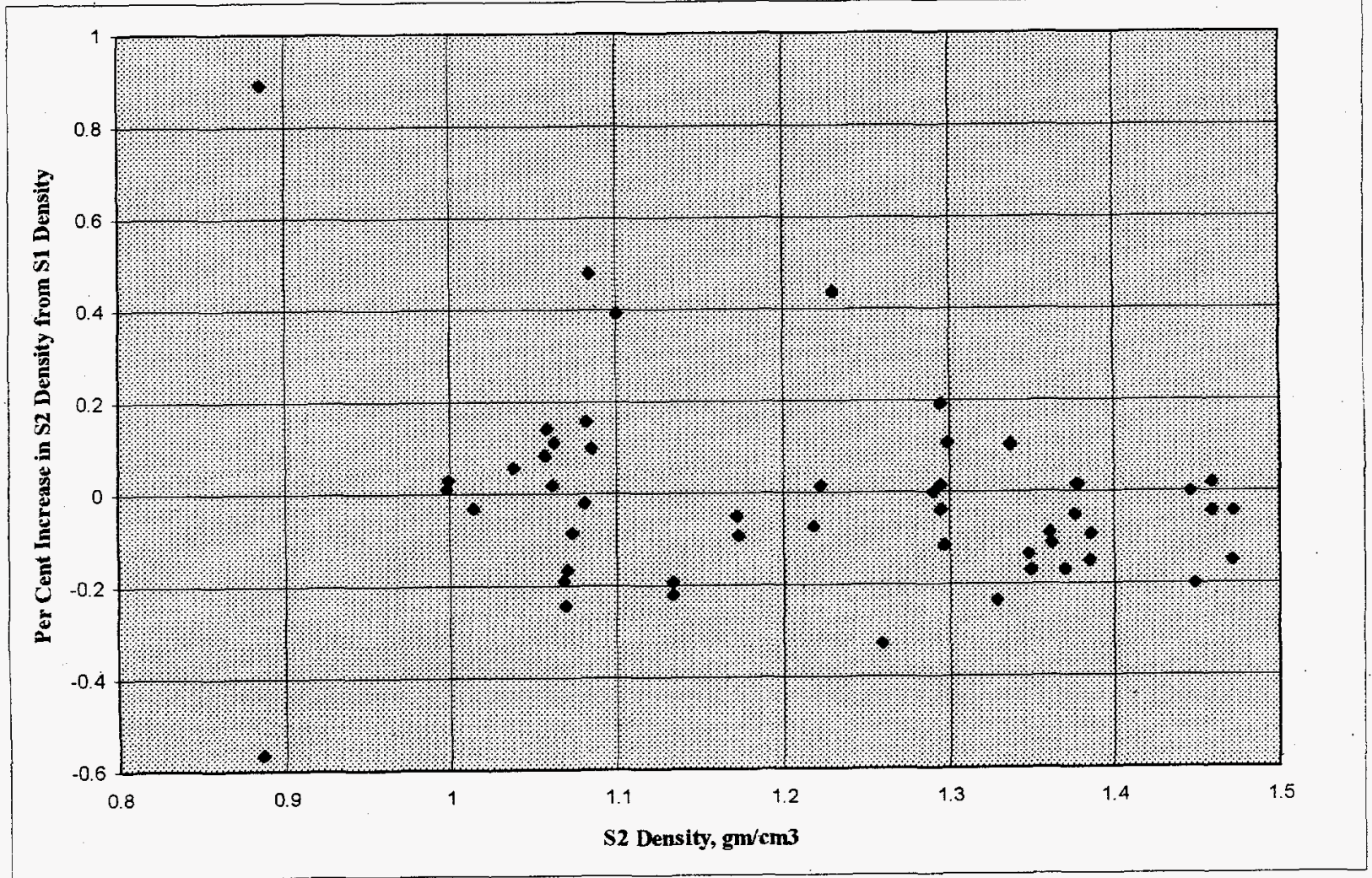

Figure 3.3. Settling in Feed Tank 
Appendix D-1). Also, a paired $\mathrm{t}$-Test of the volume\% solids measured in the laboratory showed that the difference between the S-1 solids volume\% and S- 2 solids volume\% was not statistically different from 0 (see Appendix D-2). Therefore, no settling is observed in the top layer of the feed tank.

The average density of the upflow (S-3) and downflow (S-4) samples taken in the test loop legs was plotted against the average density of the feed tank samples (S-1 and S-2) (labeled S-1/S-2 in subsequent graphs) to test whether settling may have occurred in the bottom of the feed tank (see Figure 3.3). The results show a near perfect correlation with no evidence of settling in the tank. Also, the results of a paired t-test showed that the difference between the average of the S-3 and S-4 samples and the average of the S-1 and S-2 samples was not statistically significantly different from 0 (see Appendix D-3).

\subsubsection{Micromotion vs. Analytical Values}

Figure 3.4 shows a regression analysis of the Micromotion density plotted against the average laboratory density measured by the pycnometer from Samples S-3 and S-4. The line should have a slope of one. The fit was not expected to be perfect because the temperature of slurry in the pycnometer samples may have cooled slightly during the measurement process, because of random errors in the weighing/filling process and because the S-3 and S-4 samples were not taken at the same temperatures as the Micromotion

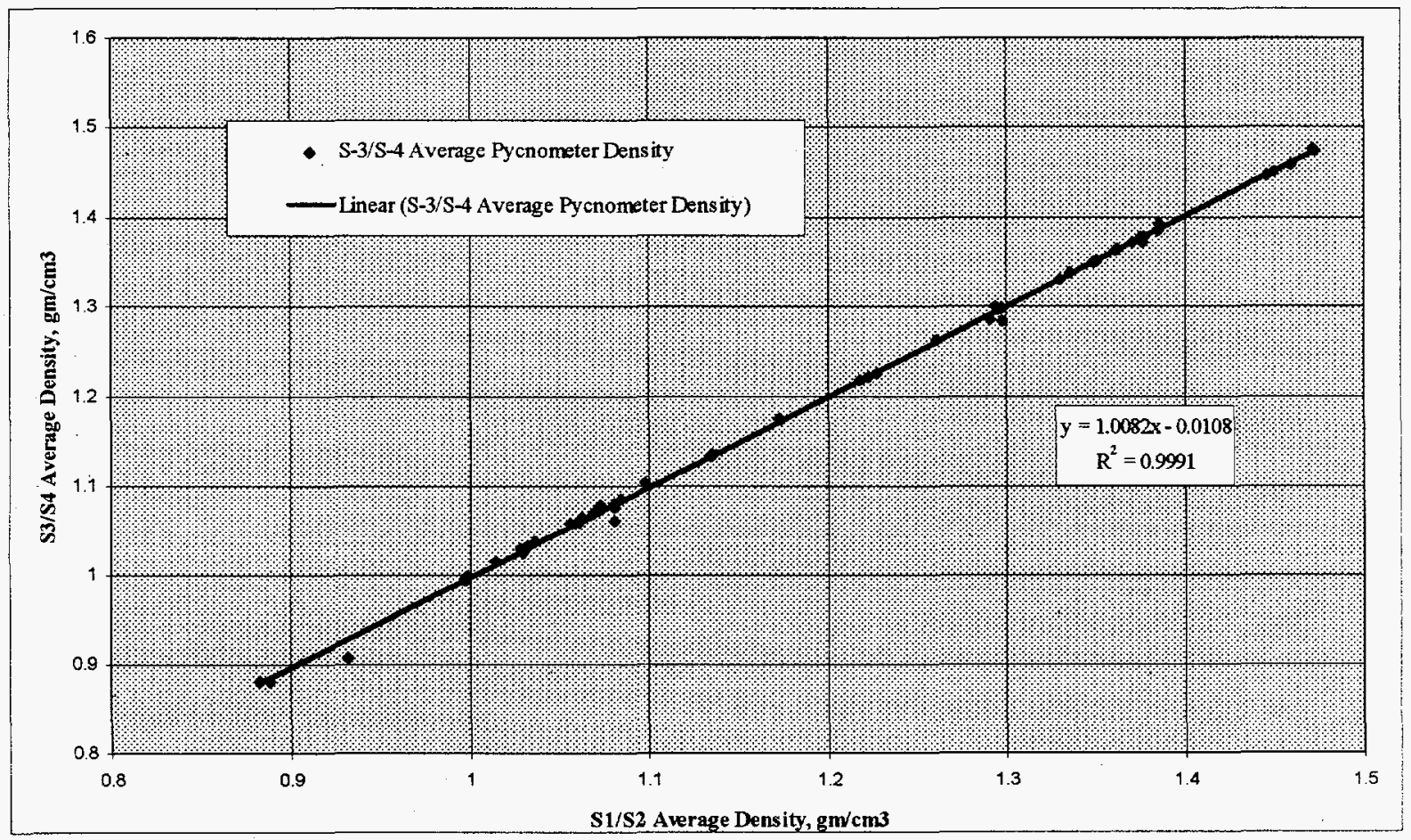

Figure 3.4. Test Loop Density vs. Feed Tank Density 
densities. The Micromotion densities were interpolated (or extrapolated) based on the slurry temperature taken simultaneously with the Micromotion density measurements to correct them to the S-3 and S-4 temperatures.

The observed regression line has a slope of 1.122 . The paired $t$-Test indicates that the difference between Micromotion density and the average of the S-3 and S-4 density is statistically significantly different from 0 (see Appendix D-4). This result is consistent with the regression line for the Micromotion data in Figure 3.5 because the Micromotion appears to read slightly high at all densities but the offset appears to be a consistent percentage high. All Micromotion densities were observed to be within the $5 \%$ allowable error tolerance specified with the exception of Run 2 . Run 2 with the plastic powder produced a thick foam in the feed vessel with large amounts of air trapped in the feed and resulted in the S-3/S-4 density of $0.88 \mathrm{gm} / \mathrm{cm}^{3}$. The $\mathrm{S}-3$ and $\mathrm{S}-4$ measured densities are about $0.1 \mathrm{gm} / \mathrm{cm}^{3}$ lower than measured by the Micromotion because the feed to the test loop is taken from the bottom of the tank and does not pick up any of this entrained air foam.

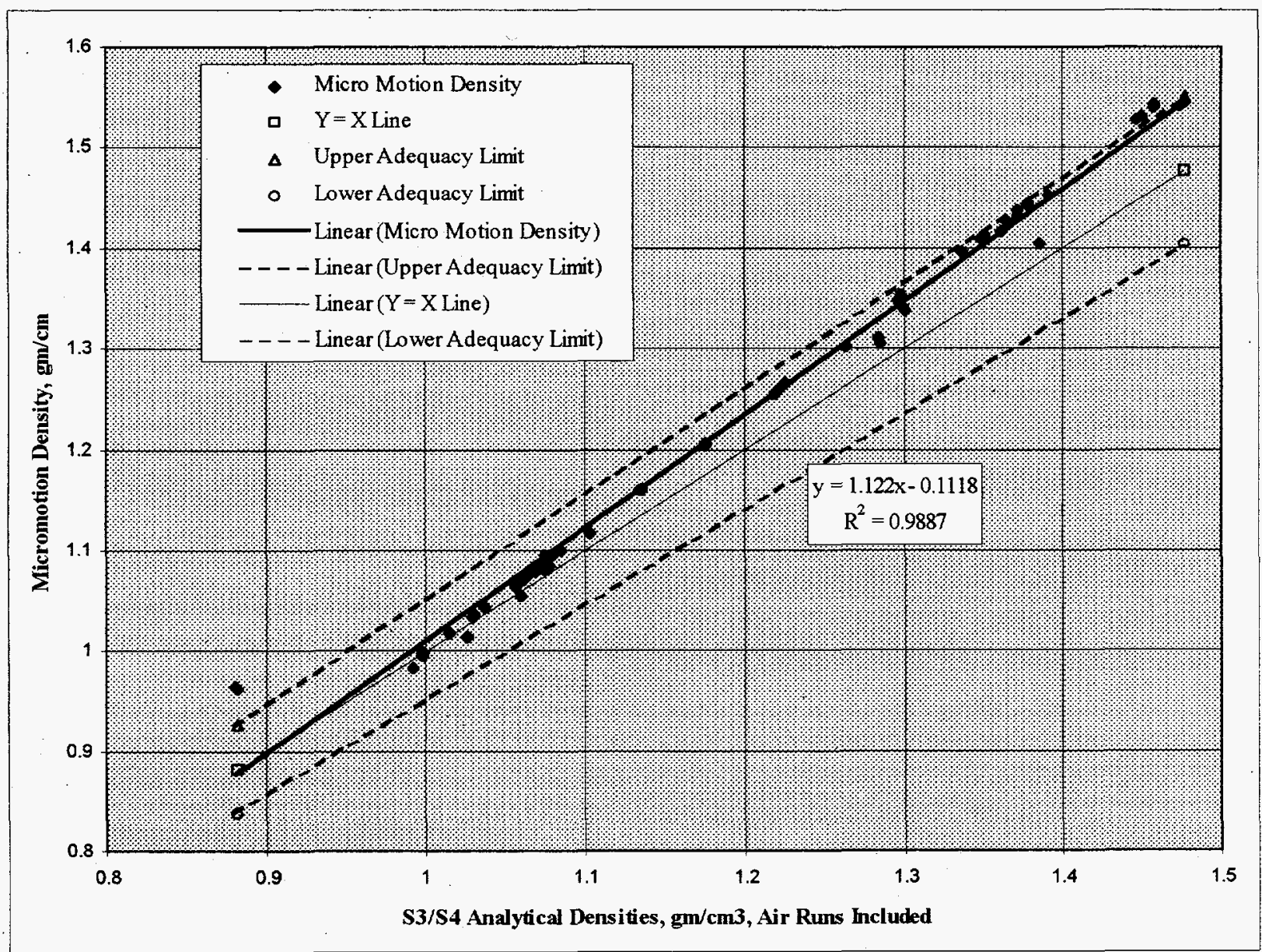

Figure 3.5. Micromotion Density vs. Average S-3 \& S-4 Density, Air Runs Included 
Figure 3.6 is the same data as in Figure 3.5 except that runs where air bubbles were deliberately introduced were excluded. The observed regression line has a slope of 1.1654 and is a slightly better correlation than in Figure 3.5.

Figure 3.7 shows a regression analysis of the Micromotion measured densities compared to the slurries densities calculated from the calibrated vessel tests. In theory, the line should have a slope of one. In this case, the Micromotion densities and calibrated vessel derived densities were measured at the same temperatures. No temperature interpolation or extrapolation was required.

The observed regression line has a slope of 1.1044. The observed fit is not as good as the previous regression. The paired $\mathrm{t}$ - test indicated that the difference between the Micromotion density and the measured density is statistically significantly different from 0 (see Appendix D-5). This is not surprising because there is more random error in measuring the calibrated feed vessel volume than the pycnometer and because the Micromotion densimeter has already been shown to read a little high. Since the calibration derived densities are derived from the measurements of the flow rates, the detailed discussion of sources of errors is presented in Section 3.3.5 for flow rates. The Micromotion appears to read slightly high at all densities but the offset appears to be a consistent percentage high. All Micromotion densities

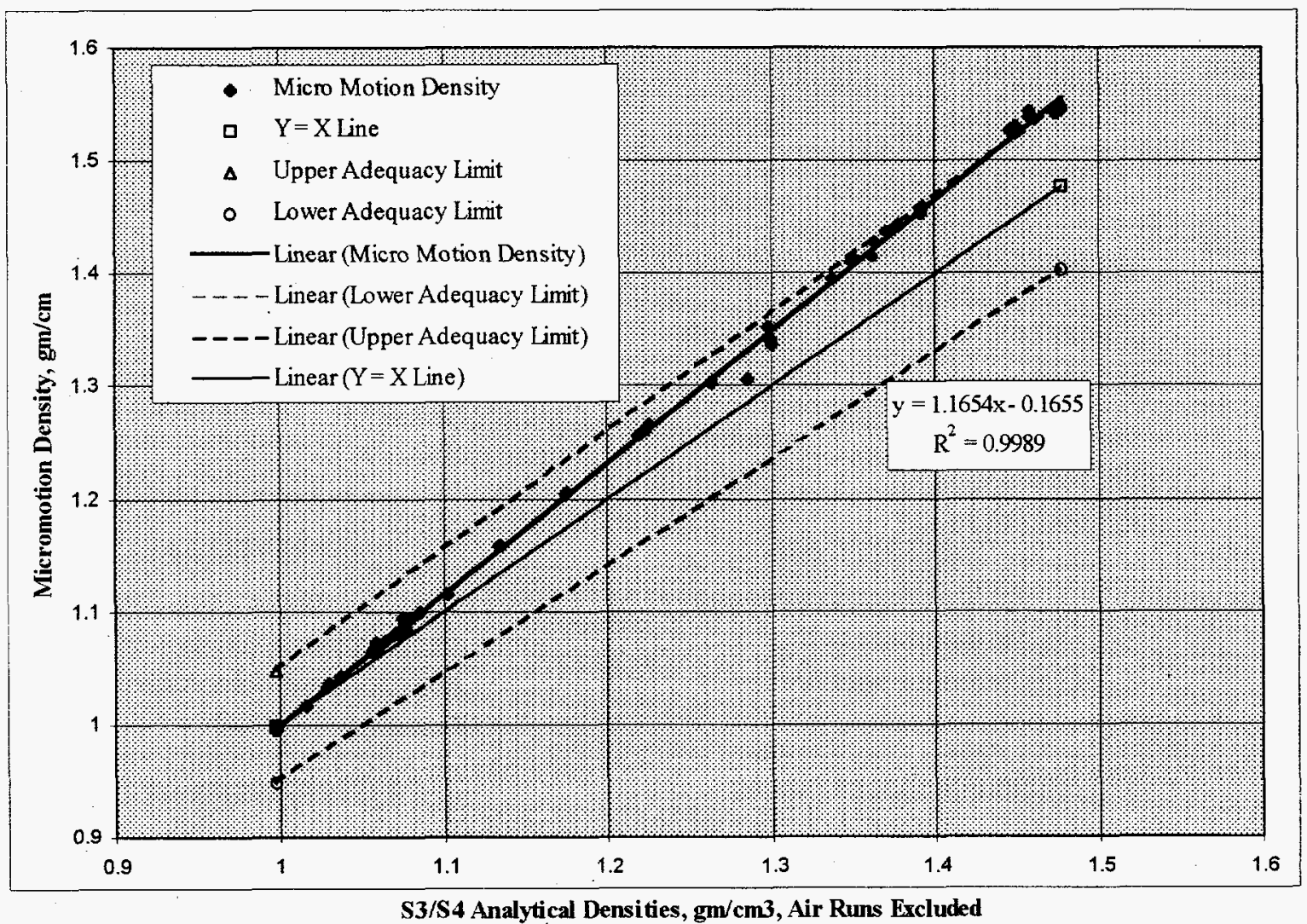

Figure 3.6. Micromotion Density vs. Average S-3 \& S-4 Density, Air Runs Excluded 


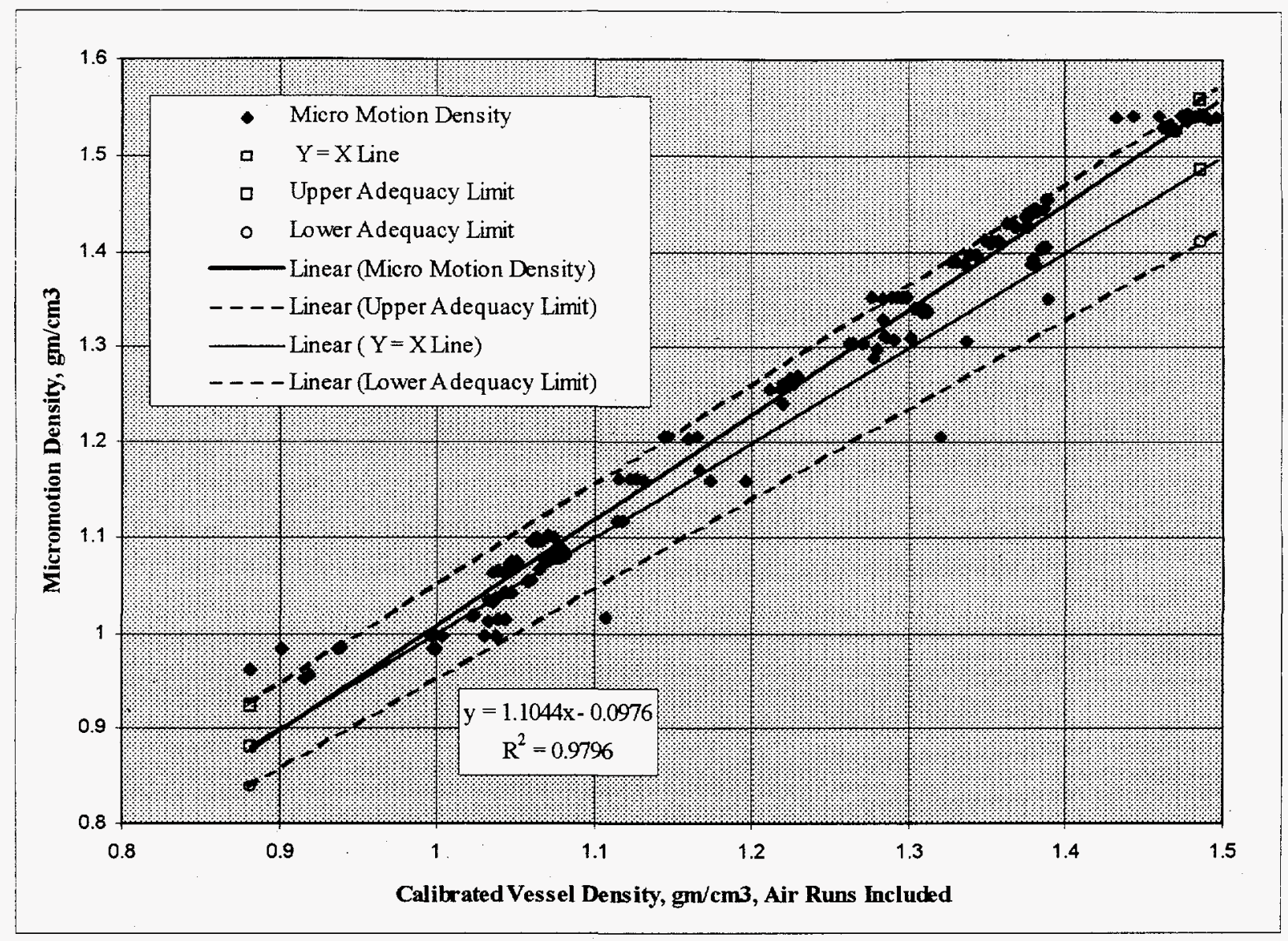

Figure 3.7. Micromotion Density vs. Calibrated Vessel Density

were observed to be within the 5\% allowable error tolerance specified with the exception of Run 2 . Run 2 with the plastic powder produced a thick foam in the feed vessel with large amounts of air trapped in the feed. The S-3 and S-4 measured densities for Run 2 are about $0.1 \mathrm{gm} / \mathrm{cm}^{3}$ lower than measured by the Micromotion.

\subsubsection{Viscosity}

The Nametre Viscoliner was difficult to install and make operational due to the vibrations in the test loop. Once operational, large spikes in viscosity were seen. The cause of these spikes was not determined but may have been random vibrational effects. The Nametre was found to give a qualitative agreement with the laboratory measurements but did not meet the desired acceptability criteria.

\subsubsection{Temperature Change Impacts}

Most tests started with a loop temperature of $10^{\circ} \mathrm{C}$ to $20^{\circ} \mathrm{C}$, but ended at around $40^{\circ} \mathrm{C}$ - to $45^{\circ} \mathrm{C}$ because of the heat added to the fluid by the pump. Between $10^{\circ} \mathrm{C}$ and $40^{\circ} \mathrm{C}$, the viscosity of water drops 
from 1.307 to $0.6529 \mathrm{cP}$ (CRC Handbook of Physics). Since most empirical relationships show a direct relationship between the slurry viscosity and the carrier liquid viscosity, it was assumed that the viscosity would decrease appreciably at higher temperatures. The simplest such relationship is the Einstein equation, which describes slurry viscosity as a function of the carrier liquid viscosity and the solids volume fraction:

$$
\mu=\mu_{c}(1+2.5 \phi)
$$

where $\mu$ is the slurry viscosity, $\mu_{c}$ is the carrier liquid viscosity (i.e., water), and $\phi$ is the solids volume fraction.

The Einstein equation applies only to dilute suspensions of spherical particles up to a void volume of approximately 0.10 . Other correlations, which are functions of only the carrier liquid viscosity and the void fraction, have been developed. The Thomas (1965) correlation, for example, was developed with particles ranging in size from 0.1 to 435 microns, and solids concentrations up to 80 volume\%:

$$
\mu=\mu_{c}\left[1+2.5 \phi+10.05 \phi^{2}+0.00273 \exp (16.6 \phi)\right]
$$

Since the slurry viscosity was expected to decrease as the temperature increased, and temperature increases as the day progresses, the run order was adjusted so that the more concentrated slurries (i.e., high viscosity) were run first (e.g., Runs 5A0 and 5A). For other runs, the more dilute slurries were run before the concentrated slurries (e.g., Run 4A - 4A3). By alternating runs in this fashion, the effects of temperature and solids concentration can be separated in the statistical analyses (i.e., decoupled) but the effects are still seen in the test data.

\subsubsection{Observed}

This section presents viscosity results from the available techniques to measure the on-line viscosity.

Nametre Vibrational Interference. Mechanical noise in the system caused problems with the Nametre readings in both the Project W-211 and the "ideal" loops. Nametre provided guidelines on the vibrational interferences that are acceptable for acceptable performance. The guideline is illustrated in Figure 3.8. The figure also plots IVF vibration (Project W-211 loop) measurements before and after mechanical isolation of the pump. Before pump isolation, the amplitude of the deflections were near or above the unacceptable region over a range of frequencies. Before pump isolation the Nametre viscosity measurements were extremely erratic, fluctuating from $\sim 1$ to $\sim 27 \mathrm{cP}$ while running water in the system, regardless of system flowrate. After isolation, the amplitude of the deflections were reduced into the acceptable region and the Nametre viscosity measurements were generally stable within $2 \mathrm{cP}$. 


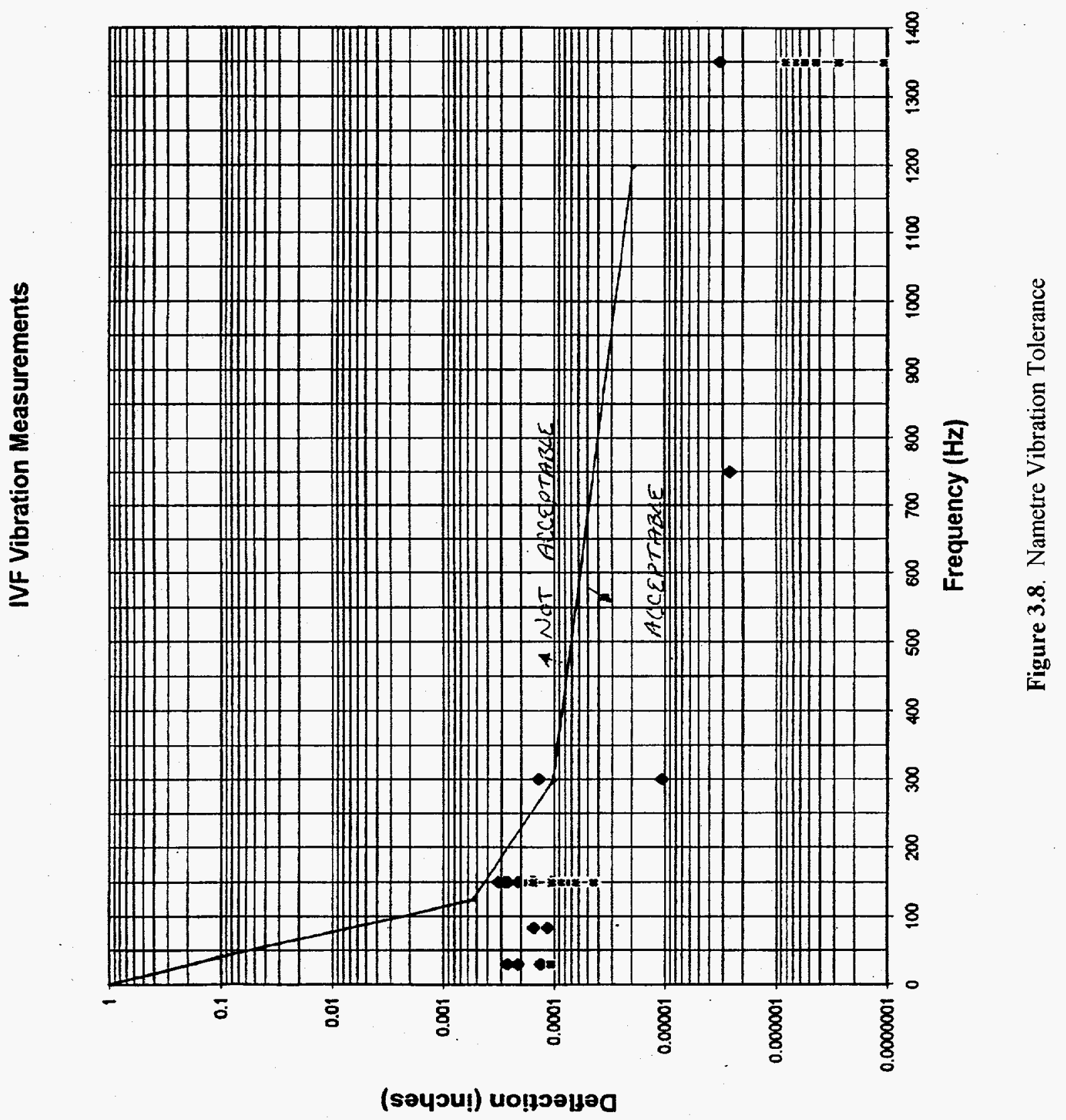


Figure 3.9 shows a plot of the Nametre viscosity versus time throughout Run 3. The solids loading was changed twice during this run. The Nametre reported viscosity jumps at each change. Within these three time periods, the Nametre fluctuated around a mean value. There were numerous spikes in the reading and then it decayed back to the nominal reading. These spikes may have been due to random vibrations entering the system from outside of the test loop but have never been satisfactorily explained. If the Nametre is to be used, it is important that an averaging routine be used so that a control action is not taken based on one of these instantaneous spikes.

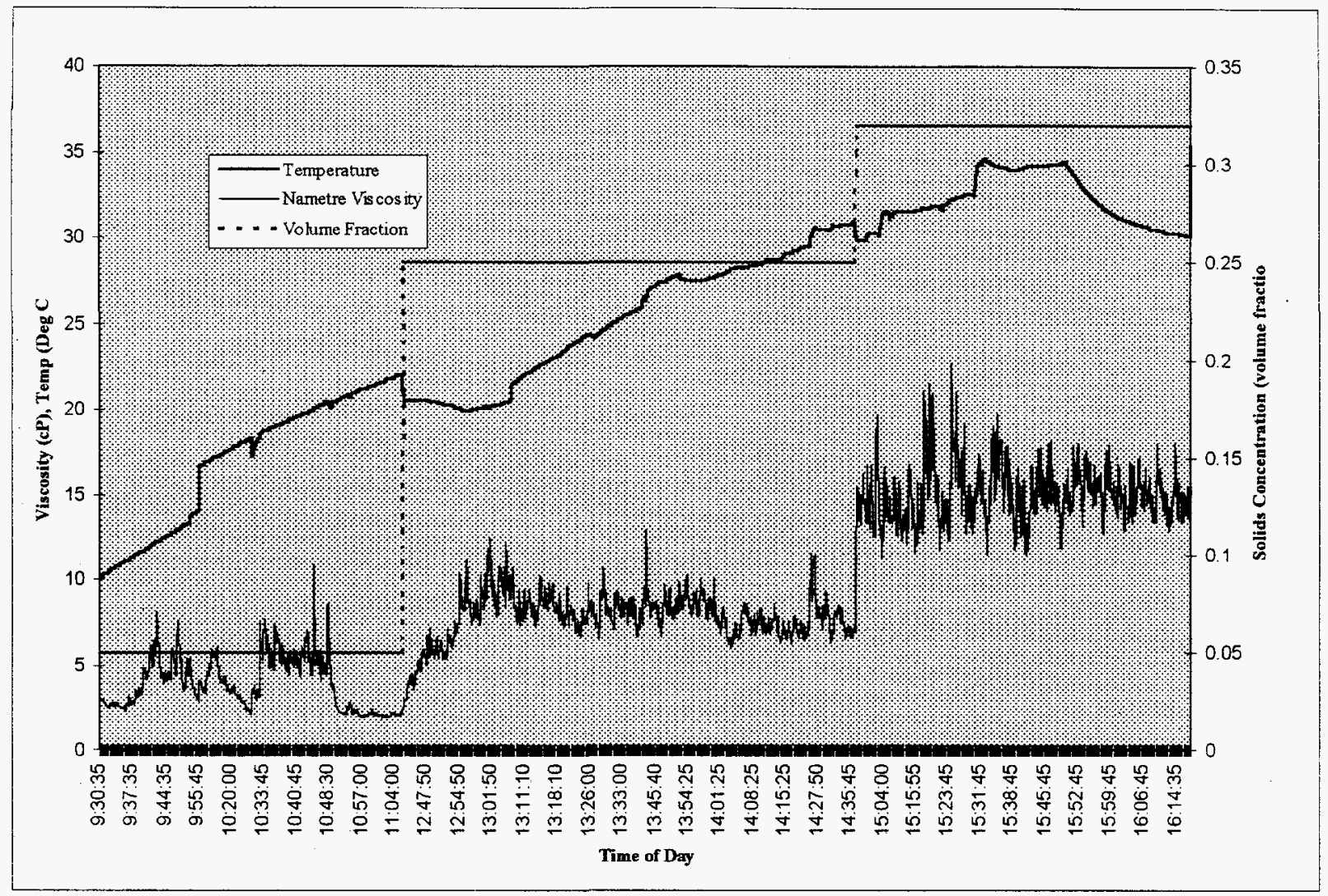

Figure 3.9. Nametre Viscosity Stability

Nametre Viscosity Correlation. The Nametre torsion-oscillation principle applies a shear to the fluid which is significantly different than the shear experienced by the slurry at the pipe wall. Slurries expected in the cross-site transfer system are generally shear thinning, so the measured viscosity is likely to be shear dependent. The Nametre viscosity is measured at a shear rate of $4084 \mathrm{sec}^{-1}$, while the estimated shear at the wall in the IVF at $6.0 \mathrm{ft} / \mathrm{sec}$ is on the order of $1000 \mathrm{sec}^{-1}$. Since most of the slurries run in the IVF were shear thinning, it is not surprising that the Nametre viscosity readout was consistently less than -expected from the laboratory Haake instrument with a maximum shear rate of $300 \mathrm{sec}^{-1}$. Figure 3.10 shows the raw data obtained from the Haake in the lab against the measured Nametre viscosity in the test loop. 


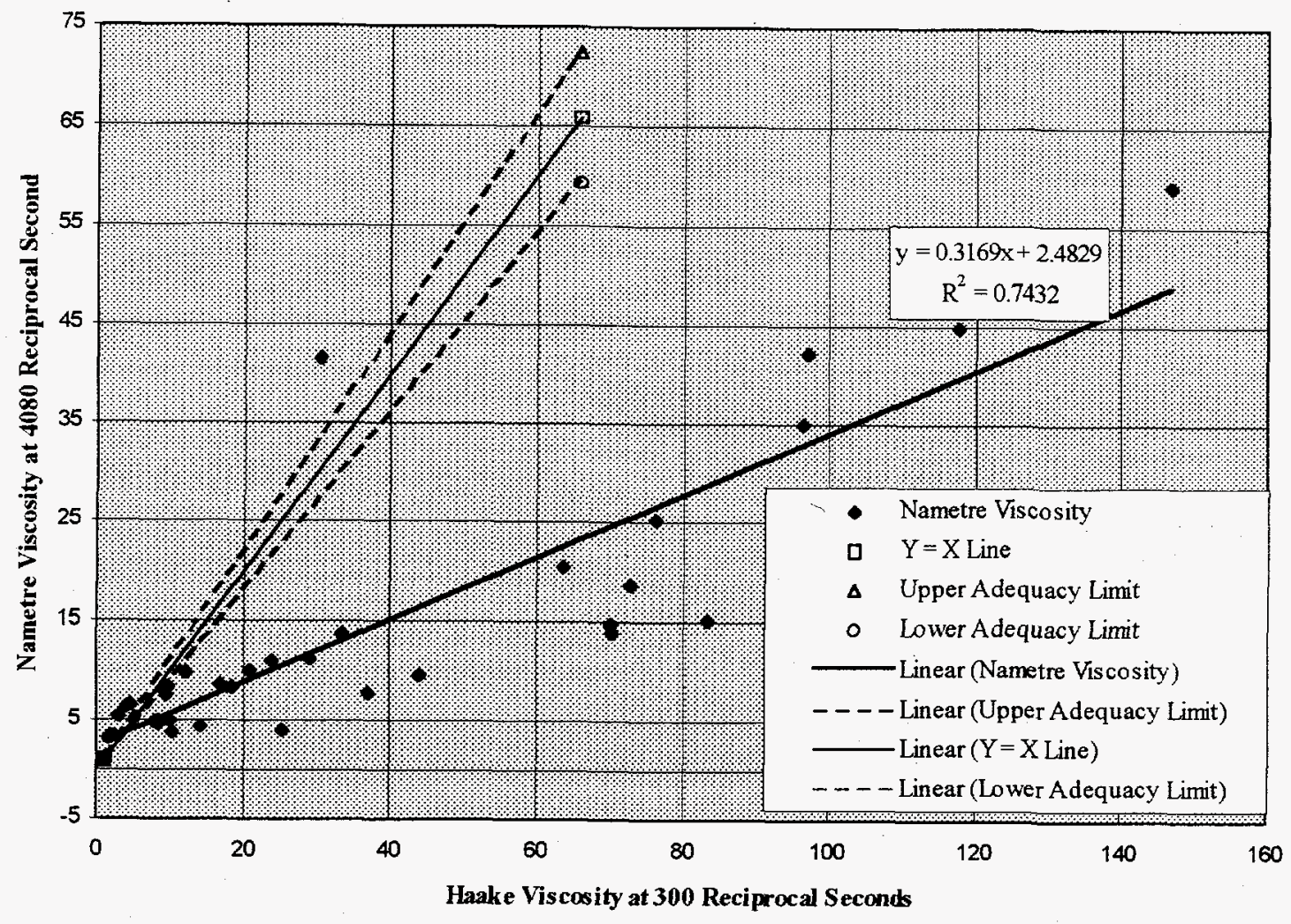

Figure 3.10. Nametre vs. Haake at $300 \mathrm{Sec}^{-1}$

Figure 3.11 presents the Nametre viscosity against the Haake viscosities extrapolated to $1000 \mathrm{sec}^{-1}$, which is the estimated shear rate at the wall in a 3-inch pipe at $6 \mathrm{ft} / \mathrm{sec}$. The pressure drop measured in the test loop should correlate to this approximate shear rate.

Figure 3.12 presents the Nametre viscosity against the Haake viscosity when extrapolated to $4084^{-1}$ reciprocal seconds. Note that a data point at a Haake viscosity of $65 \mathrm{cP}$ vs. a Nametre viscosity of $59 \mathrm{cP}$ is nearly obscured by the best-fit line and the lower adequacy limit line. The fit is surprisingly good considering the uncertainties in the extrapolation process and the operational difficulties with the Nametre. The Nametre does not, however, meet the $+/-10 \%$ accuracy criteria as specified by Project W-211 and as illustrated with the Upper and Lower adequacy limit lines. The Nametre appears to be useful as a general guide for determining if the viscosity of the fluid changes during transport and may play an important role in process debugging and control. 


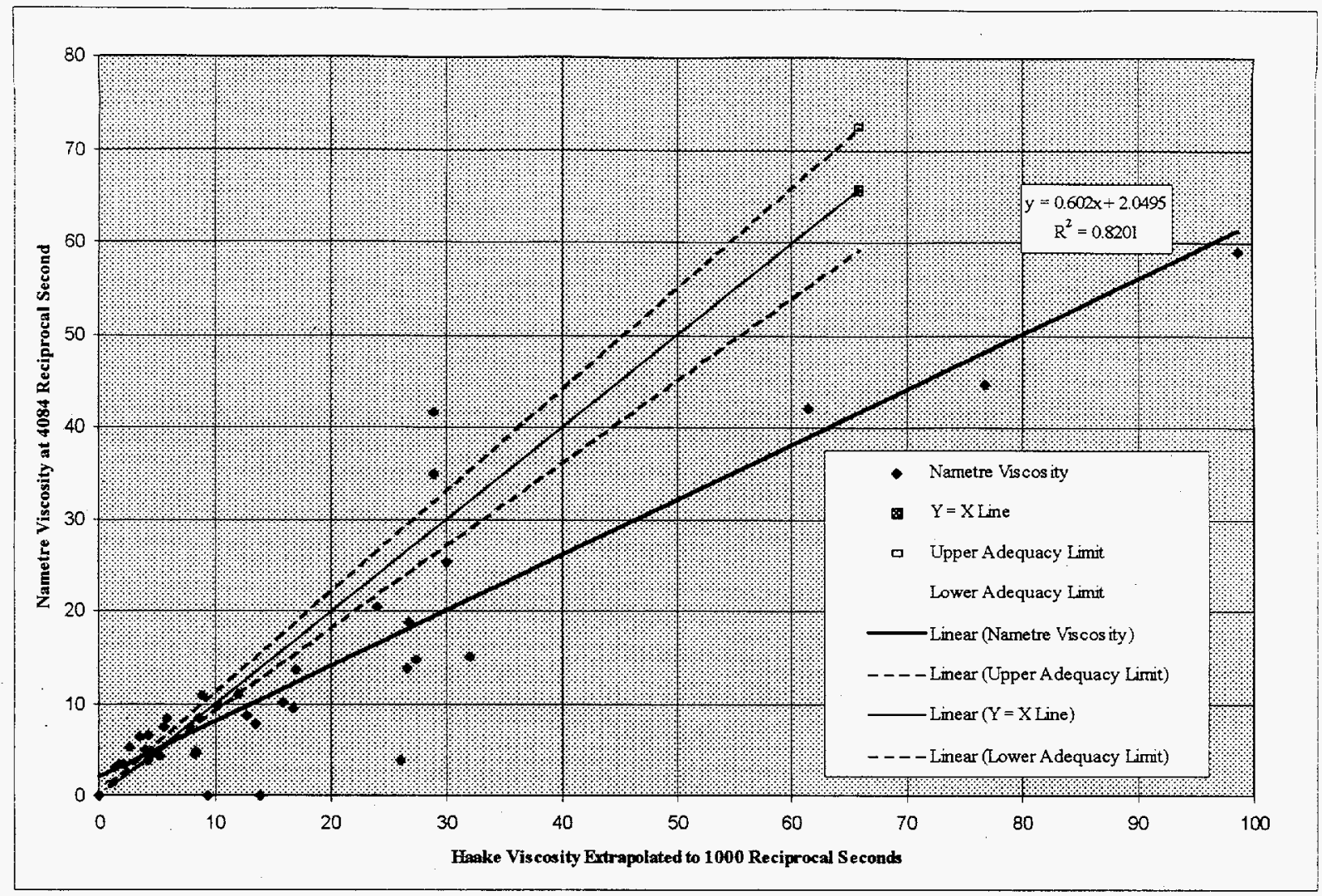

Figure 3.11. Nametre vs. Haake at $1000 \mathrm{Sec}^{-1}$

Nametre Discussion. Figure 3.12 showed that the Nametre provides a good qualitative agreement with laboratory measured viscosities and could therefore be suitable as an on-line indicator. The Nametre was used for this purpose in the testing program. However, the difficulty in installing and getting the viscometer to work in the Project W-211 loop and inability to make it work at all in the "ideal" loop must be considered equally. in the decision on whether to install or not install the Nametre in a high-radiation field environment where there is limited ability to debug the unit.

If the decision is that the qualitative indicator of the viscosity is needed, it is critical that the mechanical vibration in the Project W-211 test loop be quantified and reduced to well below the manufacturers recommendations before installation. The vibrational interference was registered in the Nametre like a switch, causing either extremely erratic reading when a threshold was exceeded or no problems when the mechanical noise was dampened.

The Nametre may be more useful for a single reasonably homogeneous real tank wastes slurry than the slurries tested because there would be a longer baseline and a more uniform feed. Any change in the Nametre value would provide information about changes in the slurry being transported. 


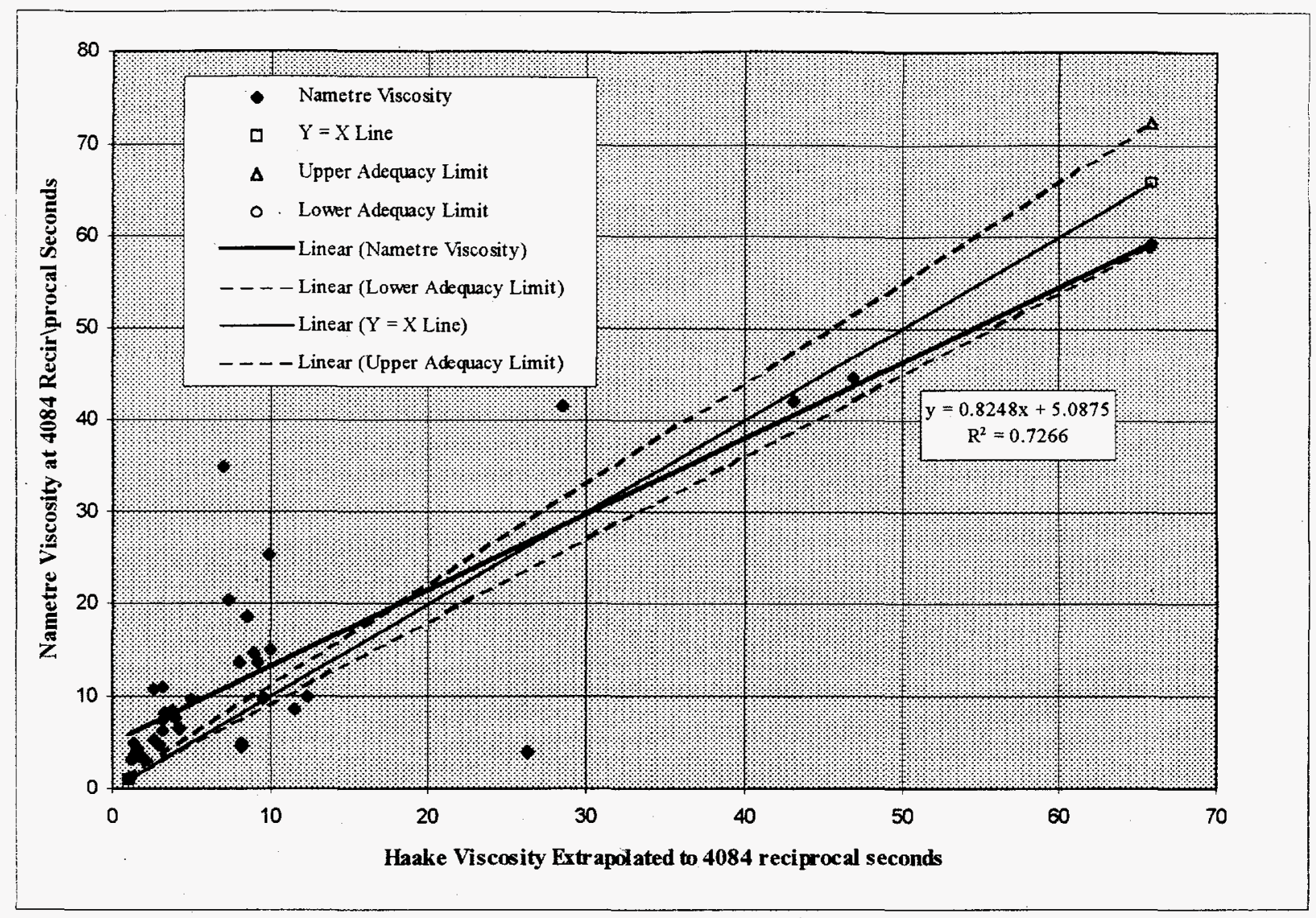

Figure 3.12. Nametre vs. Haake at $4084^{-1}$ Seconds

Viscosities from Pressure Drop. Figure 3.13 shows the measured pressure drop as a function of the Nametre viscosity. A positive correlation exists although there is some scatter in the data. Based on this data, the possibility exists for using a pressure drop measurement as a replacement for the Nametre viscometer. To further explore this possibility, the literature was searched for correlations that would enable back-calculation of the slurry viscosity from pressure drop measurements. The prime driver for this is the fact that since the viscosity limits of $10 \mathrm{cP}$ at $6 \mathrm{ft} / \mathrm{sec}$ and $30 \mathrm{cP}$ at $4.5 \mathrm{ft} / \mathrm{sec}$ were derived from the Cross-Site Transfer Line pressure drop calculations. Back-calculation of viscosity from line pressure drop is the most direct method to ensure that slurry properties do not exceed the line design criteria.

For all fluids, the pressure drop can be calculated from

$$
\Delta \mathrm{P}=\frac{2 \rho \mathrm{v}^{2} \mathrm{fL}}{\mathrm{D}}
$$




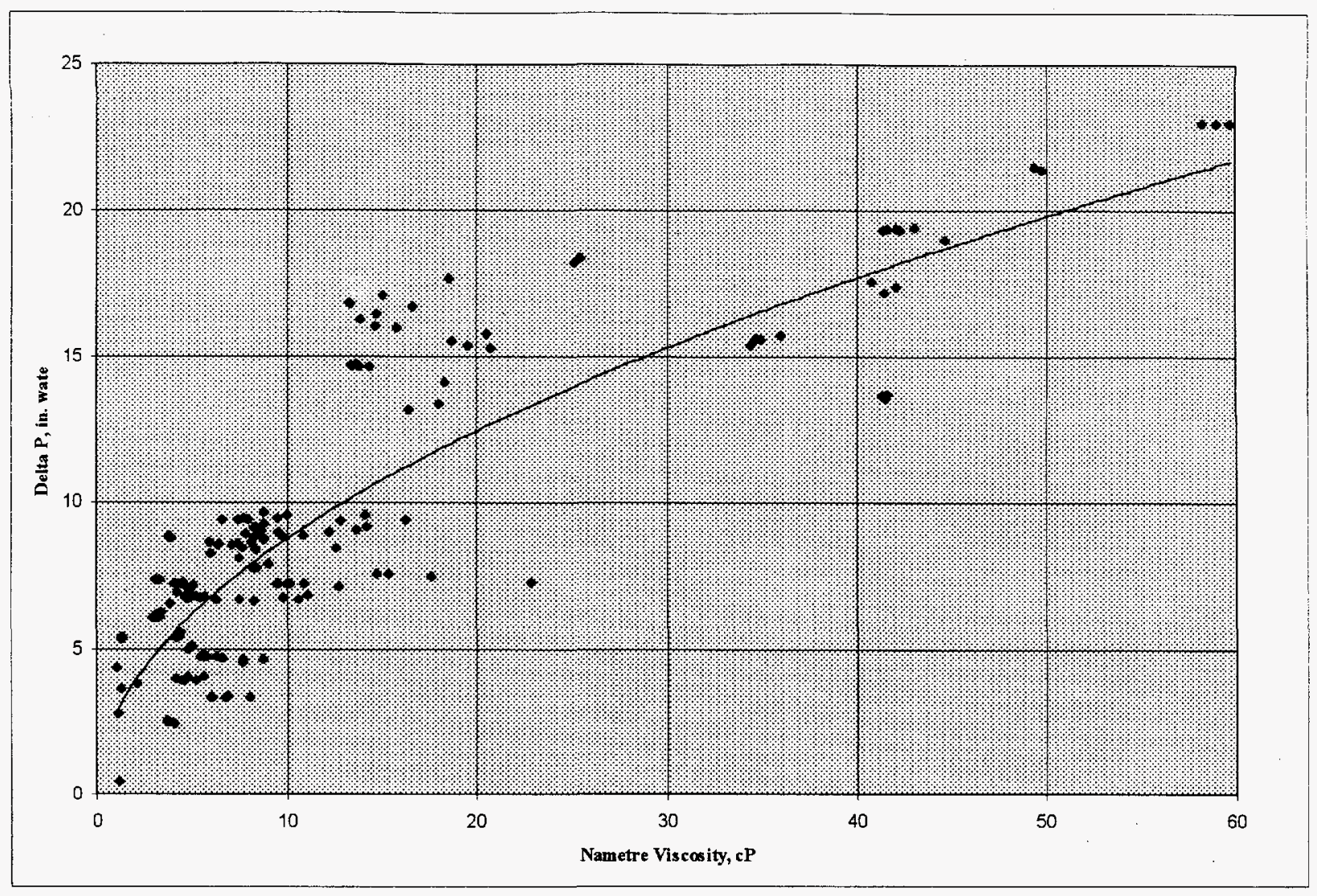

Figure 3.13. Pressure Drop vs. Nametre Measured Viscosity

where $\rho$ is the slurry density, $L$ is the length of pipe over which $\Delta P$ is measured, $D$ is the pipe diameter, $v$ is the fluid's average velocity, and $f$ is the Fanning friction factor. The friction factor, in turn, is a function of the Reynolds number ( $R e$ ), slurry rheological properties (e.g., the consistency parameter, yield stress, and the flow behavior index). The Colebrook formula is a popular correlation for the friction factor of a Newtonian (Denn 1980), turbulent fluid in a rough pipe $(4 . \mathrm{E} 3<\operatorname{Re}<2$.E7):

$$
\frac{1}{\sqrt{\mathrm{f}}}=-4.0 \log _{10}\left(\frac{\mathrm{k}}{\mathrm{D}}+\frac{4.67}{\operatorname{Re} \sqrt{\mathrm{f}}}\right)+2.28
$$

where $k$ is the surface roughness parameter for pipe (taken as $0.05 \mathrm{~mm}$ for rough steel). The Reynolds number, $\mathrm{Re}$, is commonly defined as 


$$
\operatorname{Re}=\frac{\rho v D}{\mu}
$$

where $\mu$ is the slurry viscosity. Although the Colebrook formula is a popular correlation, it is also a transcendental equation that requires a root finding algorithm to obtain each new value of friction factor.

An explicit equation for the friction factor of a Newtonian fluid in a rough pipe that agrees well with the Colebrook formula is given by Serghides (Serghides 1984):

$$
\begin{gathered}
A=-2.0 \log _{10}\left(\frac{\mathrm{k}}{3.7}+\frac{12.0}{\mathrm{Re}}\right) \\
\mathrm{B}=-2.0 \log _{10}\left(\frac{\mathrm{k}}{3.7}+\frac{2.51 \mathrm{~A}}{\mathrm{Re}}\right) \\
\mathrm{f}=\frac{1}{4} \frac{1}{\left(\mathrm{~A}-\frac{(\mathrm{B}-\mathrm{A})^{2}}{\mathrm{C}-2 \mathrm{~B}+\mathrm{A}}\right)^{2}} \\
\mathrm{C}=-2.0 \log _{10}\left(\frac{\mathrm{k}}{3.7}+\frac{2.51 \mathrm{~B}}{\mathrm{Re}}\right)
\end{gathered}
$$

Even though non-Newtonian models best describe the slurries that were run through the slurry pipe test loop, using a non-Newtonian friction factor calculation is likely to prove unwieldy for field use because the non-Newtonian rheological parameters may be difficult to obtain (these parameters are normally obtained from laboratory- generated rheograms). However, a good non-Newtonian model for the friction factor should yield similar results to a Newtonian model when Newtonian parameters are used with the nonNewtonian model.

The non-Newtonian friction factor correlation recommended in a previous PNNL paper ${ }^{(a)}$ (Erian 1994) is the Torrance equation:

(a) Erian, F. F., R. L. McKay and E. A. Daymo. 1994. TWRS Retrieval Technology Project: NonNewtonian Hanford Waste Slurry Transport Calculations Using Rheological Data of Tanks 101-SY, 101-AZ, and 102-AZ. Letter Report dated August 1994. 


$$
\sqrt{\left(\frac{2}{f}\right)}=(A-1.5 n B)+B 2.303 \log (1-x)+B 2.303 \log \left(\operatorname{Re}_{(\mathrm{PLC})} \sqrt{f^{(2-n)}}\right)+0.347(5 n-8) B
$$

where $n$ is the flow behavior index. $A, B$, and $x$ are given by

$$
\begin{aligned}
& A=\frac{3.8}{n} \\
& B=\frac{2.78}{n} \\
& x=\frac{\tau_{y}}{\tau_{w}}
\end{aligned}
$$

where $\tau_{w}$ is the wall shear stress and $\tau_{y}$ is the slurry yield stress. $\tau_{w}$ is defined as

$$
\tau_{w}=\frac{f \rho v^{2}}{2}
$$

The modified Reynolds number $\left(R e_{P L C}\right)$ for the Torrance equation is given by

$$
\operatorname{Re}_{\mathrm{PLC}}=\frac{8 \rho v^{2}}{\mathrm{~K}\left(\frac{8 \mathrm{~V}}{\mathrm{D}}\right)^{\mathrm{n}}}
$$

where $K$ is the consistency factor (i.e., Bingham viscosity).

Note that when the slurry is Newtonian, $K=\mu, R e=R e_{P L C}, n=1, \tau_{y}=0$, and the Torrance equation becomes (Denn 1980) 


$$
\frac{1}{\sqrt{\mathrm{f}}}=4.53 \log (\operatorname{Re} \sqrt{\mathrm{f}})-2.3
$$

This equation is similar in form to the von Kármán-Nikuradse equation (KN equation), which is an empirical correlation for Newtonian fluids over the entire turbulent region ( $\operatorname{Re}>4000)$ :

$$
\frac{1}{\sqrt{f}}=4.0 \log (\operatorname{Re} \sqrt{f})-0.4
$$

To back-calculate the viscosity from the pressure drop, a golden section search root finding technique was used to find the viscosity, $\mu$ (or $K$ ), which predicts the measured pressure drop. It is assumed that the temperature, pressure drop, fluid velocity, and density are known (constant) parameters: temperature (Moore Industries thermocouple), pressure drop (DP cells), flow rate (Yokogawa), and density (Micromotion) were averaged over ten seconds to smooth out normal fluctuations in the instrument readings.

The roughness parameter for the Serghides friction factor equation was determined empirically from a water-only test. Specifically, the pressure drop was measured during Run 1A when the temperature was $16.5^{\circ} \mathrm{C}$. The viscosity of water at $16.5^{\circ} \mathrm{C}$ is approximately $1.09 \mathrm{cP}$ (CRC Handbook of Physics and Chemistry), so the empirical roughness factor can be estimated such that the back-calculated viscosity is calibrated to a water standard at this temperature, flow rate, and pressure drop. The empirical roughness factor was determined to be $0.036 \mathrm{~mm}$ (compared to a literature value of $0.05 \mathrm{~mm}$ for commercial steel).

The Torrance relationship does not have an empirical factor to "normalize" the equation to the IVF system. Consequently, the length over which the pressure drop was measured was increased (from $3.03 \mathrm{~m}$ to $3.55 \mathrm{~m}$ ). After adjusting the roughness parameter for the Newtonian friction factor correlation, and the effective pipe length for the non-Newtonian friction factor correlation, the viscosity of water in Run 1A matched that of the CRC Handbook.

Figure 3.14 is a plot of viscosity back-calculated from the pressure drop using a Newtonian friction factor correlation vs the viscosity calculated from an extrapolation of the Haake rheogram to $1000 \mathrm{sec}^{-1}$. As discussed previously, $1000 \mathrm{sec}^{-1}$ is the assumed shear rate at the wall, and the principal viscous resistance that causes the observed pressure drop. Notice that there is little correlation between the two viscosity measurements. The lack of a correlation between the two viscosity measurements could either be because the shear rate at the wall is different from $1000 \mathrm{sec}^{-1}$ and/or because the Newtonian friction factor relationship is insufficient to describe the pressure drop of a non-Newtonian slurry.

There is, however, a correlation between the consistency factor of a yield-pseudoplastic material and the consistency factor back-calculated from the pressure drop calculation using the Torrance friction factor relationship (Figure 3.15). 


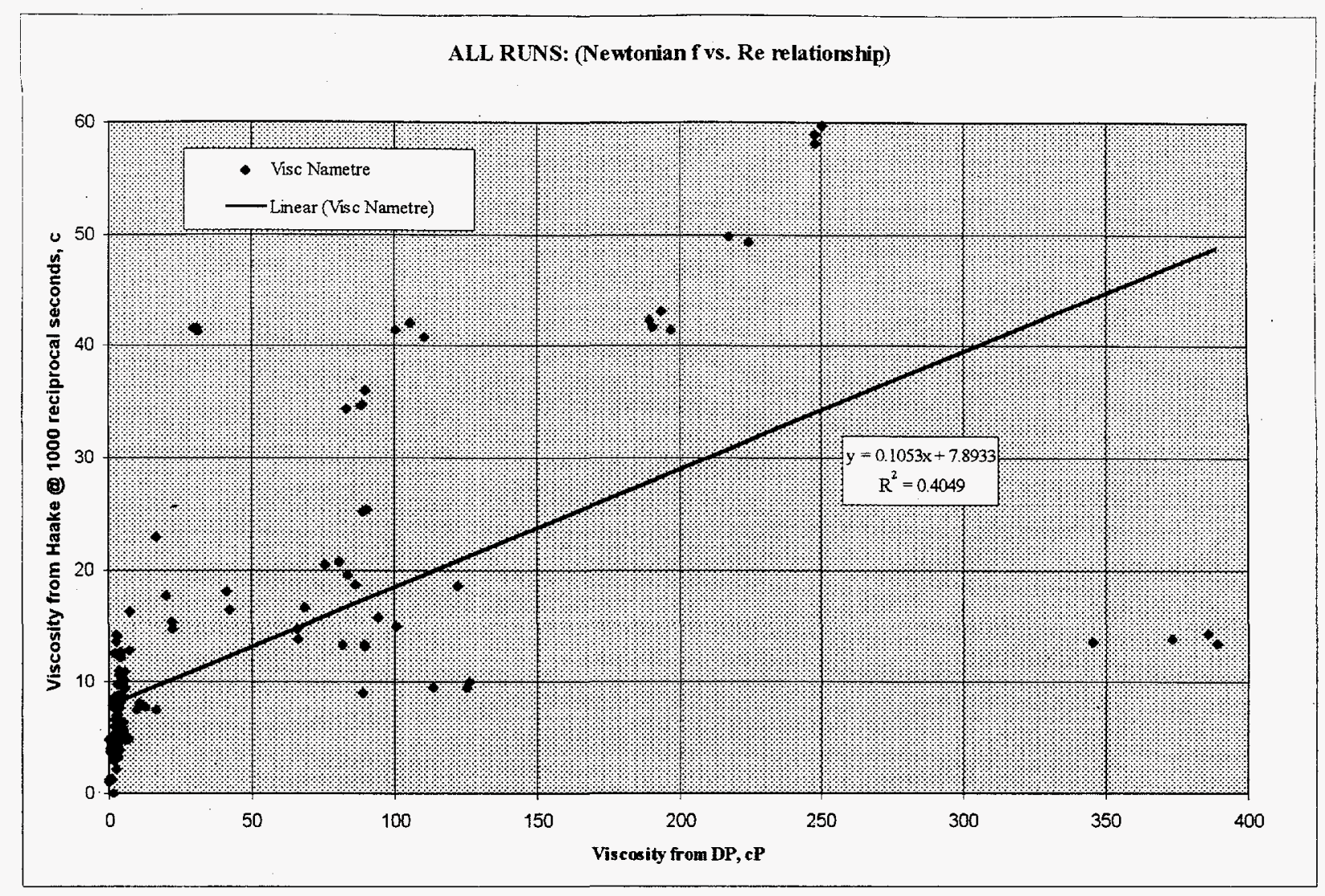

Figure 3.14. Haake Viscosity vs. Back Calculated Viscosity

The relationship is not perfect, though, for several reasons. First, the Torrance equation assumes that the rheogram is of the form of a yield-pseudoplastic (which includes Bingham plastics, where $n=1$, and power law fluids, where $\tau_{0}=0$ ):

$$
\tau=\tau_{0}+K \dot{\gamma}^{\mathrm{n}}
$$

However, not all of the slurries were described by this rheological equation. Graphite, gibbsite-graphite, bentonite, and bentonite-mica slurries were better described by the Casson or logarithmic shear stress (shear rate relationships). The Casson and logarithmic equations are of drastically different form than the rheogram for a yield-pseudoplastic, so the fitted parameters from the Haake instrument for these rheological equations are not applicable for the Torrance equation:

\section{Casson Equation:}

$$
\sqrt{\tau}=\sqrt{\tau_{0}}+\sqrt{\mathrm{K} \dot{\gamma}}
$$




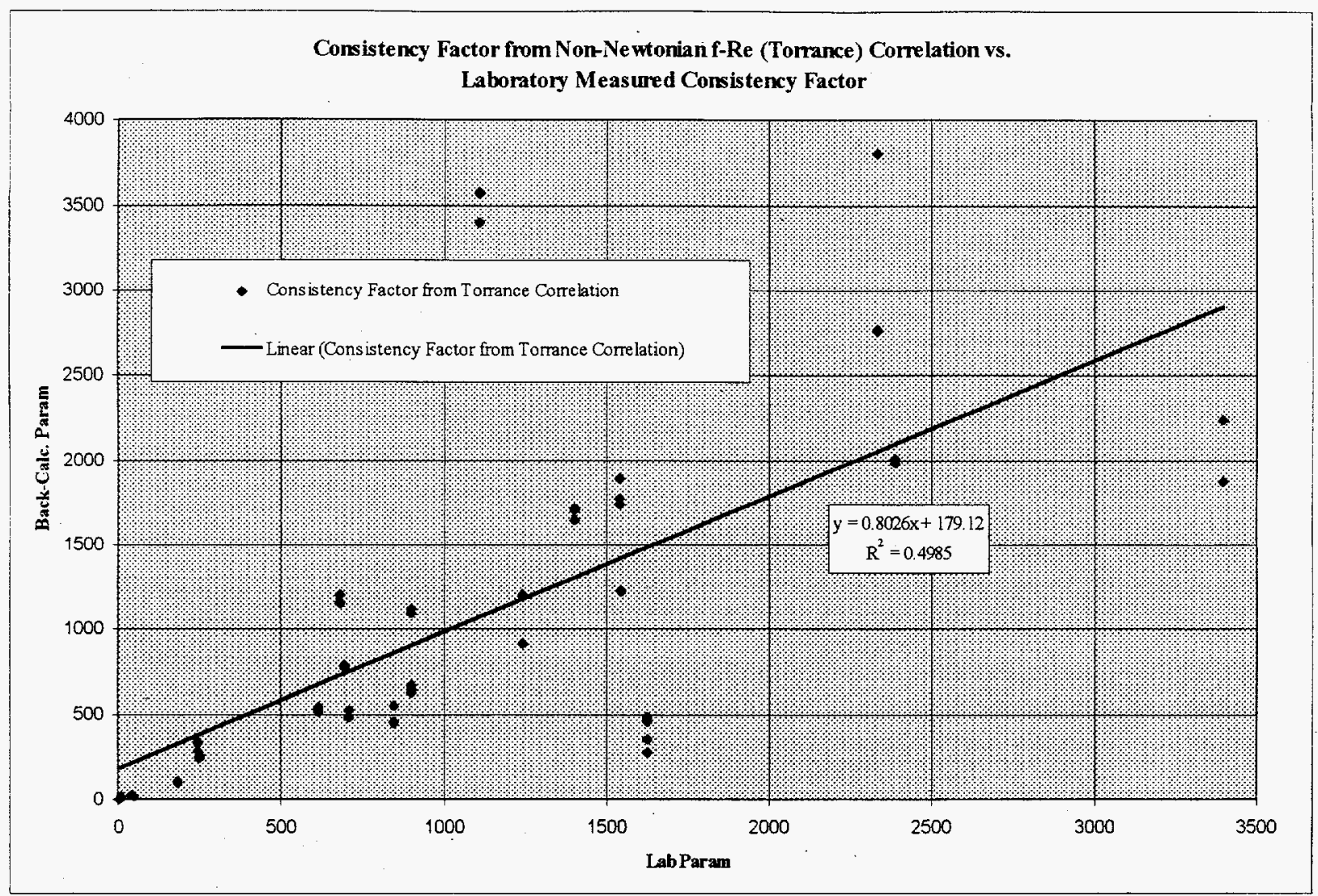

Figure 3.15. Back Calculated vs Laboratory Measured Consistency Parameters

Logarithmic Rheogram:

$$
\tau=K+b l n(\dot{\gamma})
$$

As a result, rheological parameters $\left(\tau_{0}, \mathrm{n}\right)$ for the Torrance equation were obtained from the Haake fit of either the Bingham, power law, or yield-pseudoplastic equations, even though the $\mathrm{R}^{2}$ for these fits was often between 0.7 to 0.8 .

Another reason why it was difficult to compare the back-calculated "viscosity" from the Torrance equation to laboratory measurements is because the Torrance equation is highly sensitive to the value of the exponent $n$. A 0.1 change in the (unitless) value of $n$ could shift the back-calculated "viscosity" by as much as $100 \%$. For some runs, the Haake fitted value of $n$ varied by as much as 0.1 .

Considering the errors which were faced in determining the back-calculated parameters, Figure 3.15 shows a surprisingly good correlation between the back-calculated "viscosity" and the laboratory measured parameter, $\mathrm{K}$. 
Even though there seems to be a good qualitative correlation between the pressure drop and the laboratory measured viscosity, the usefulness of this correlation must be questioned. It is expected that the tank waste slurries will exhibit non-Newtonian behavior, but the Newtonian friction factor correlation did not correlate well with the laboratory measured viscosity extrapolated to $1000 \mathrm{sec}^{-1}$. However, the nonNewtonian friction-factor Reynolds number correlation requires information about the yield stress and the rheological exponent, $n$. These two parameters may not be available since they can only be determined from laboratory measurements. In addition, the non-Newtonian back-calculation method obtains the value of the constant $K$ in the yield-pseudoplastic rheological equation. Depending on the value of the exponent $n, K$ may not have units of viscosity (e.g., cP, Pa-sec). Since the back-calculated parameter will have the same units of viscosity only when the fluid is a Bingham plastic $(n=1)$, it is difficult to compare the calculated constant $K$ to the 10 or $30 \mathrm{cP}$ limit of the Cross-Site Transfer System.

In summary, extracting useful quantitative information by the back-calculation methods presented here is unlikely to be of real use to Project W-211 operators. In fact, perhaps the entire approach of measuring the viscosity should be abandoned in favor of measuring the allowable $\Delta \mathrm{P}$ per length of pipe. After all, the $\mathrm{W}-058$ viscosity specification is really to make sure that the $\Delta \mathrm{P}$ per length of pipe is not exceeded. The viscosity is not particularly relevant provided that the $\Delta \mathrm{P}$ per length is not exceeded.

\subsubsection{Flow Rates}

The volumetric flow rates of the Fischer \& Porter and Yokagawa flow meters were compared to a flow rate measured in a calibrated volumetric vessel by measuring how much volume was delivered in a specific period of time.

The flow calibration tank volume was established mathematically from the geometry of the vessel. The column tank was constructed from a ten foot length of 16 -inch schedule 30 pipe. This geometry was chose to minimize air entrainment during the slurry discharge into the tank. The gas bubbles are confined to a thin layer near the surface but since the area is small, the error in determining the volume is also small.

The average wall thickness was 0.376 inch which corresponds well to the published wall thickness (for 16-inch schedule 30 pipe) of 0.375 inch. The cross sectional area of such a pipe, if it is a perfect cylinder, is $182.65 \mathrm{in}^{2}$. This cross sectional area represents the maximum area barring any severe stresses to the pipe which might cause a ballooning distortion. Because the wall thickness of the pipe matched the published values, the possibility of a ballooning stress was not considered further.

The inside diameter of the pipe was measured with micrometers. The smallest and largest diameters measured were 14.950 inches and 15.406 inches, respectively. These two diameters were perpendicular to one another. Assuming the flow calibration tank to be an ellipse, the cross sectional area would be 180.89 in $^{2}$. The difference in cross sectional areas between the perfect cylinder (maximum cross sectional area) and the elliptical cylinder was assumed to be our volumetric uncertainty. Comparing the elliptical crosssectional area with that of the perfect cylinder one finds a $0.97 \%$ difference. The error in reading 
the height measurement is thought to be less than $1 / 4$ inch or $+1-0.2 \%$ of full scale. The addition of these two uncertainties ( $1.2 \%$ of full scale) was assumed to be the error associated with the flow calibration tank.

The column tank was used to calibrate the load cells. The column tank was filled with water to various heights and the calculated mass was compared to the load cell displayed mass. All displayed masses from the load cells matched the calculated mass within $0.8 \mathrm{lbs}$ between 0 and $757 \mathrm{lbs}$.

During the experiment, a three-way valve was thrown to divert the flow of slurry from returning to the feed tank to the calibrated vessel. The three-way valve was diverted for an operator selected period of time to yield a reasonable height of slurry in the vessel. The height of this interface was recorded. Simultaneously, the original weight of the vessel before diversion and after diversion was recorded. Based on the volume of material added to the vessel and the time of diversion, the volumetric flow rate could be determined. The volumes from the Yokagawa and Micromotion flow meters were recorded simultaneously. The percentage error from the Yokagawa or Micromotion was calculated and used as the primary data for flow rate evaluation.

These experimental flow rate error determinations are subject to random experimental error. Specifically, for some slurries it was very difficult to measure the interface height in the sight glass because solids collected on the walls and obscured the interface. In this case, the height of the interface was measured from the inside top of the calibrated vessel. Also, as the higher solids loading slurries were very viscous, there was a significant time lag between the end of the diversion time and when the height of the interface in the sight glass finally equilibrated.

\subsubsection{Yokagawa Flow Meter}

Figure 3.16 shows a run chart of the Yokagawa flow rate over a 30-minute time period for Run 4Alb ( $25 \mathrm{vol} \%$ gibbsite). The steady downward drift is from the throttle valve shifting slightly. The data was fit and the residuals were examined to determine the noise inherent in the Yokagawa flow rate measurement. The average residual had a value of 0.0 and a normal distribution indicating a very good fit. The standard deviation of the residual was 0.0155 (liter $/ \mathrm{sec}$ ). Since events more that three standard deviation away from the mean occur only $0.03 \%$ of the time, any change from an established Yokagawa flow rate that exceeds 0.0465 (liter/sec) is a good indicator that a change has occurred in the process and should be watched very closely.

Figure 3.17 plots the average error in the Micromotion volumetric flow rate error against the average Yokagawa volumetric flow rate error. Two individual data points that were rerun were excluded because they were not consistent with the three other observations. Data from Run 5B1 (gibbsite/graphite) in the Project W-211 loop test and "ideal" loop test were excluded because the observations were extreme outliers with values of $-22.9 \%,-30.7 \%,-36.4 \%$ for the Project W-211 loop test and $-36.4 \%,-45.3 \%,-51.1 \%$, $-36.5 \%$ for the "ideal" loop test. Both of these runs were graphite runs. 


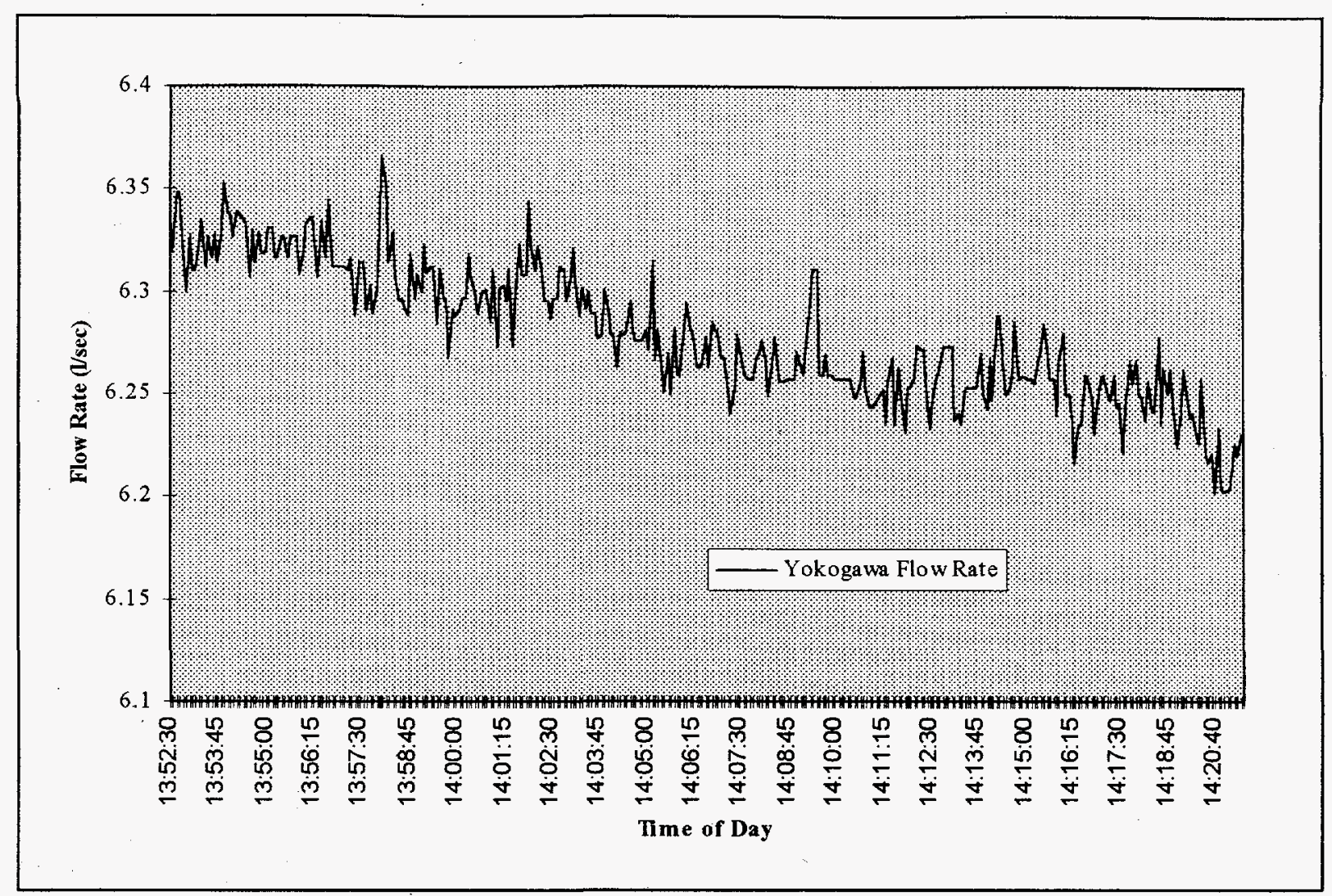

Figure 3.16. Yokagawa Flow Rate vs. Time

Of all the solids run in the IVF, only graphite caused operational problems. Graphite was observed to form a slimy coating on the inside of the slurry pipe, interfering with the electrodes and producing artificially low readings. Twice after graphite runs, the Yokagawa was removed from the pipe loop and cleaned even though the performance was recovered by back-flushing the instrument in the loop. After cleaning, the observed flow rate returned to normal. Any material that could coat the electrodes would interfere with the performance of the flow meters. Since it is not possible to know whether Hanford Site tank wastes would form these slimy coatings, it is recommended that any exposed electrodes be coated to prevent erroneous operation.

If the on-line flow meters report the same flow rates as was measured in the flow calibration tank, then the flow rate error for the flow meters should be equal to 0 . This was not observed with either flow meter. Specifically, the Yokagawa was observed to be on average $2.1 \%$ low. Since the error in the flow calibration tank was determined to be about $\pm 1.2 \%$, the Yokagawa error could be as low as $0.9 \%$ low or as high as $3.3 \%$ low compared to the reference. This range overlaps the acceptability limit of $\pm 2 \%$ (see Appendix D-8 for the distributional statistics). The above analysis includes pure water runs. 


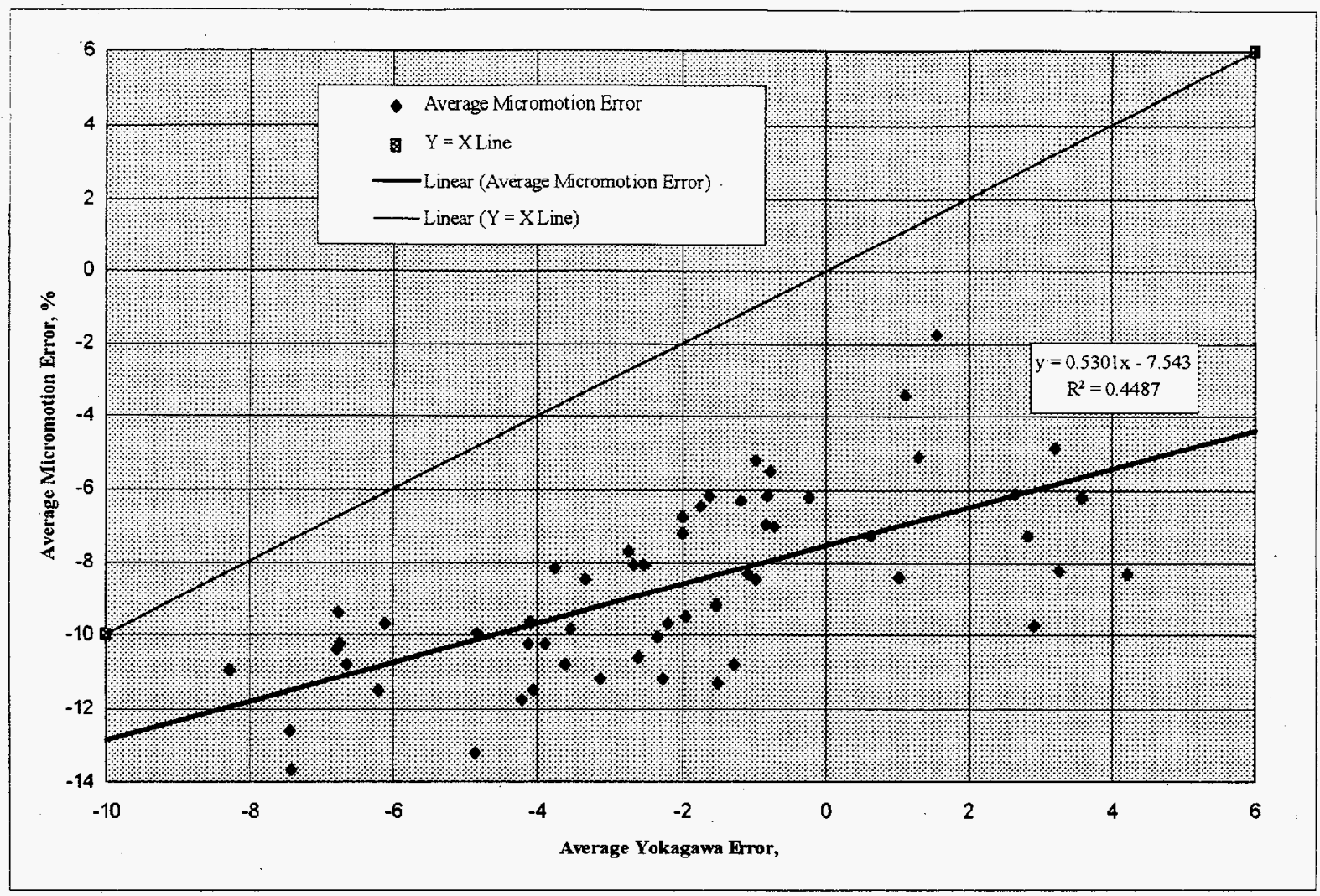

Figure 3.17. Yokagawa Instrument Volumetric Flow Rate Errors

For the water runs, the Yokagawa flow error ranged from -0.43 to $-1.47 \%$ low and averaged $-0.99 \%$ low. Therefore, the performance with slurries is about $1.1 \%$ low compared to testing with water. This is within the desired accuracy limit of $\pm 2 \%$.

The Micromotion was observed to be on average $8.5 \%$ low. Since the error in the flow calibration tank was determined to be about $\pm 1.2 \%$, the Micromotion error could be as low as $7.3 \%$ low or as high as $9.7 \%$ low compared to the reference. This is not within the $5 \%$ acceptability limit and it cannot be recommended as is as a suitable instrument.

For the water runs, the Micromotion flow error ranged from -4.88 to $-8.56 \%$ low and averaged $-6.2 \%$ low. Therefore, the performance with slurries is about $2.3 \%$ low compared to testing with water. The implication is that if the flow meters are calibrated to pure water, rather than relying on the factory calibrations, the performance with slurries should be within $5 \%$ acceptability limit. The manufacturer states that the unit can be user-calibrated and therefore, it should fit the desired accuracy criteria.

If the discrepancy between the measured flow rate errors for either instrument is caused by the method for determining the flow rate in the volumetric tank, then the two instruments should give the same error 
and fall along the " $Y=X$ " line in Figure 3.17. (This figure was prepared from the average value observed in a run and not the individuals.) However, the Micromotion tends to have a higher error fairly consistently across all of the runs but with some scatter.

\subsubsection{Fischer and Porter Flow Meter}

Figure 3.18 plots the average error in the Fischer \& Porter volumetric flow rate against the average Yokagawa volumetric flow rate error Yokagawa. One data point in the Run 5a "ideal" loop that was rerun was excluded because it was not consistent with the three other observations. Another data point was excluded because it was not consistent with the other two data points and was also exactly equal to four significant digits to the error from the Micromotion flow meter.

Data from Run 5B1 was excluded because the three you list four values observations were extreme outliers with values of $-36.4 \%,-45.0 \%,-49.3 \%$, and $-52.8 \%$. Data from Run $5 \mathrm{~B} 0$ was also excluded (values of $-26.9 \%,-27.0 \%,-28.0 \%$, and $-28.6 \%$ ) because it was run several hours after Run $5 B 1$. Both of these runs were graphite runs.

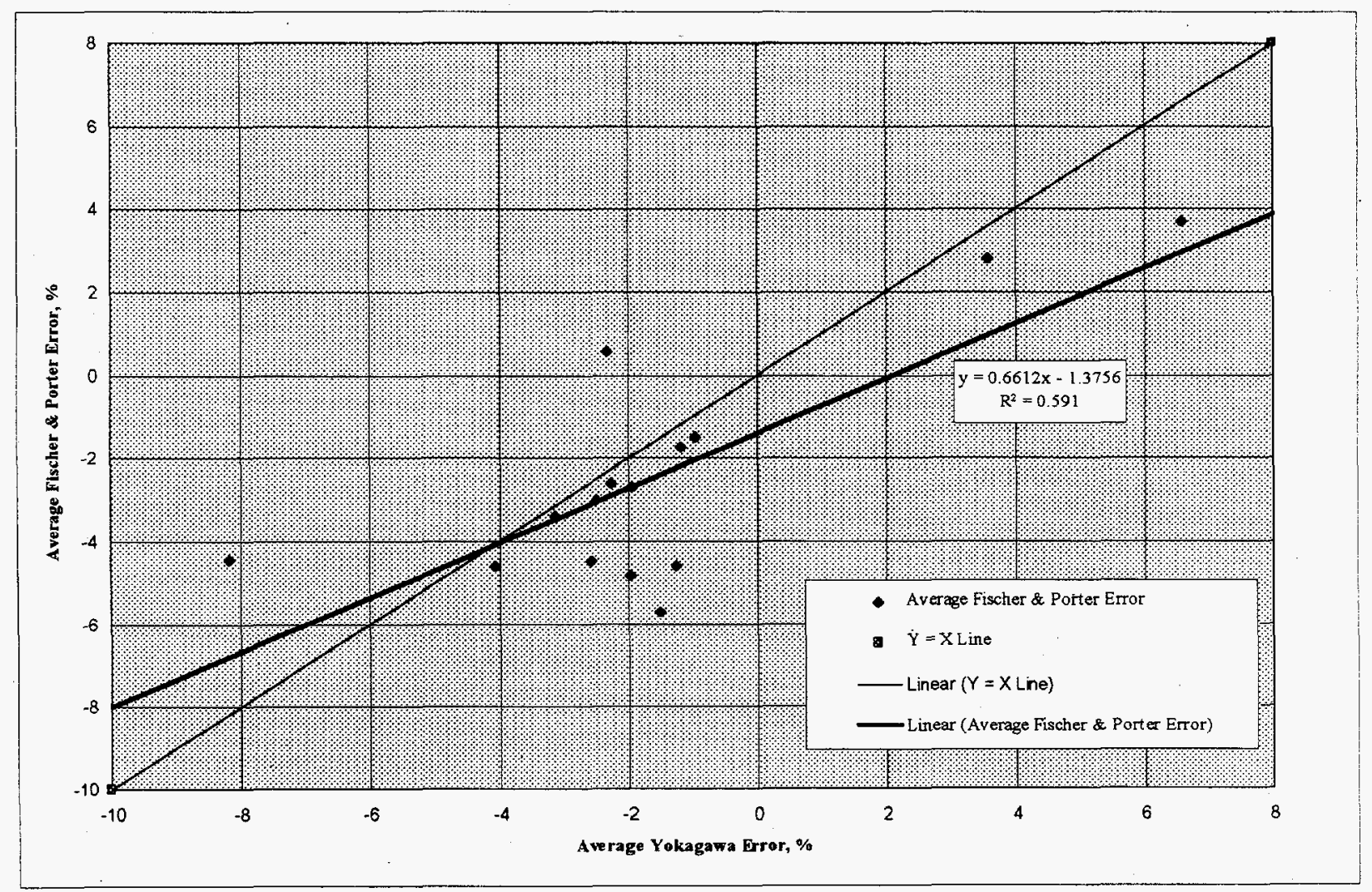

Figure 3.18. Fischer and Porter Volumetric Flow Rate Errors 
After the normal back-flushing, the observed flow rate did not return to normal and the flow meter had to be removed to clean it for further use. It is recommended that if either magnetic flowmeters are selected for use in the cross-site transfer system, that unit should have electrodes that are covered. The manufacturers state that such a selection should prevent interference with the measurements if a coating should form.

If the online flow meters report the same flow rates as was measured in the flow calibration tank, then the flow rate error for the flow meters should be equal to 0 . This was not observed with either flow meter. The Fischer \& Porter was observed to be on average 2.0 vol\% low. Since the error in the flow calibration tank was determined to be about $\pm 1.2 \%$, the Yokagawa error could be as low as $0.8 \%$ low or as high as $3.2 \%$ low compared to the reference. This range overlaps the acceptability limit of $\pm 1 \%$, but just barely.

The flow errors for pure water ranged from $-1.38 \%$ to $-2.01 \%$ with an average of $-1.6 \%$ low. Therefore, the performance with slurries is about $0.4 \%$ low compared to testing with water. This is within the desired accuracy limit of $1 \%$.

If the discrepancy between the measured flow rate errors for either instrument is caused by the method for determining the flow rate in the volumetric tank, then the two instruments should give the same error and fall along a " $\mathrm{Y}=\mathrm{X}$ " line in Figure 3.18 (Note that Figure 3.18 was prepared from the average value observed in a run and not all of the individuals.) The agreement with the " $Y=X$ " line is reasonable. The paired t-Test revealed that the Fischer \& Porter and Yokagawa flow meters gave the same reading at the $95 \%$ confidence level (see Appendix D-6). This indicates that the Yokagawa performs as well as the Fischer \& Porter and would be a suitable replacement flow meter. It is not clear why the acceptability limit for the Fischer \& Porter was set at $1 \%$ when the Yokagawa was set at $2 \%$.

A principal component analysis for the Fischer \& Porter flow rate errors was performed and reported in Section 3.5.4. This analysis indicates that the errors observed in the flow calibration tests are random and do not depend on the simulant material or properties.

\subsubsection{Particle Size Distribution Measurement}

This section will discusses the PSD test performed with the Lasentec and Horiba particle size analyzers. As has been previously discussed, the two techniques employ different methods to measure solids concentrations. The Horiba essentially measures equivalent spherical diameters based on sedimentation in very dilute slurries and the Lasentec measures chord lengths by laser scanning in highly concentrated slurries. Since the two techniques operate in extremely different solids concentration regimes, it is conceivable that both results are correct and are accurately measuring the PSD that they see. 


\subsubsection{Bi-Modal Particle Size Distributions}

During Runs $5 \mathrm{C}$ and $6 \mathrm{Cl}$, two or more solids were mixed in an attempt to create a bi-modal PSD. By varying the relative proportions of the solids, the shape of the distribution could be made to change. The PSDs from Run 5C containing graphite and Gibbsite from the Horiba and Lasentec did not clearly show that a bi-modal PSD was created or that the mean particle size changes with the varying proportions of solids. The probable cause is that the mean particle size of the graphite ( 2.9 microns) and gibbsite (4 microns) were too close and with too broad of a PSD to show up as separated peaks in the PSD.

However, the Lasentec PSDs from Run 6Cl containing bentonite (mean particle size of 0.8 microns) and Mica (mean particle size of 6.3 microns) shows a substantial shift in the mean particle size. It is not clear that the resulting distribution is bi-modal (see Figure 3.19).

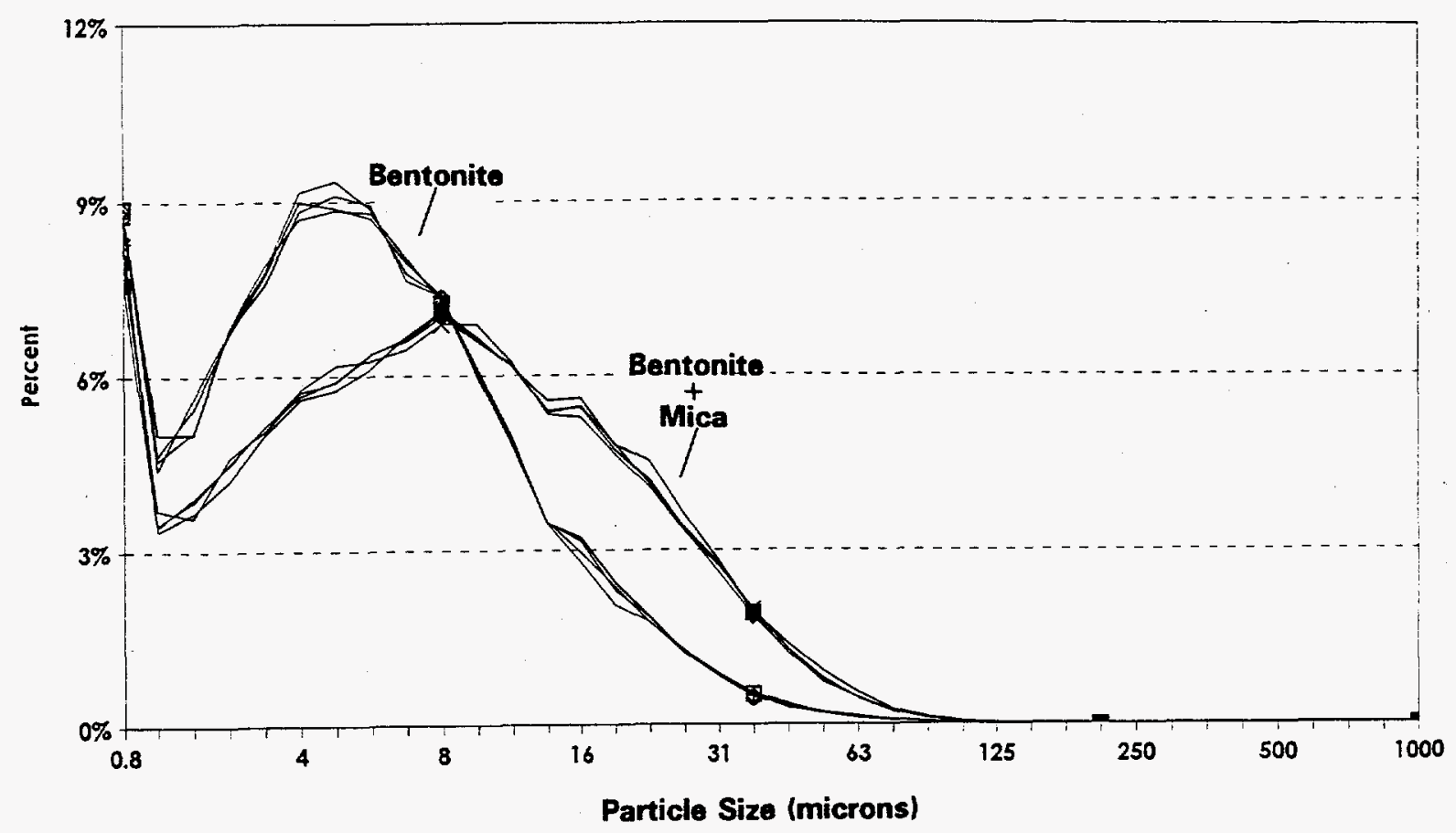

Figure 3.19. Particle Size Distribution Shift in Run $6 \mathrm{Cl}$

\subsubsection{Color Changes}

During Run $7 \mathrm{Cl}$ ( 4 vol\% bentonite), a total of 25 red and orange food coloring bottles ( 0.2 gal) were added to the feed tank (containing 210 gallons of slurry) to change the color of the carrier liquid from clear to orangish. The simulant changed color from olive-green to peach. This test was to see if the change in color contrasts resulted in changes in the measured PSDs. The Lasentec showed no change in the average size distribution compared to the data scatter as a result of this color change, as indicated in Figure 3.20. 


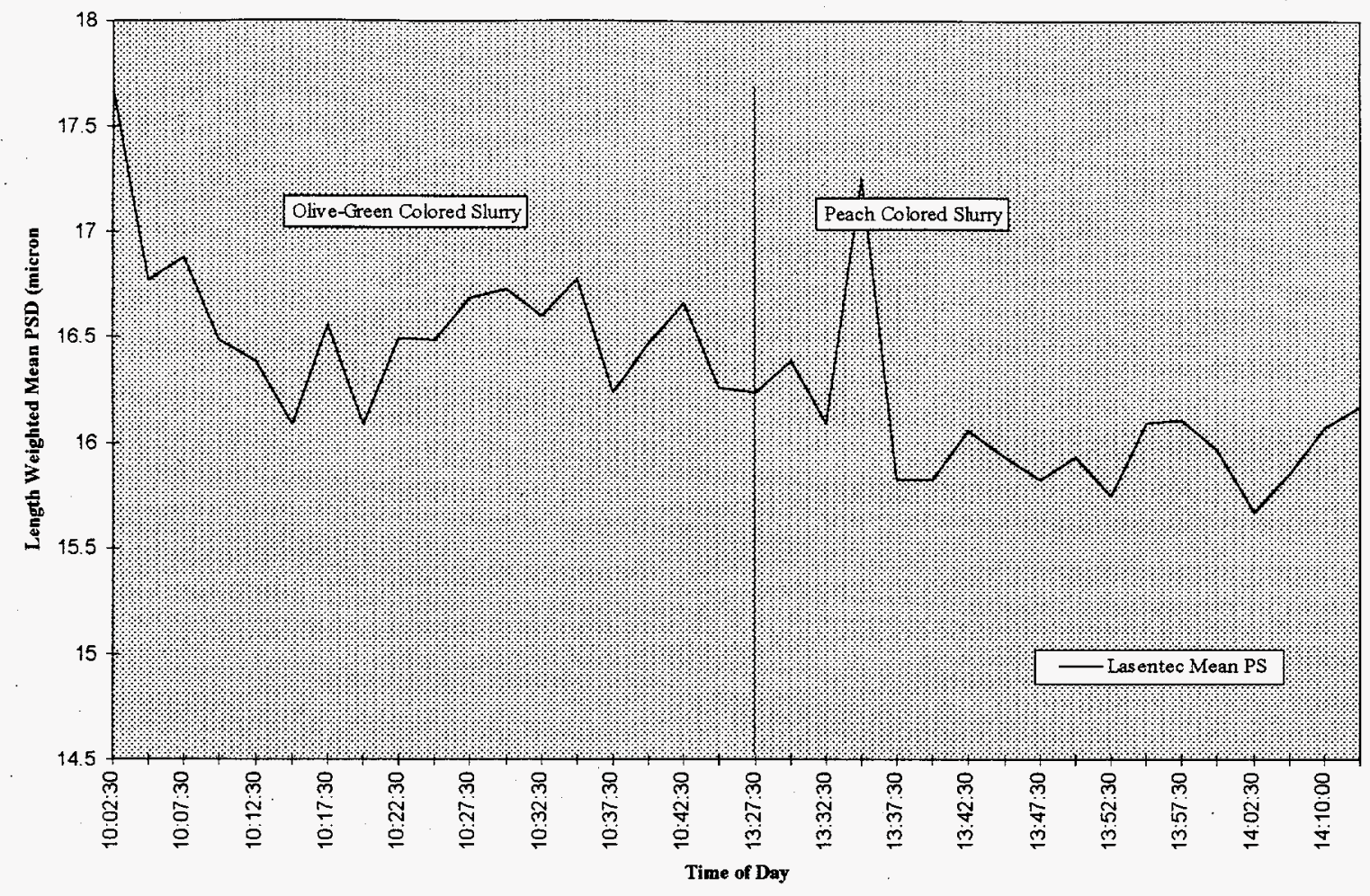

Figure 3.20. Lasentec Color Effects

\subsubsection{Bubbles}

The presence of bubbles can potentially affect the PSD measurement (since air bubbles also reflect light). In Figure 3.21, the average particle size of a 2 vol\% graphite slurry is compared when the bubbler is both off and on. The measurement of average particle size did not change.

A partial least square (multivariate statistical) analysis for the mean particle size was performed and reported in Section 3.5.3. This analysis shows that none of the instruments tested in the IVF measure properties which adequately correlate to the laboratory measured mean particle size. Interestingly, the multivariate analysis alsow showed that the Lasentec and Horiba lab instruments did not correlate well with each other either, probably because different particle sizing techniques are used by each manufacturer.

\subsubsection{Comparison with Laboratory Data}

Comparison of the median particle size between the Lasentec and Horiba analyzers must be tempered with a knowledge of the measurement techniques. The Horiba analyzer assumes a constant density for all solids, hence it can confuse a smaller but denser particle with a larger but less dense solid. The Horiba also measures an equivalent spherical diameter based on the principle of sedimentation rates. Tests were run on a selected slurry simulant to determine the repeatability of the testing (see Table 3.1). 


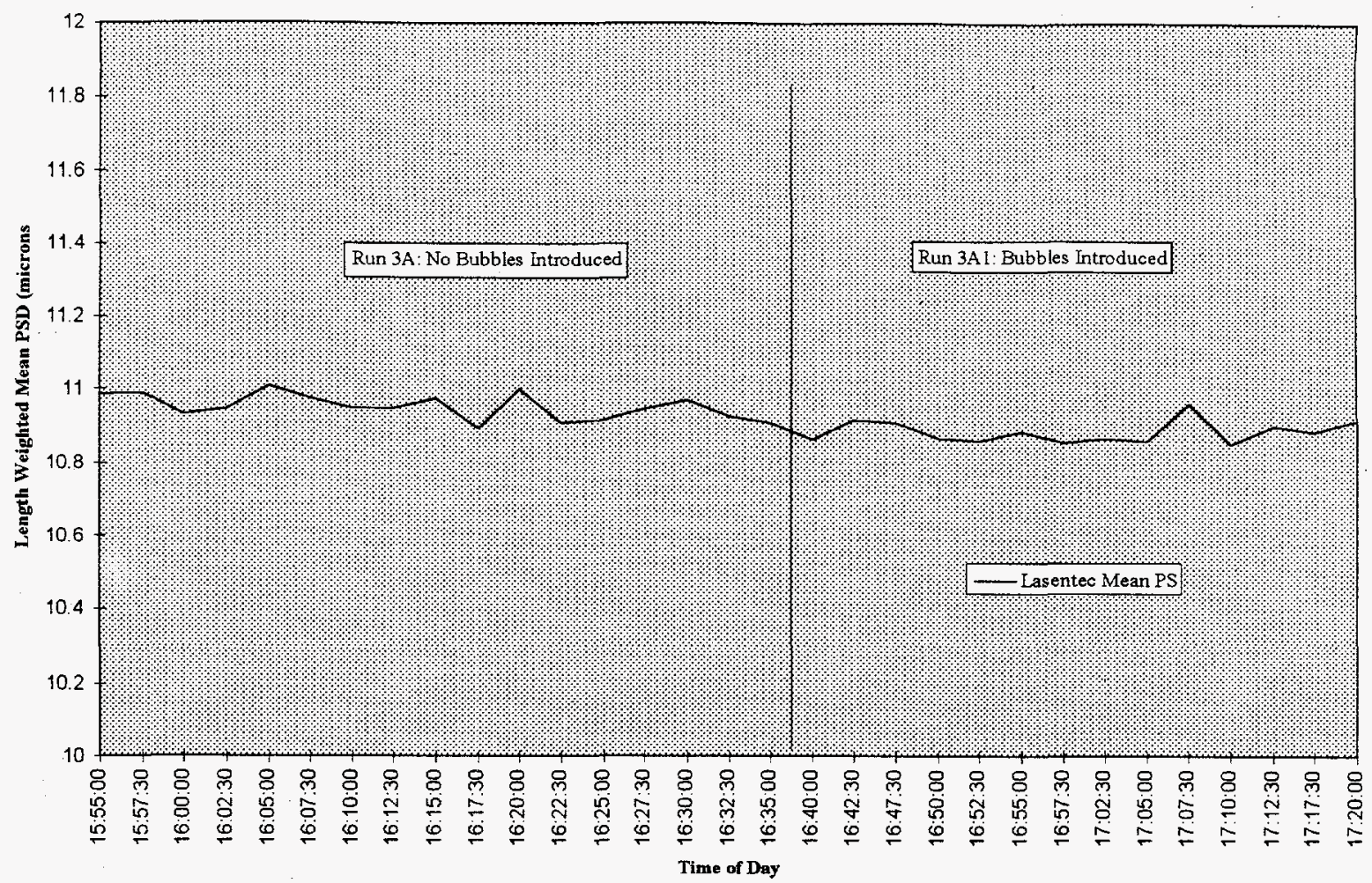

Figure 3.21. Impact of Bubbles on Measured Particle Sizes

Table 3.1. Horiba PSD Instrument Repeatability with Run 4A "Ideal" Loop Sample

\begin{tabular}{|c|c|c|}
\hline Trial & Mean (Microns) & $\begin{array}{c}\text { Standard Deviation } \\
\text { (Microns) }\end{array}$ \\
\hline 1 & 7.43 & 4.86 \\
\hline 2 & 5.58 & 4.2 \\
\hline 3 & 6.5 & 4.41 \\
\hline 4 & 8.16 & 4.33 \\
\hline 5 & 8.34 & 4.95 \\
\hline 6 & 7.73 & 4.48 \\
\hline
\end{tabular}

The mean particle size is about 7.29 microns with a standard deviation of the means of 1.06 microns. Therefore, the true mean is $7.29+/-1.11$ microns at the $95 \%$ confidence level (see Appendix D-8). This variability must be considered in the interpretation of any results based on the laboratory PSDs. A comparable analysis should have been performed on the Lasentec but this was not possible to perform in the field. 
If settling is occurring at the lower flow rates, both the Horiba and the Lasentec should be able to detect these changes. Only for Gibbsite did the Horiba consistently report a lower average particle size ( 1 micron) at the lower flow rate $(6.25$ liters/sec). The Lasentec, however, did not report a lower average particle size at the lower flow rates. Since the mean particle size change of 1 micron is within the $95 \%$ confidence limits of 1.11 microns, it is very likely that the shift is an artifact of the laboratory measurement technique and does not reflect settling in the pipe loop.

A comparison between the median particle sizes measured by the Lasentec and Horiba is presented in Figure 3.22. The Lasentec did not measure the expected mean particle size as the reference Horiba particle size analyzer. Particle size measurement is a difficult analytical measurement to perform and even more difficult to perform on-line. It is tempting to say that the Lasentec does not measure the correct mean particle size but that cannot really be stated with high confidence because of the difference in analytical techniques and slurry environments.

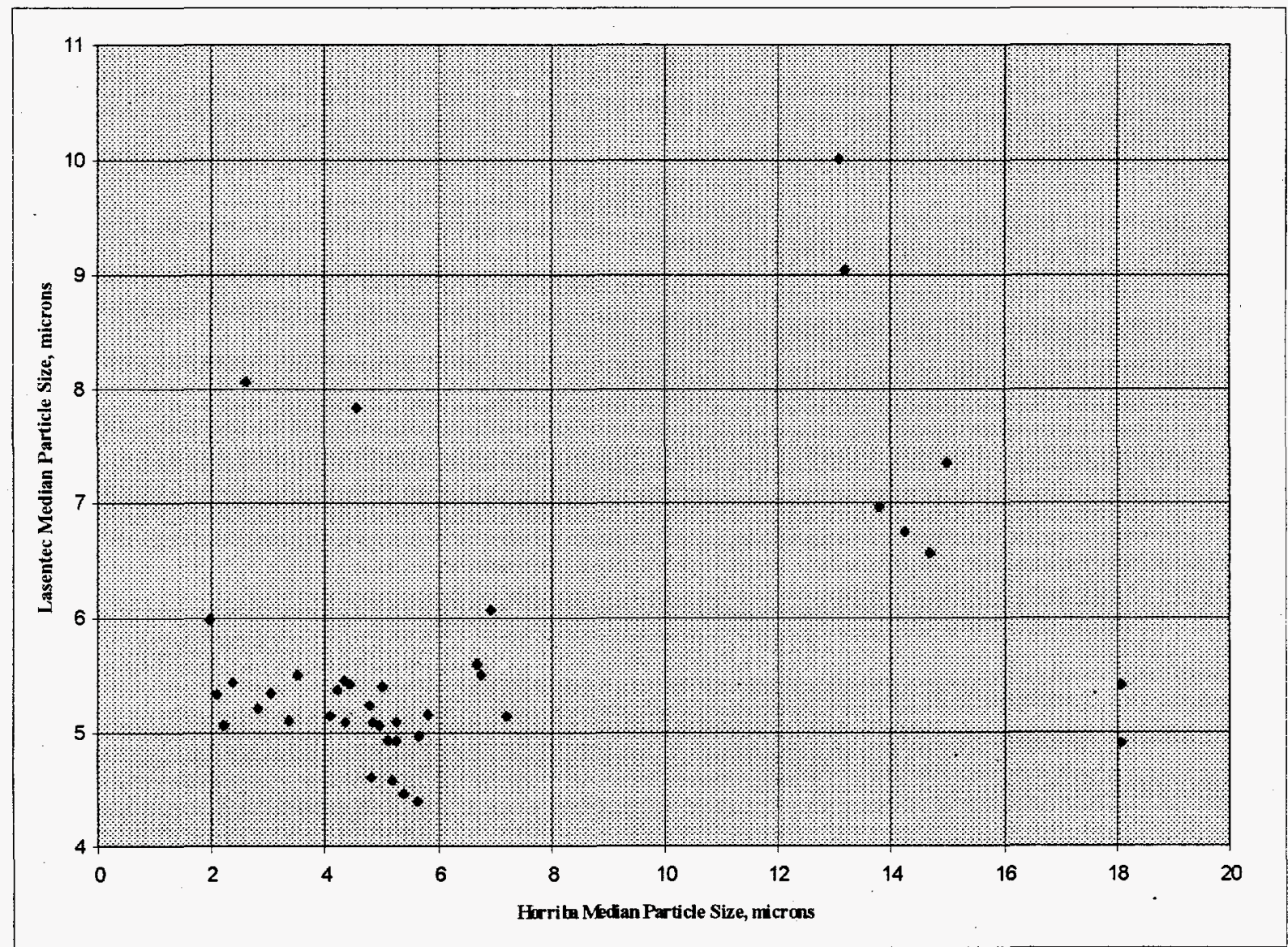

Figure 3.22. Lasentec vs. Horiba Particle Size Distributions 
Both the laboratory and Lasentec measurements showed that the average particle size was fairly consistent for each material, regardless of flow rate, solids concentration, and the presence of bubbles. Since the laboratory and Lasentec data showed no evidence of settling in-line, the Lasentec may not have been tested to its fullest capacity. That is, if the Lasentec is to be further evaluated in the future, much lower flow rate tests are recommended so that solid particles are purposely settled out when the flow rate is below that of the critical velocity for solids suspension.

In all of the PSDs, both analytical techniques detected small particles less than 1 micron in diameter. However, there was no indication that either particle size analyzer was able to distinguish the low concentration of 500-micron particles specifically added in run $5 \mathrm{C} 1$. No change in the flow behavior was observed with the inclusion of this low concentration of very large solids.

\subsubsection{Recommendation}

The mean measured particle size from the Lasentec did not correspond to the mean measured particle size from the Horiba particle size analyzer. The reasons for this have been previously discussed.

Bubbles barely influenced the Lasentec, so their presence did not make the instrument unreliable. Alternatively, the instrument was not effective in determining if bubbles were present in the system. The color of the carrier fluid in the simulant also had little bearing on the ability of the instrument to consistently measure the same average particle size.

The Lasentec particle size measurement instrument was useful in determining when steady state was reached. Slight shifts in the PSD were noticed as solids were added to the system and as the flow rate increased or decreased drastically (e.g., 6.25 liters/sec to 9 liters/sec). Typically, the Lasentec reported steady-state values within minutes of system startup throughout the entire operation, across all solids. However, this finding is of relatively little value to Project W-211.

What would be of high value to Project W-211 is the ability to detect crystallization or precipitation of solids. Since the simulants tested did not have soluble salts that could precipitate or form gels in the test loop, the ability of the instrument to detect crystallization or precipitation of solids in solution was not tested. (One of Lasentec's primary markets is the measurement of PSD in-line systems that precipitate.) The precipitation of material would both increase the particle count and shift the PSD. These deviations from steady state simultaneously with an increase in viscosity and line pressure could indicate the onset of adverse precipitation. The instrument is well suited for remote installation in the valve pit if properly engineered .

\subsection{Instrument Elimination}

Since the Micromotion thermocouple corresponded well with the Moore Industries thermocouple and since the Micromotion also provides good measurements of the density as well as potentially adequate measures of the mass flow rate, the Moore Industries thermocouple can be eliminated from the actual 
instrument tree. Unfortunately, Micromotion does not produce a transmitter capable of sending three 4-20 mA signals to the PLC. On the IVF system, density and flow rate were sent over the only two 4-20 mA outputs.

\subsubsection{Temperature}

There are three methods to send temperature, density, and flow rate signals to the PLC:

1. Move the flow rate output to the pulse output on the transmitter. The PLC will require a high speed counter card to convert the signal to the appropriate flow rate. For example, a $8000-\mathrm{Hz}$ signal from the pulse output on the Micromotion transmitter can correspond to a 14-liter/second flow rate.

2. Move the flow rate output to the pulse output on the transmitter and then use an external (third party) signal converter to change the frequency output to a 4-20 mA signal. The converted flow rate signal, along with the normal 4-20 mA signals for temperature and density from the Micromotion transmitter, can all be interfaced with a PLC using a normal 4-20 $\mathrm{mA}$ input board.

3. Purchase a MODBUS board (or some board which uses the HART protocol) to allow a full digital connection between the transmitter and the PLC. A digital connection will allow all information shown on the rack mounted display (mass flow rate, volumetric flow rate, density, temperature, etc) to be processed by the PLC. The 505-5184 MODBUS card for the Siemens SimaticTI-545 PLC has a list price of $\$ 1825$ (as of April 1996).

\subsection{Multivariate Statistical Analysis Results}

The following sections presents the results of the multivariate statistical analyses for viscosity, solids concentration, PSDs, and flow rate errors. Good models were prepared for the viscosity and solids concentration. Very poor models were prepared for PSDs and flow rate errors.

\subsubsection{Viscosity Multivariate Analysis}

Figure 3.23 is a model overview showing the percent of the Haake viscosity data at $300 \sec ^{-1}$ which is explained by the cumulative sum of the principle components. The first component alone explains $80 \%$ of the variation in the data, whereas all three components explain nearly $90 \%$ of the variation. A general rule of thumb is that a good model can explain at least $90 \%$ of the variation in the data. A poor model, on the other hand, would explain less than $60-70 \%$ of the variation of the data.

Figure 3.24 is a VIP (Variable Importance in the Projection) plot, showing the relative importance of the measured parameters to the prediction of the Haake (laboratory measured) viscosity at $300 \mathrm{sec}^{-1}$. As expected, the direct tap DP cells and the Nametre in-line viscometer correlate best to the measured viscosity at $300 \sec ^{-1}$. 


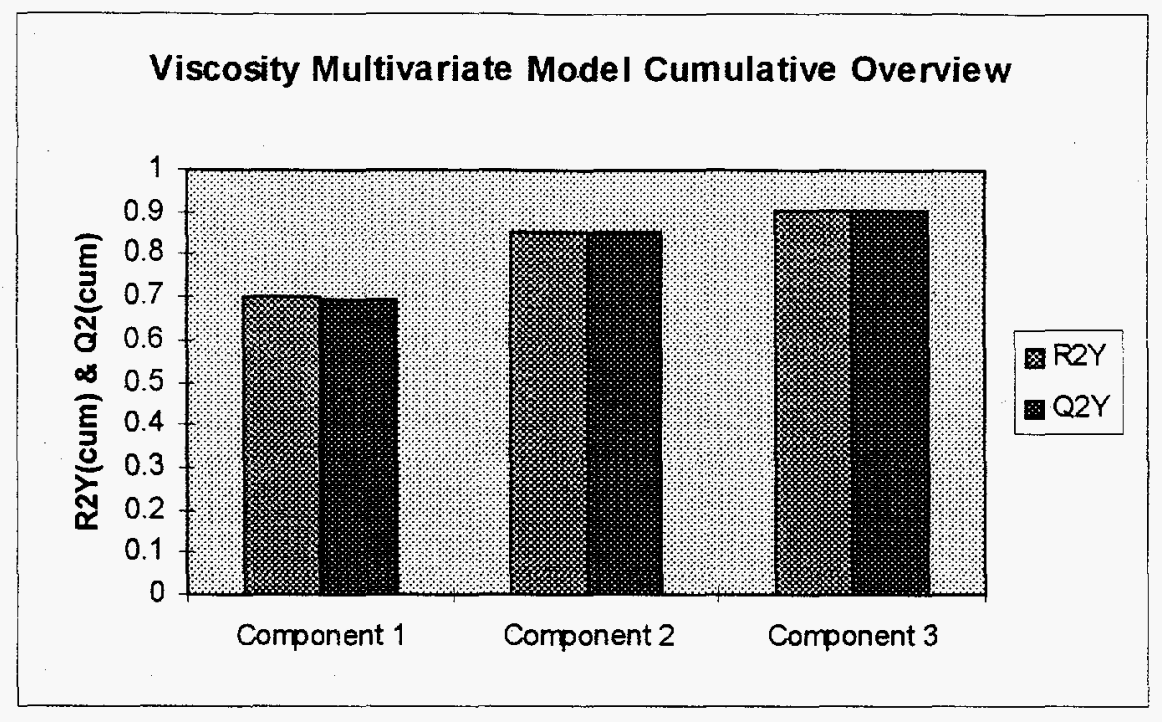

Figure 3.23. Model Overview

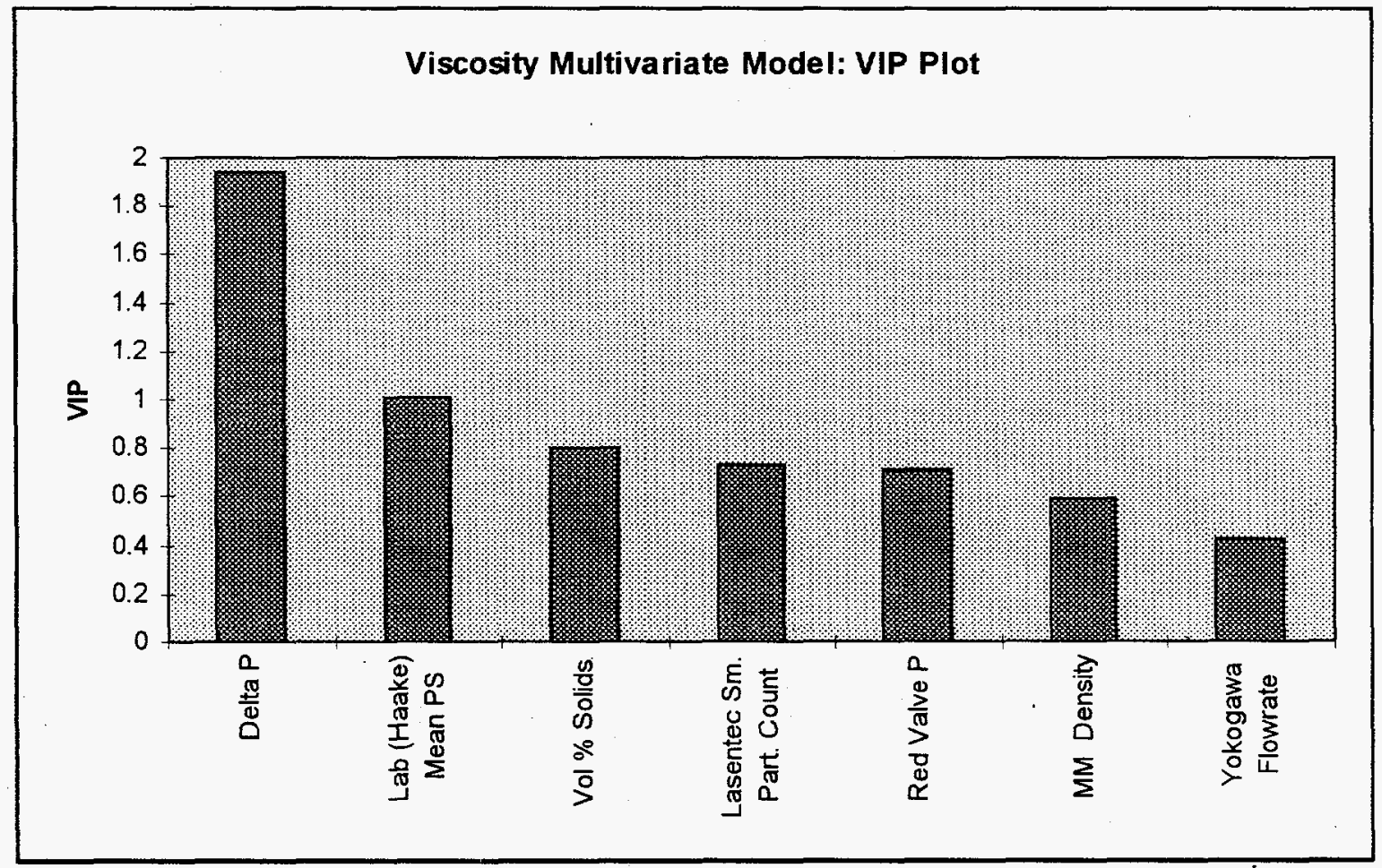

Figure 3.24. VIP Plot of Haake to Measured Parameters 


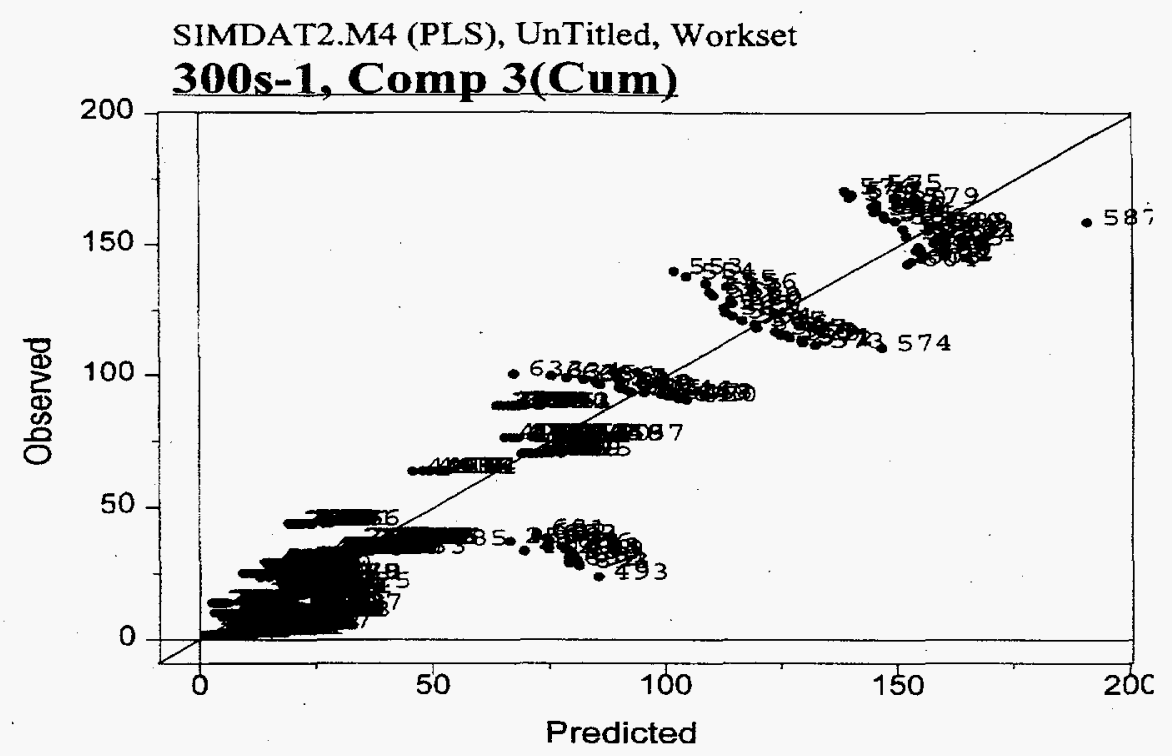

Figure 3.25. Predicted vs. Observed Viscosity

Figure 3.25 shows that the observed viscosity matches well with the predicted viscosity. Here the predicted viscosity is a linear combination of process variables:

$$
\mu_{\text {Haake, } 300 \mathrm{sec}^{-1}}=0.85602+0.57276 \Delta \mathrm{P}+0.41032 \mu_{\text {Nametre }}+\mathrm{f} \text { (other variables) }
$$

Note that this function should not necessarily be used to predict the laboratory measured viscosity of actual tank waste: this is a correlation that explains the laboratory data only from the IVF experiments. Another model was also created without the Nametre viscosity as an input parameter; it too showed that the Haake viscosity at $300 \mathrm{sec}^{-1}$ correlated extremely well with the pressure drop. Thus, even if a direct quantitative relationship is not well established between the pressure drop and the slurry viscosity (i.e., through a friction factor/Reynolds number correlation), a multivariate statistical package (such as Simca-P) could develop an empirical correlation between pressure drop and lab measured viscosity if enough data is available.

\subsubsection{Solids Concentration Multivariate Analysis}

The overall fit of another model to determine the solids concentration is shown in Figure 3.26. Note that this model is not as good as the previous one: only around $75 \%$ of the variation in the data is explained by all four components (reduced variables).

From the VIP plot (Figure 3.27), the Micromotion density is the biggest contributor to the correlation between solids concentration and the measured process variables. The laboratory measured mean particle 


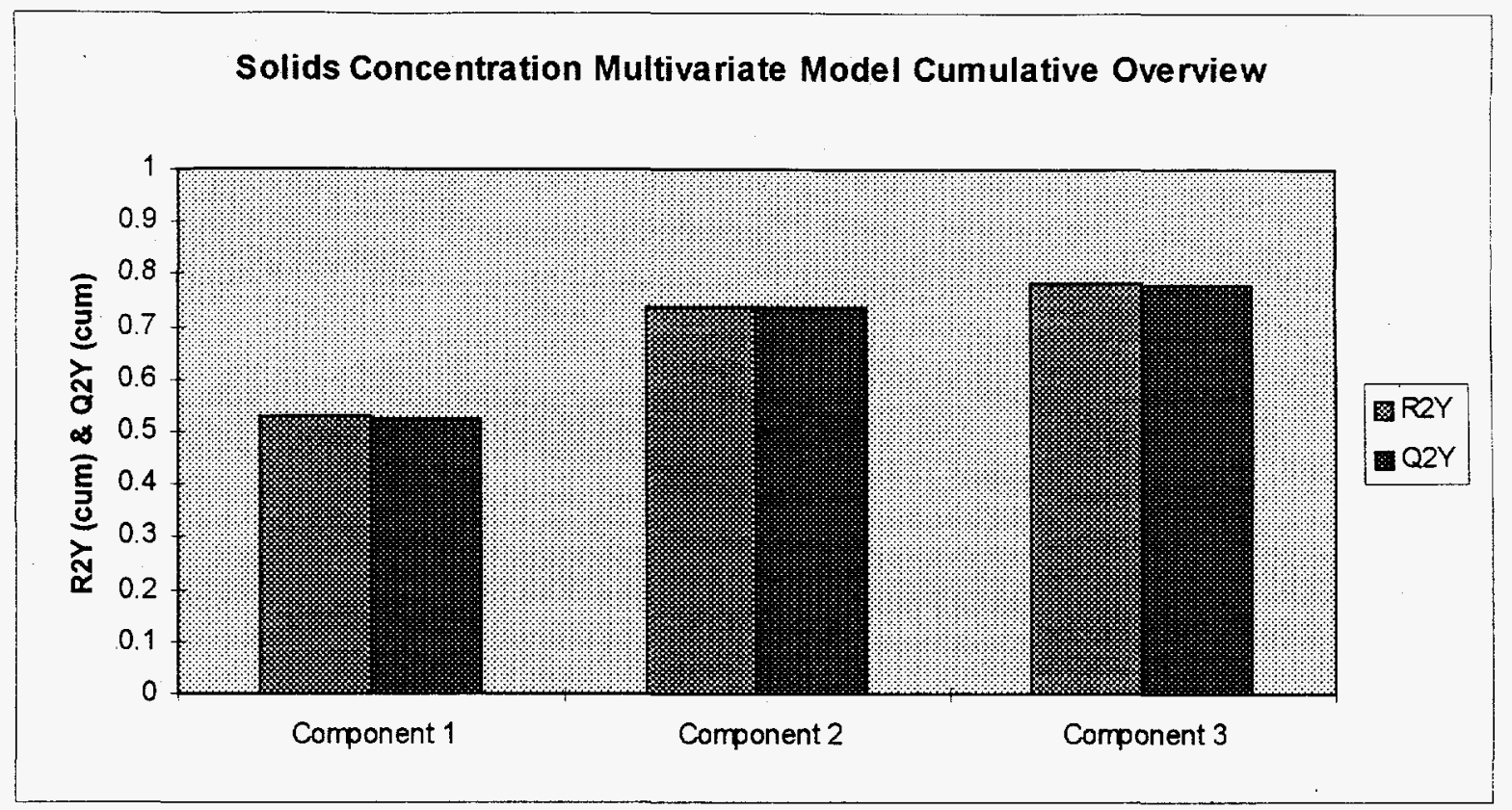

Figure 3.26. Solids Concentration Model

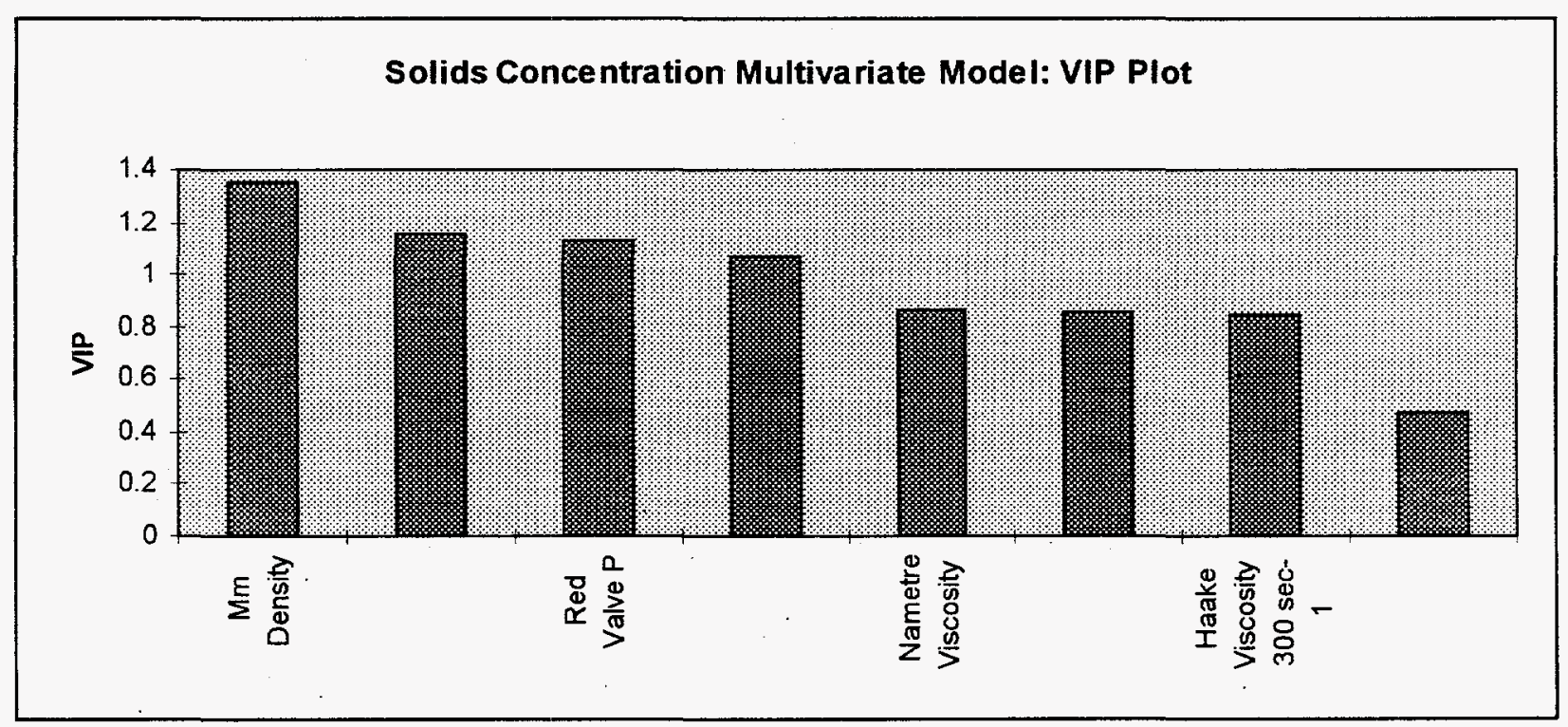

Figure 3.27. VIP Plot for Solids Concentration 
size, the Red Valve line pressure, and the Lasentec small particle count also are shown to have a significant correlation (VIP $>1.0$ ) to the solids concentration. While it makes sense that the number of small particles counted by the Lasentec would increase with solids loading, the laboratory mean particle size and the line pressure are practically poor indicators of solids concentration. The positive correlation with laboratory mean PSD may be an artifact of the measurement technique: the Horiba lab instrument determines the number of particles in each size classification through an optical absorbance technique. As the solids concentration increases, the absorbance of the solution changes. Since the absorbance changes, the reported number of particles in each size channel is also different, as is then the PSD. As the distribution changes, the mean also shifts. The Red Valve line pressure, on the other hand, should increase as the solids concentration increases.

However, it is doubtful whether a quantitative correlation between solids loading and density would be successful, unless the feed is fairly uniform with respect to solids density. A combination of the slurry density, line pressure, and the small particle size count may do a good enough job to allow qualitative trends to be recognized. Figure 3.28 is a plot of the predicted solids loading vs. observed solids loading. The correlation is not "ideal", but at least there is hope that general solids concentration trends could be seen with these measured process variables.

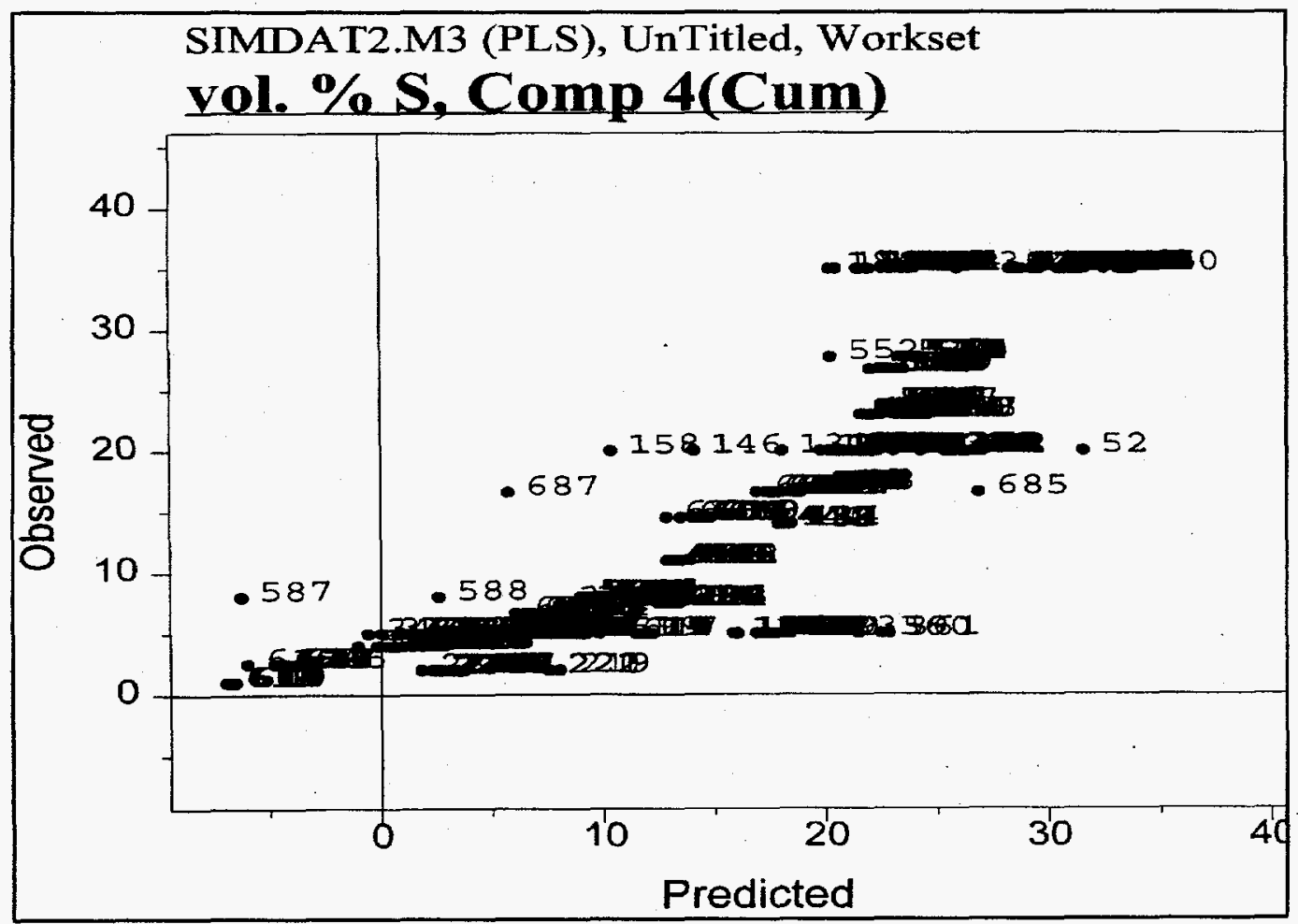

Figure 3.28. Predicted Solids Loading vs. Observed Solids Loading 


\subsubsection{Particle Size Multivariate Analysis}

Figure 3.29 is the model overview for the prediction of the laboratory measured mean particle size from the measured parameters, including the Lasentec measured mean particle size. As can be readily seen from the bar graph, the model is very poor. This suggests that there is no correlation between the laboratory measured mean particle size and other process variables. Interestingly, the Lasentec measured mean particle size does not necessarily compare well with the laboratory (Horiba) measured mean particle size. This discrepancy may be due to the fact that the lab data has a $95 \%$ confidence error of 1.11 microns when the same sample is repeatedly analyzed. The Lasentec mean particle size is more constant over the duration of the run.

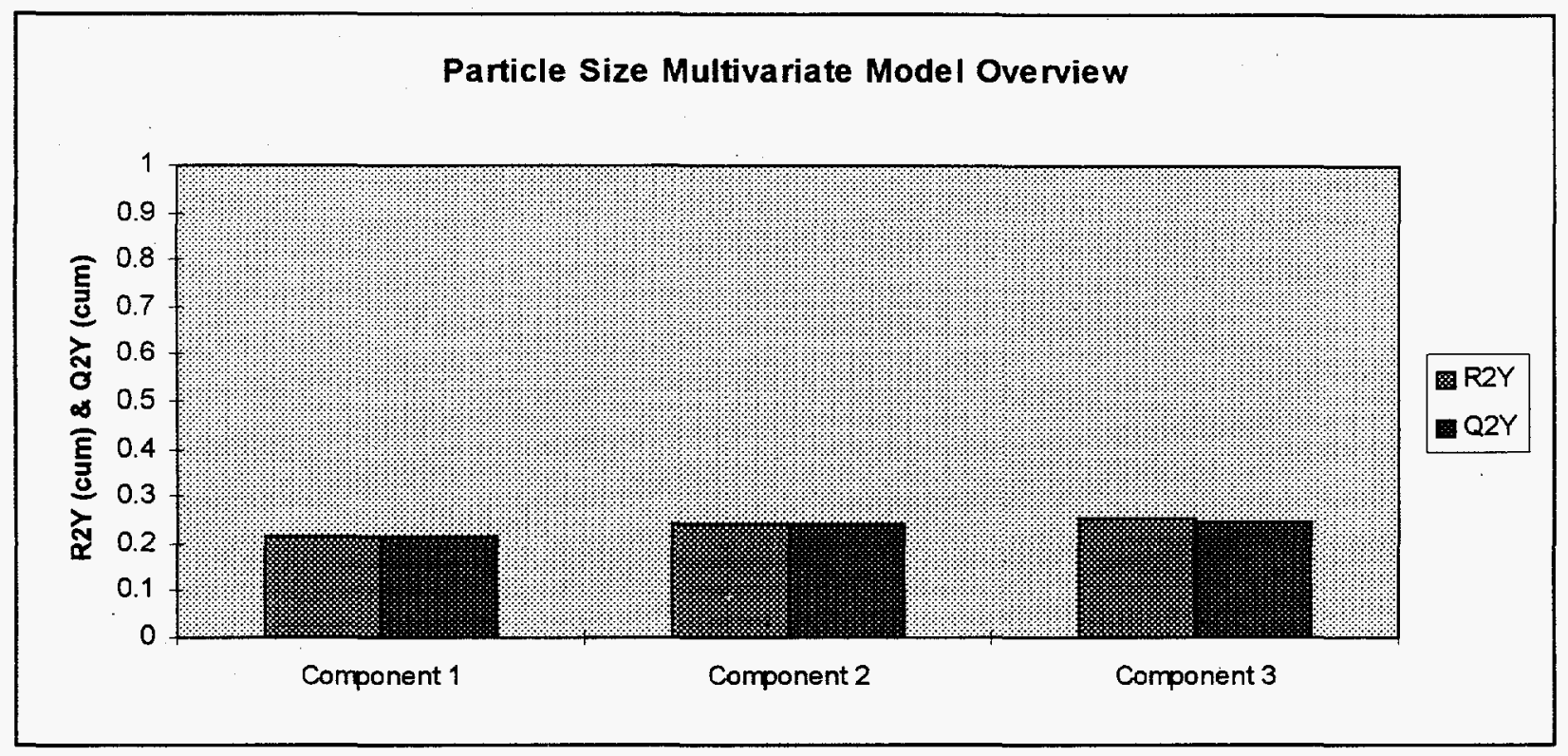

Figure 3.29. Particle Size Model

\subsubsection{Flow Rate Error Multivaraite Analysis}

Partial least squares analyses of the Yokagawa, Micromotion, and Fischer \& Porter flow rate errors were conducted to determine if the error was associated with any of the measured slurry or processing parameters. The analysis showed that the error in flow rate could not be modeled well by the other measured parameters. Specifically, the Yokagawa flow rate error model explained $20 \%$ of the variation in flowrate error (relative to the calibrated standard), the Micromotion flow rate error model explained 35\% of the variation in the flowrate error (relative to the calibrated standard), and the Fischer $\&$ Porter flow rate error model explained $40 \%$ of the variation in the flow rate error (relative to the calibrated standard). The presence of bubbles and viscosity were the largest contributors to the Yokagawa and Micromotion models. Temperature and viscosity were the largest contributors to the Fischer \& Porter model. In all three cases, the model was so poor that no conclusions will be drawn from the analysis. 


\subsection{Conclusions and Recommendations}

Four test objectives were outlined in Section 1.2. The conclusions from the testing of each objective will be discussed in the following four sub-sections.

\subsection{Instrument Validation Conclusions}

1. The Micromotion Density analyzer is recommended as meeting the desired accuracy for density measurements.

2. The baseline Fischer \& Porter magnetic flow meter provides good measurements of the flow rate. The Yokagawa flow meter is as accurate as the baseline Fischer \& Porter. Both instruments were observed to form a slimy solids deposit with one solids slurry that catastrophically interfered with the proper measurement of flow rates. While this may be unique to graphite, the instrument to be installed in the Project W-211 test loop should have the electrodes coated to prevent this from happening with the solids in tank wastes.

3. The Micromotion mass flow meter does not meet the desired accuracy limit; however, had it been user calibrated for any of the slurries or water (rather than simply relying on the factory calibration), it probably would have met the desired accuracies.

4. The Moore Industries Thermocouple and Micromotion densimeter thermocouple give equivalent and adequate temperature results.

5. The Red Valve pressure analyzer is recommended for use in the Project W-211 test loop.

6. The Lasentec particle size analyzer is not recommended to measure the absolute particle size of a given slurry or the solids concentration. It can be used qualitatively to monitor gross process changes in the slurry being injected into or transported through the cross-site transfer line.

7. The Nametre on-line viscometer, while providing a qualitative indication of the viscosity of a slurry, does not meet the desired accuracy limits. It is very sensitive to vibration and easily damaged. The Nametre is not recommended for use in the Project W-211 loop unless there is a critical need to have an on-line viscosity measurement.

8. An alternative method of indirectly monitoring the viscosity is to measure the pressure drop across any straight run of transport loop or, although not tested, across the instrument loop or the cross-site transfer line itself. The correlation with pressure drop is nearly as good, the instrumentation is far simpler than the Nametre, easier to maintain, and is a direct measurement of the key process parameter of interest (i.e., the allowed pressure difference across the cross-site transfer line). 


\subsection{Instrument Elimination Conclusions}

Project W-211 desires to reduce the number of instruments to the bare minimum while ensuring that the cross-site transfer line does not plug. The original intent was to measure or infer the value of the three primary process variables (i.e., density, viscosity, and solids concentration) specified in the FDC. This work suggests that the instrumentation to measure two of these primary process variables (i.e., solids concentration and viscosity) does not meet the desired accuracy limits. However, the original intent may not be the only control method to use to assure that the cross-site transfer line does not plug.

For example, an alternate scenario to radically reduce the required instrumentation is to simply measure the flow rate and monitor the pressure drop across the instrument loop and at various points in the cross-site transfer line. If the flow rate is measured in the test loop and is maintained constant and the pressure drop across each section of pipe remains constant, no plugging occurs. This scenario is more credible with multiple pressure drop measurements installed at various points in the cross-site transfer line or as the length of pipe over which the pressure drop is measured is increased. This scenario also provides information as to where the plug is developing.

Another alternate scenario is to measure the flow rate and pressure entering the cross-site transfer line and measure them again in an identical test loop at the exit of the cross-site transfer line. Any increase in the pressure drop and a simultaneous decrease in flow rate exiting the test loop are indicative of plugging occurring.

Both of these alternate scenarios can be used to monitor the development of plugs and with a minimum of required instrumentation. Both, however, require a rethinking of the control scheme and cross-site line design.

If the original objective of measuring all slurry properties at a single point for ensuring that a plug does not form is maintained, it is still possible to somewhat simplify the instrument loop design and eliminate some of the original instrumentation. The Micromotion mass flow meter can be re-calibrated to correct the offset observed in this testing, therefore this single instrument can provide density, flow rate, and temperature information. (This could eliminate the need for the Yokagawa flow meter in the pump pit.) When the Micromotion results are combined with a pressure drop measurement (which was shown to be strong function of the viscosity and solids loading in the multivariate statistical analyses) across the test loop and with the process model, it may be possible to detect pluggage of the cross-site transfer line with only these two instruments. The ability of the model to explain the variation improves as the ability to independently measure the viscosity or solids loading is improved.

\subsection{Test Loop Design Conclusions}

The design of the current instrument test loop (i.e., the Project W-211 loop) is adequate for measuring the specified slurry properties. 


\subsection{Evaluation of Alternate Instrumentation}

The Yokagawa is recommended as an alternate flow meter and performs as well as the Fischer \& Porter.

The Moore Industries thermocouple is not recommended as the Micromotion thermocouple performs equally well and is part of the density measurement.

\subsection{Other Conclusions and Recommendation}

If further testing is to be performed on the test loop, a temperature control system should be installed to prevent un-intentional temperature changes and the resulting complex data analysis. 



\subsection{References}

Bird, B., W. Stewart, and E. Lightfoot. 1960. Transport Phenomena. John Wiley and Sons, New York.

Denn, M. 1980. Process Fluid Mechanics. Prentice-Hall, Inc., Englewood Cliffs, New Jersey.

Liu, K., U. Choi, and K. Kasza. 1988. Measurements of Pressure Drop and Heat Transfer in Turbulent Pipe Flows of Particulate Slurries. ANL-88-15, Argonne National Laboratory, Argonne, Illinois.

Serghides, T. 1984. "Estimate friction factor accurately." Chemical Engineering March 5, 1984.

Thomas, D.G. 1965. "Transport Characteristics of Suspension: VIII. A Note on the Viscosity of Newtonian Suspensions of Uniform Spherical Particles." J. Colloid Sci. 20:267-277. 
Appendix A

Detailed Loop Designs 


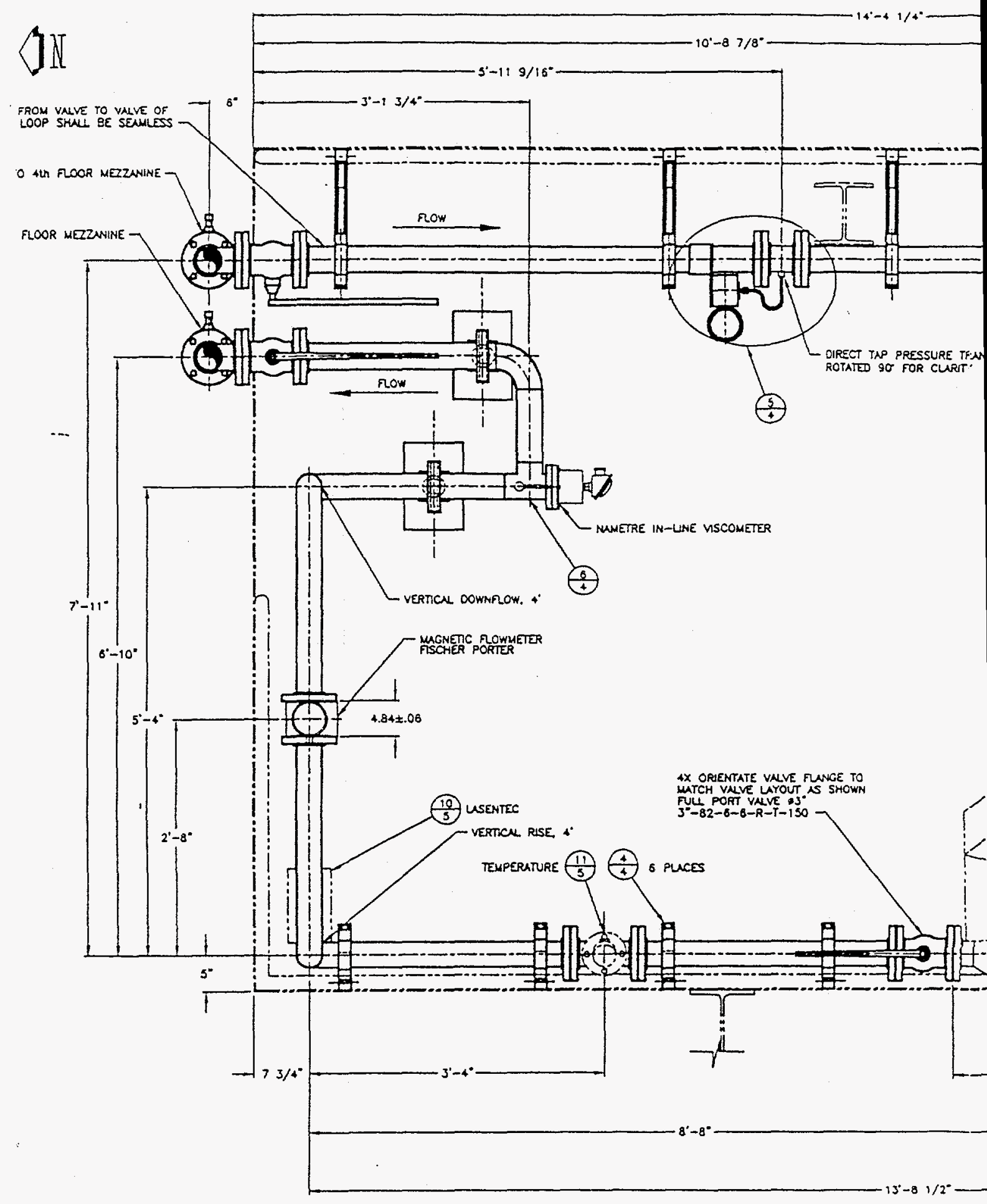

PLAN VIEW EE:

Figure A.1. Ideal Lc 


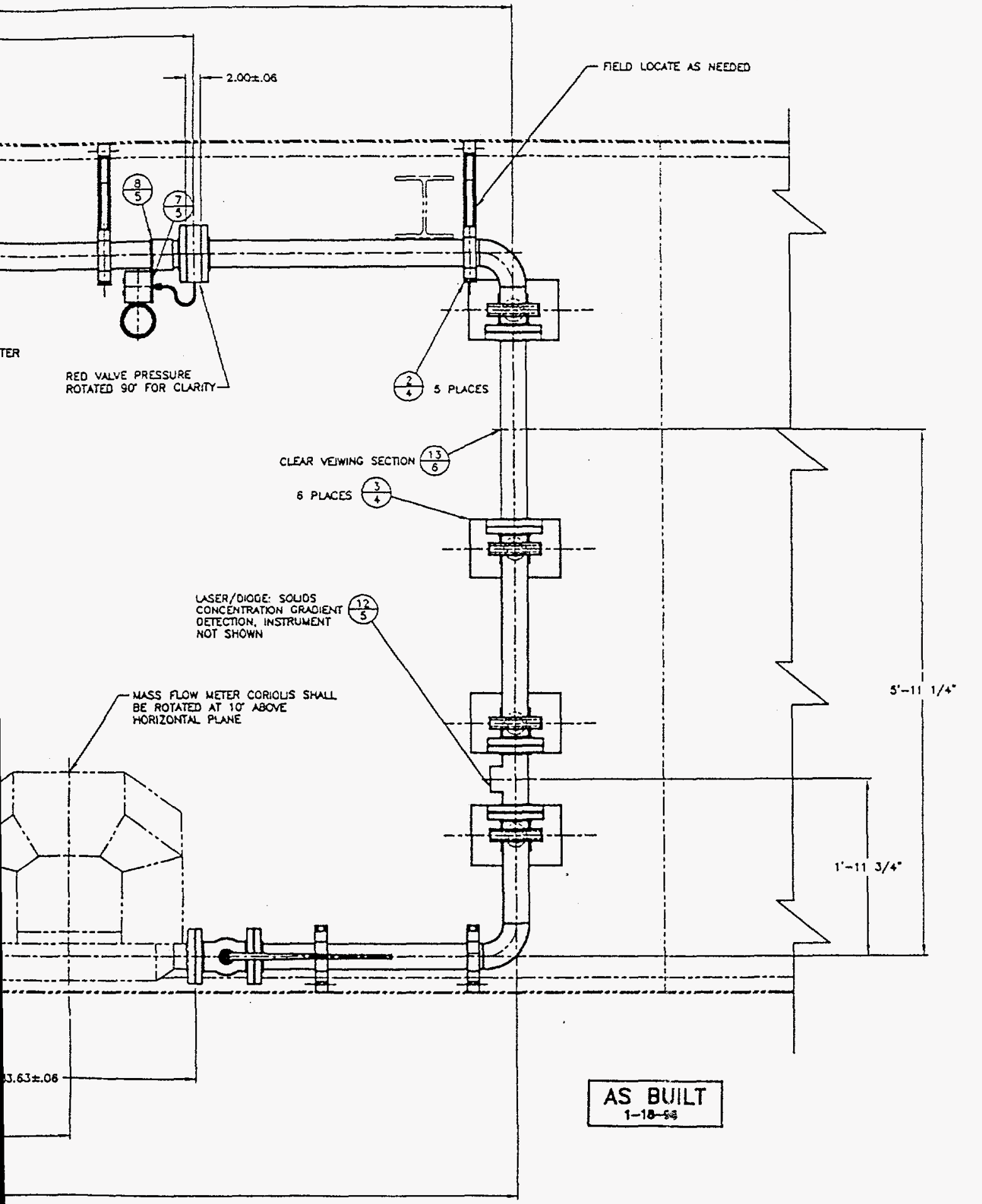

$1 / 27$

\begin{tabular}{|c|c|c|}
\hline \multicolumn{3}{|c|}{ ENGINEERING WORKSHEET } \\
\hline 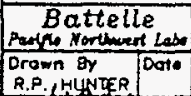 & $\begin{array}{l}\text { SLURF } \\
\text { TEST L }\end{array}$ & \\
\hline Engler & 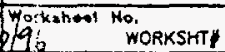 & ${ }_{\text {III Lonet }}^{\text {Impoed }}$ \\
\hline Rathowad Ny date & Reti owg. & 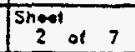 \\
\hline
\end{tabular}




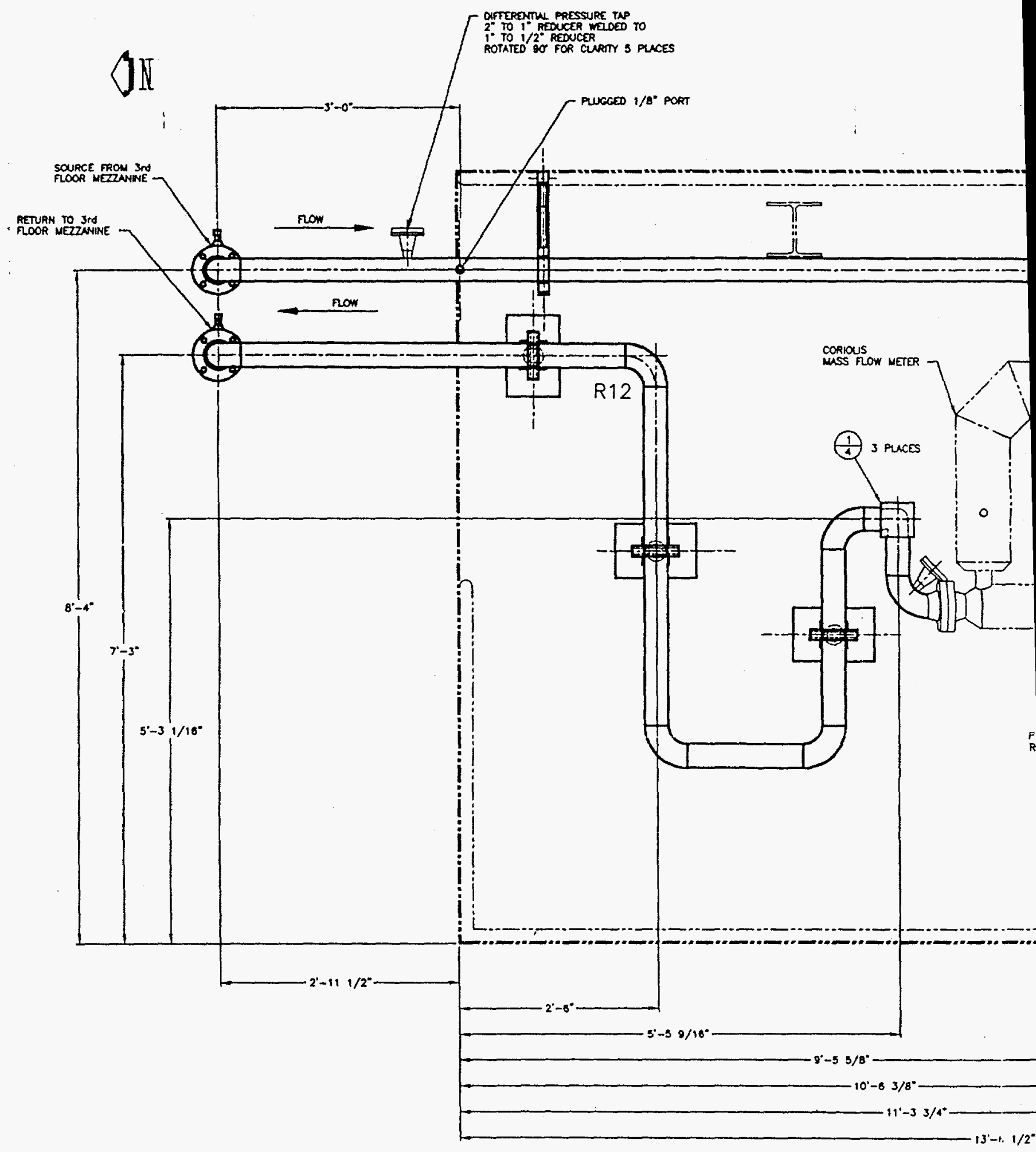

PLAN VIEW

Figure A.2. Project W2-11 I 
Appendix B

Simulant Development 
Figure B.1. Instrument Validation Sin

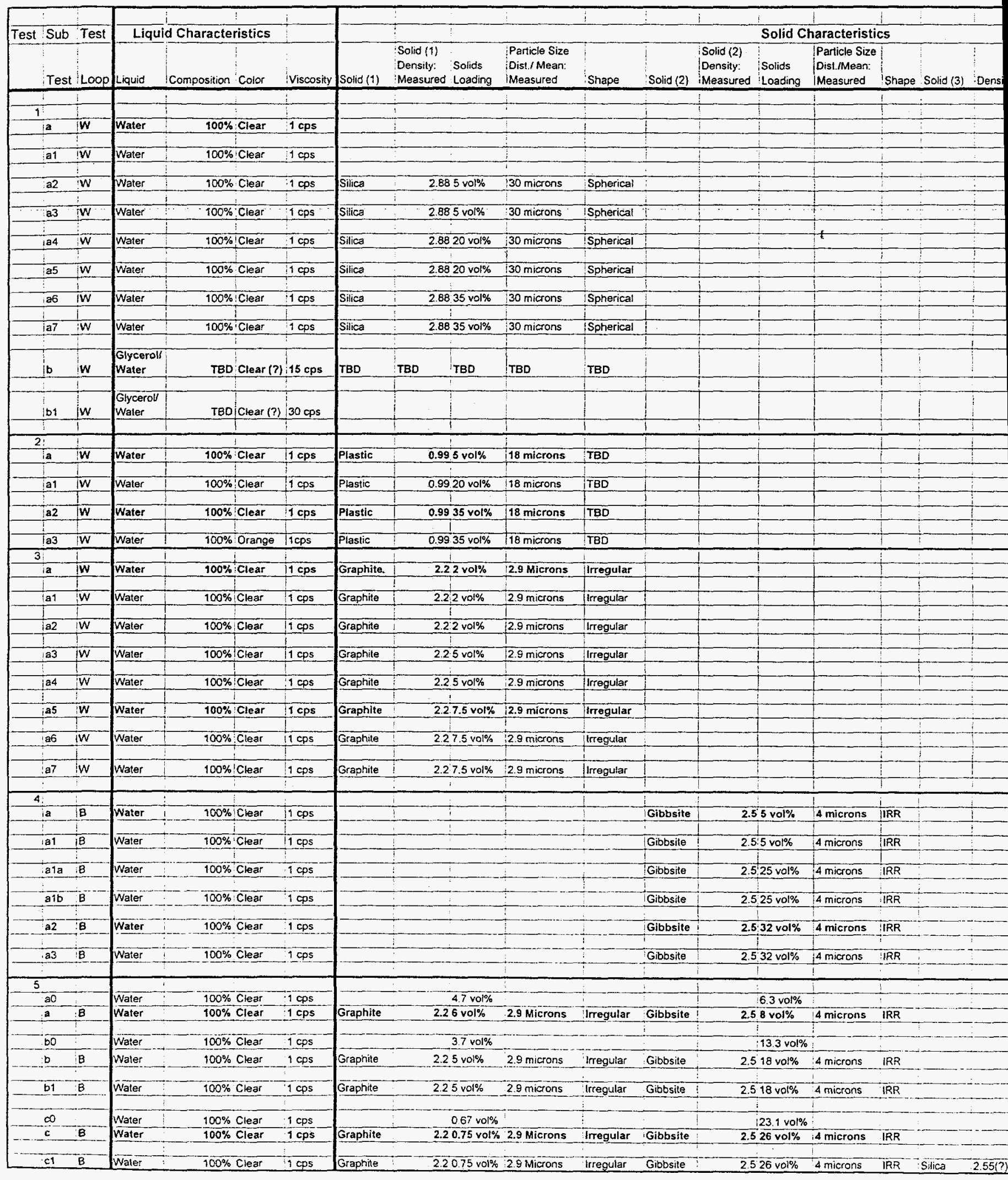




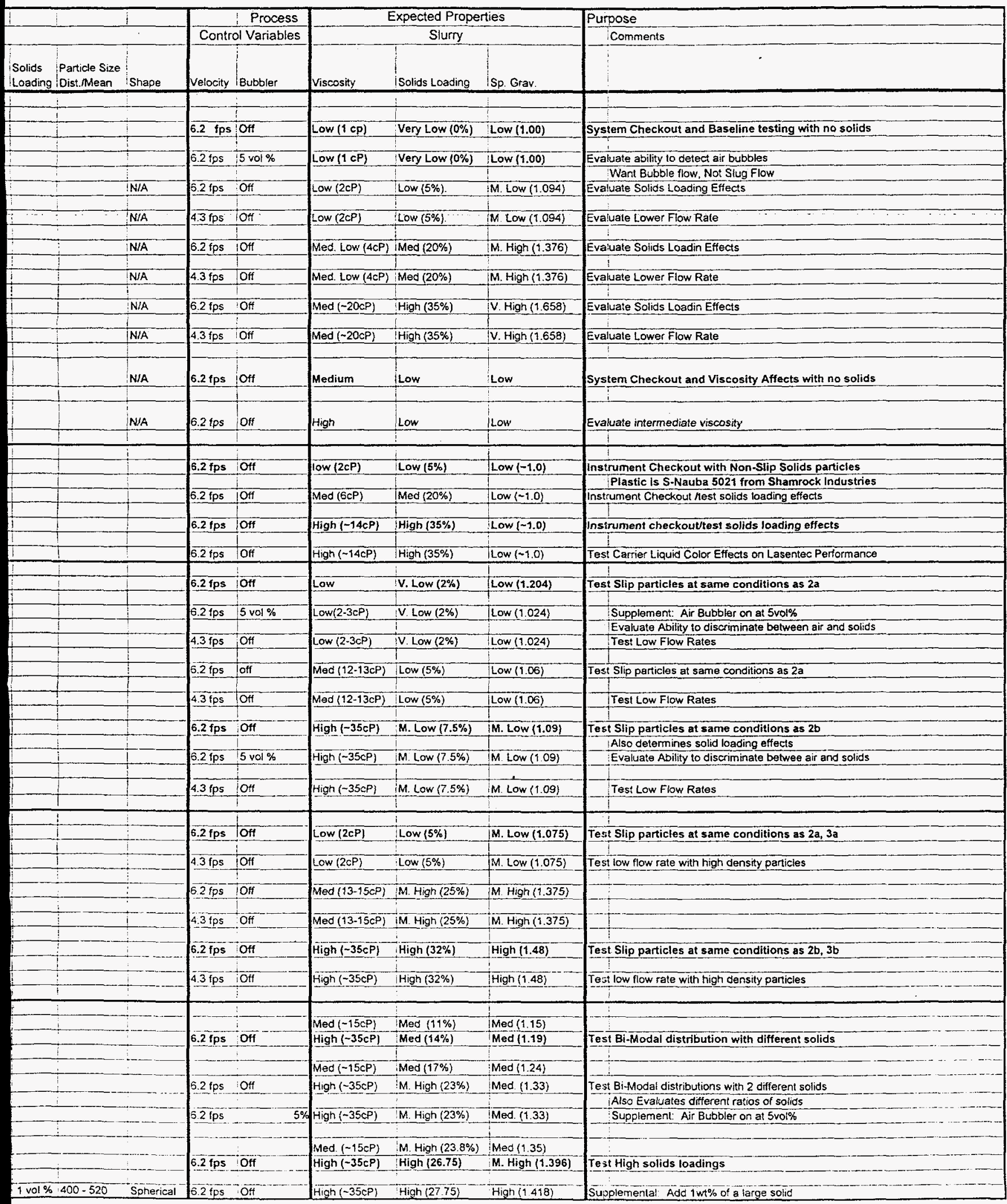


Figure B

\begin{tabular}{|c|c|c|c|c|c|c|c|c|c|c|c|c|c|c|c|c|c|c|}
\hline & $!$ & & & $\therefore$ & & $i$ & & & & & $\vdots$ & & 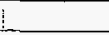 & $!$ & $!$ & & & \\
\hline Test & Sub & Test & Liqui & d Character & istics & & & & & & & & & Solid C & haracteristic & & & \\
\hline & Test & Loop & Liquid & Composition & Cotor & Viscosity & Solic (1) & $\begin{array}{l}\text { Solid (1) } \\
\text { Oensity: } \\
\text { Measured }\end{array}$ & $\begin{array}{l}\text { Solids } \\
\text { Loading }\end{array}$ & $\begin{array}{l}\text { Particle Size } \\
\text { Dist./ Mean: } \\
\text { Measured }\end{array}$ & Shape & Solid (2) & $\begin{array}{l}\text { Solid (2) } \\
\text { Density: } \\
\text { Measured }\end{array}$ & $\begin{array}{l}\text { Solids } \\
\text { Loading }\end{array}$ & $\begin{array}{l}\text { Particle Size } \\
\text { Dist.Mean: } \\
\text { Measured }\end{array}$ & Shape & Solid (3) & Density \\
\hline & $c 2$ & $B$ & Water & $\quad 100 \%$ & Clear & $1 \mathrm{cps}$ & Graphite & 2.2 & 0.75 vol\% & 2.9 microns & Irregular & Gbosite & & 526 vol\% & 4 microns & IRR & Silica & $2.55(?)$ \\
\hline & 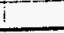 & & & $i$ & & & & & 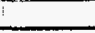 & 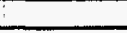 & & & 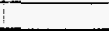 & 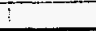 & & & & \\
\hline 6 & & & & $!$ & & & & & & $!$ & & & & $i$ & & & & \\
\hline & $a$ & $w$ & Water & $100 \%$ & Clear & $1 \mathrm{cps}$ & TBD & TBO & 5 yol\% & 1.5 Microns & Rod-Like & & & 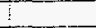 & 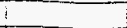 & & & \\
\hline & & & & 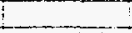 & & & & & 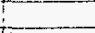 & 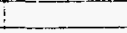 & & & 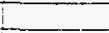 & $\vdots$ & 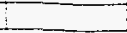 & & & \\
\hline & a1 & $\bar{w}$ & Waler & $100 \%$ & Orange & $1 \mathrm{cps}$ & TBD & TBD & 5 vol\% & $1-5$ microns & Rod-Like & & 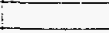 & 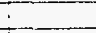 & & & & \\
\hline & & & $-6+$ & $\vdots$ & & & & & 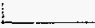 & $\vdots \quad \ldots$ & & & & 3 & & & & \\
\hline & $b$ & $w$ & Water & $100 \%$ & Clear & 1 cps & Bentonite & & 4 บol\% & 0.8 micron & Disc-Like & & & $i$ & & & & \\
\hline & 61 & $w$ & Water & $100 \%$ & Clear & $1 \mathrm{cps}$ & Bentonite & & $4 \mathrm{Vol} \%$ & 0.8 micron & Disc-Like & Mica & 2.75 & 54 vol\% & -6.3 microns & Disc & & \\
\hline & & & & & & 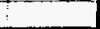 & & & & 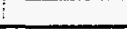 & & & i & 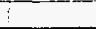 & & & & \\
\hline 7 & & & & & & & & & 1 & 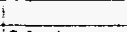 & & & 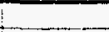 & 7 & & & & \\
\hline & $a$ & $w$ & Water & $100 \%$ & Clear & $14 \cos$ & Bentonite & & 1 vol\% & 0.8 micron & Disc-Like & & & & & & & \\
\hline & - & & & & & & & & & & & & & 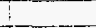 & 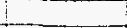 & & & \\
\hline & $b$ & $w$ & Water & $100 \%$ & Clear & $1 \mathrm{cps}$ & Bentonite & & 2.5 vol\% & 0.8 micron & Disc-Like & & & $\vdots$ & & & & \\
\hline & & & & $i$ & & & & & & 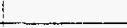 & $1 \ldots$ & & & $\vdots$ & 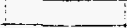 & & & \\
\hline & c & $w$ & Water & $100 \%$ & Clear & $1 \mathrm{cps}$ & Bentonite & & 4 vol\% & 0.8 micron & Disc-Like & & & 1 & 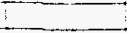 & & & 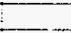 \\
\hline & & & & 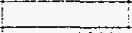 & & & & & & & & & & $\vdots$ & $\vdots$ & & & 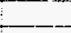 \\
\hline & 1 & $w$ & Water & $100 \%$ & Orange & $1 \mathrm{cps}$ & Bentonite & 2.4 & 4 vol\% & 0.8 micron & Disc-Like & & & $i$ & 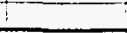 & & & \\
\hline 8 & & & & 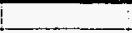 & & $\vdots$ & & & & & & $!$ & 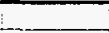 & 1 & 1 & & 1 & $\vdots$ \\
\hline & $a$ & $w$ & Unknown & 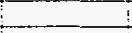 & 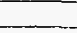 & $\vdots$ & TBD & T8D & & & & & 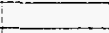 & $!$ & & & 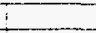 & \\
\hline & & & & 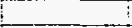 & E. & & & & & & I & & & I & 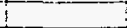 & & ! & \\
\hline & b & W & Unknown & & 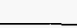 & & $\mathrm{TBD}$ & TBD & & & 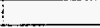 & & $i$ & & I & & $i$ & 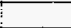 \\
\hline & 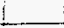 & & & i & 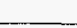 & & & 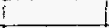 & & & & & 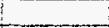 & 1 & & & 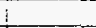 & $i$ \\
\hline & $c$ & $W$ & Unknown & & & & $\mathrm{YBD}$ & TBD & & I & & & i & $!$ & & 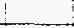 & $\vdots$ & 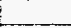 \\
\hline & & & & & & & & & & i & & & 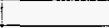 & 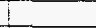 & & 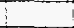 & $!$ & \\
\hline & dd & $w$ & Unknown & 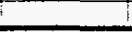 & 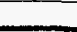 & 1 & TBD & TBD & & $i$ & & & 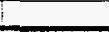 & $i$ & & $i$ & & 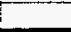 \\
\hline & $i$ & & 1 & 1 & 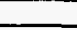 & $i$ & & 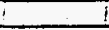 & I & 1 & & & i & & & 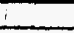 & & \\
\hline
\end{tabular}

Note: 1) All Quantified Values May change based on Simulant Development Testing 


\section{(contd)}

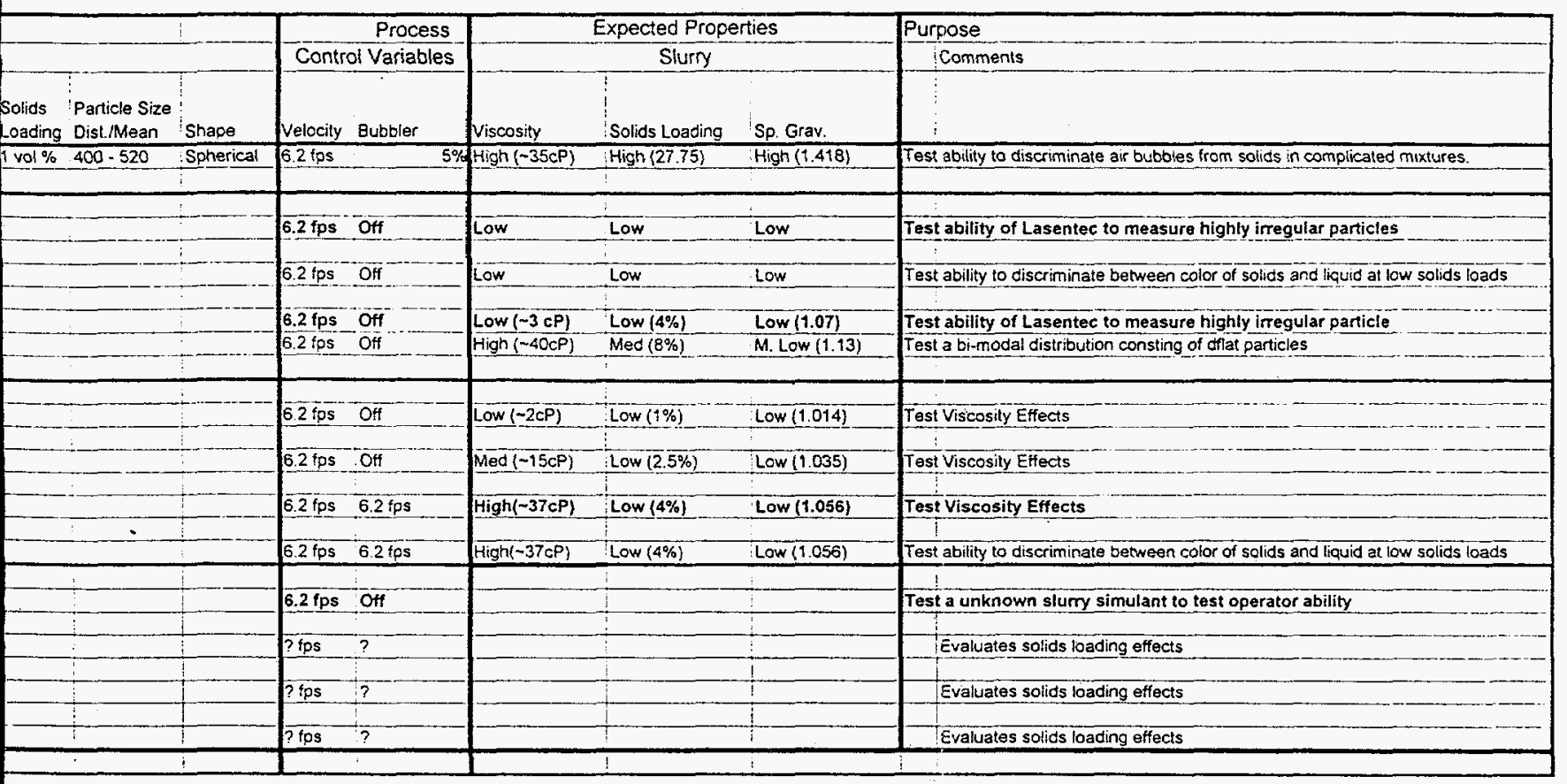


Appendix C

Experimental Data 


\section{Appendix C}

\section{Experimental Data}

The table is composed of four sections.

Section 1: The first section contains the run numbers, test numbers, and what loop was tested ("W" stands for W-211 and "I" stands for ideal). The run number is identified by a number (e.g., 3). The test number is identified by an alphanumeric code (e.g., 3a, 3a1, 3a2). The alpha part of the test number is typically changed when the composition of the slurry is modified. (Since this table has been modified from the original test plan submitted on October 1, 1995, based on additional simulant characterization tests, the combination of run number and test number is confusing. It is also generally not used within this report.)

Section 2: The second section contains the liquid and solid characteristics that constitute the slurry.

Section 3: The third section contains the processing conditions to be evaluated during the run.

Section 4: The fourth section contains the expected slurry properties based on laboratory testing and the goal of each experiment. 
Table C.1. Instrument Valid

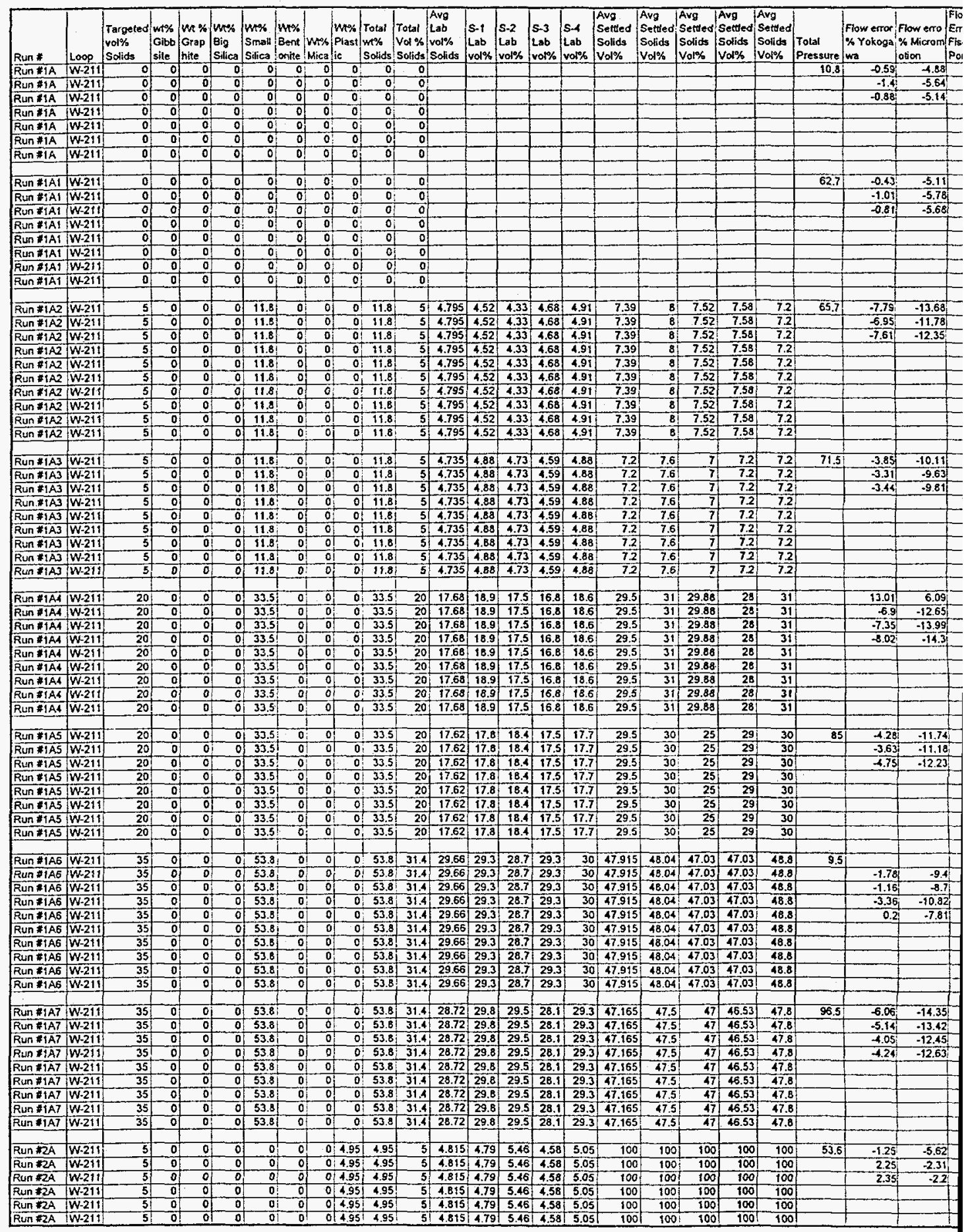


ion Experimental Data

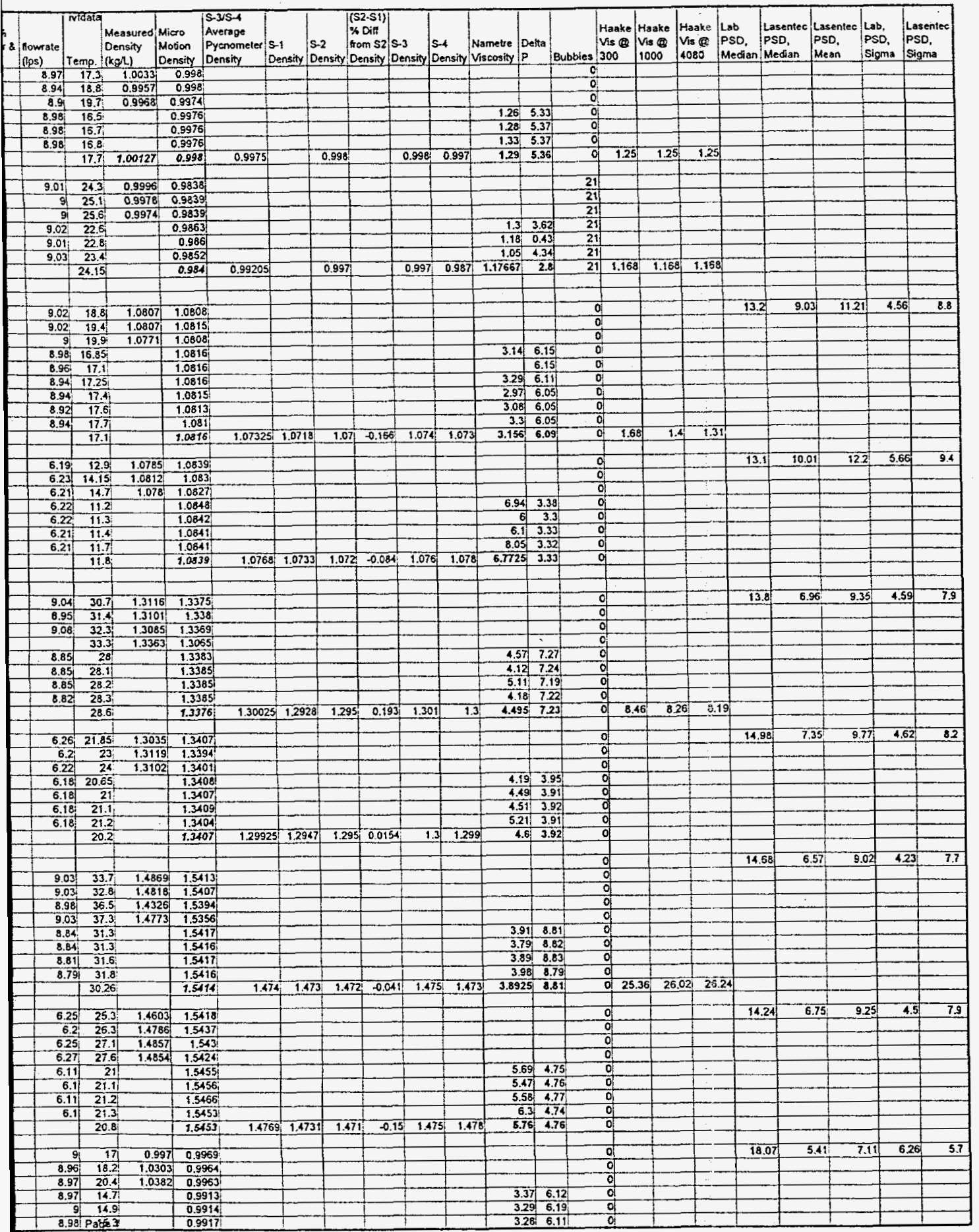




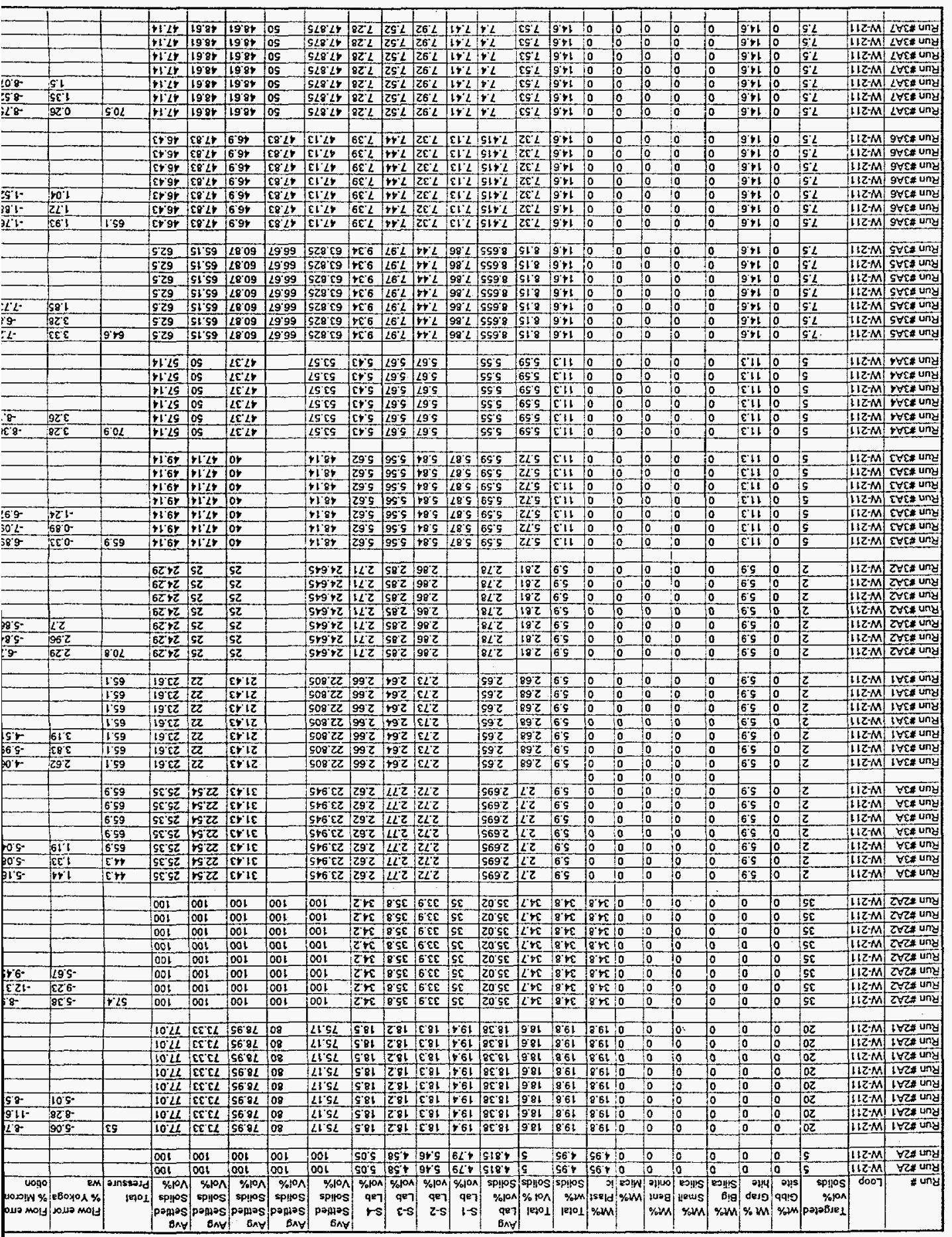

I $\mathcal{S}$ әवृ I 


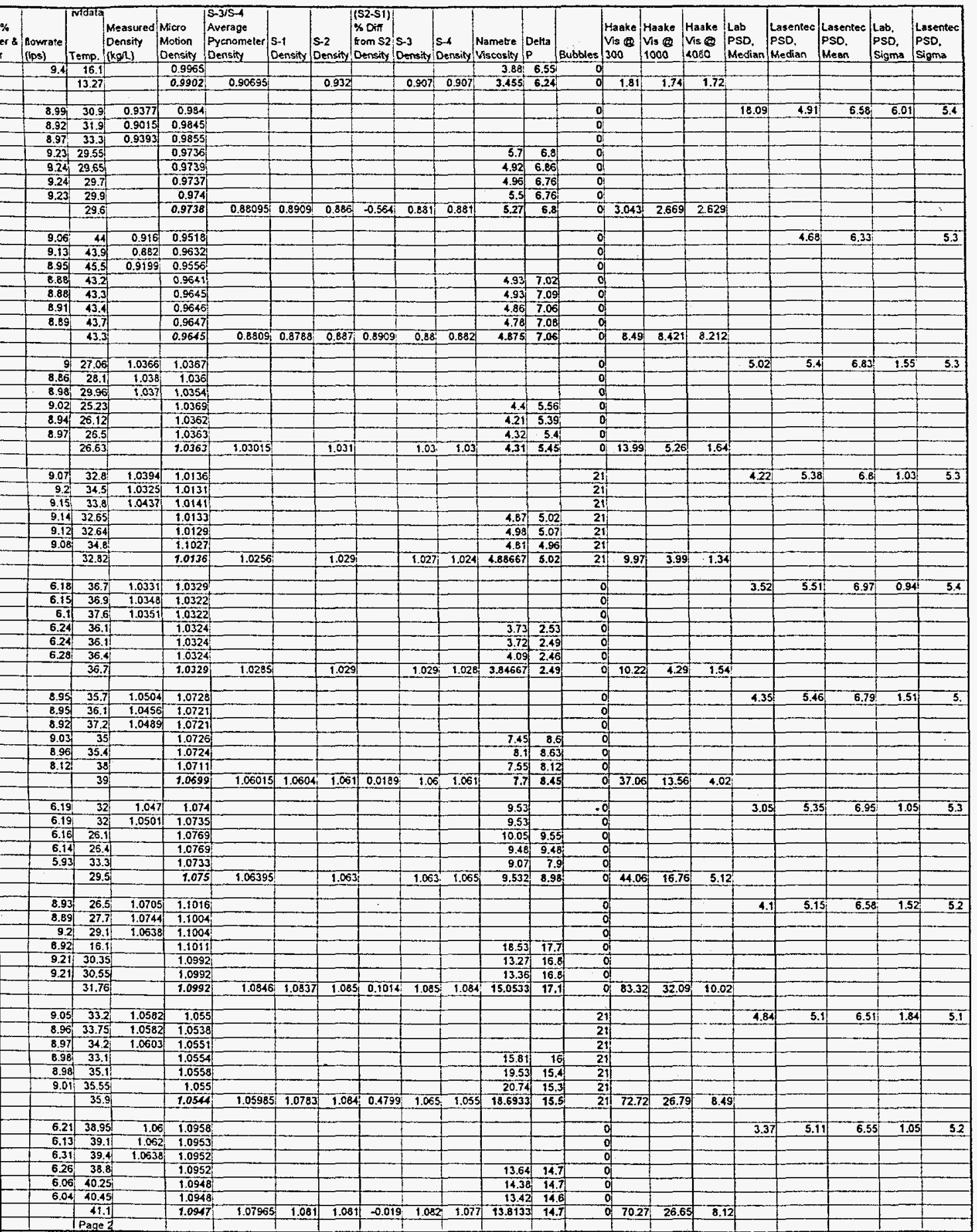


Table C.1. (contd

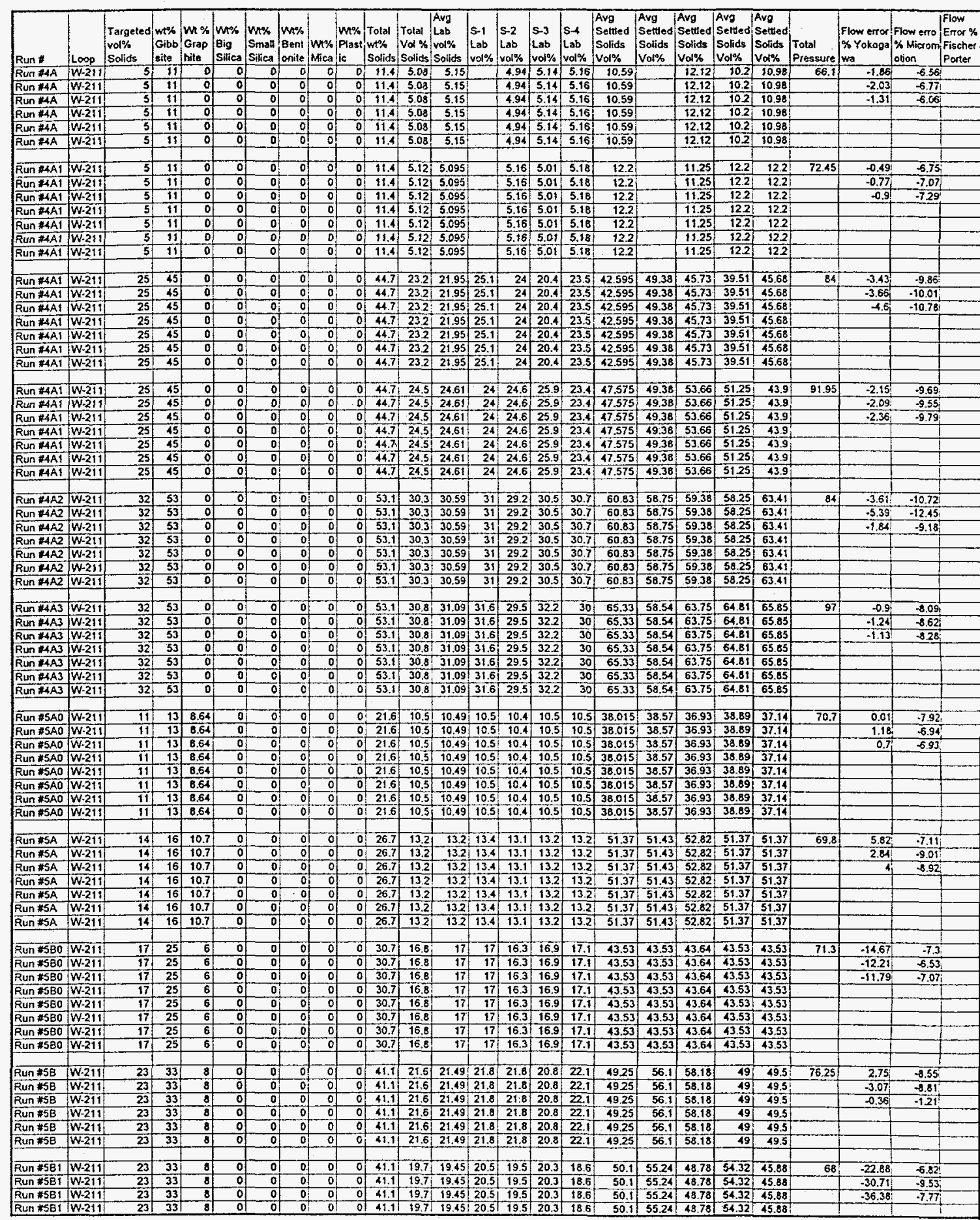




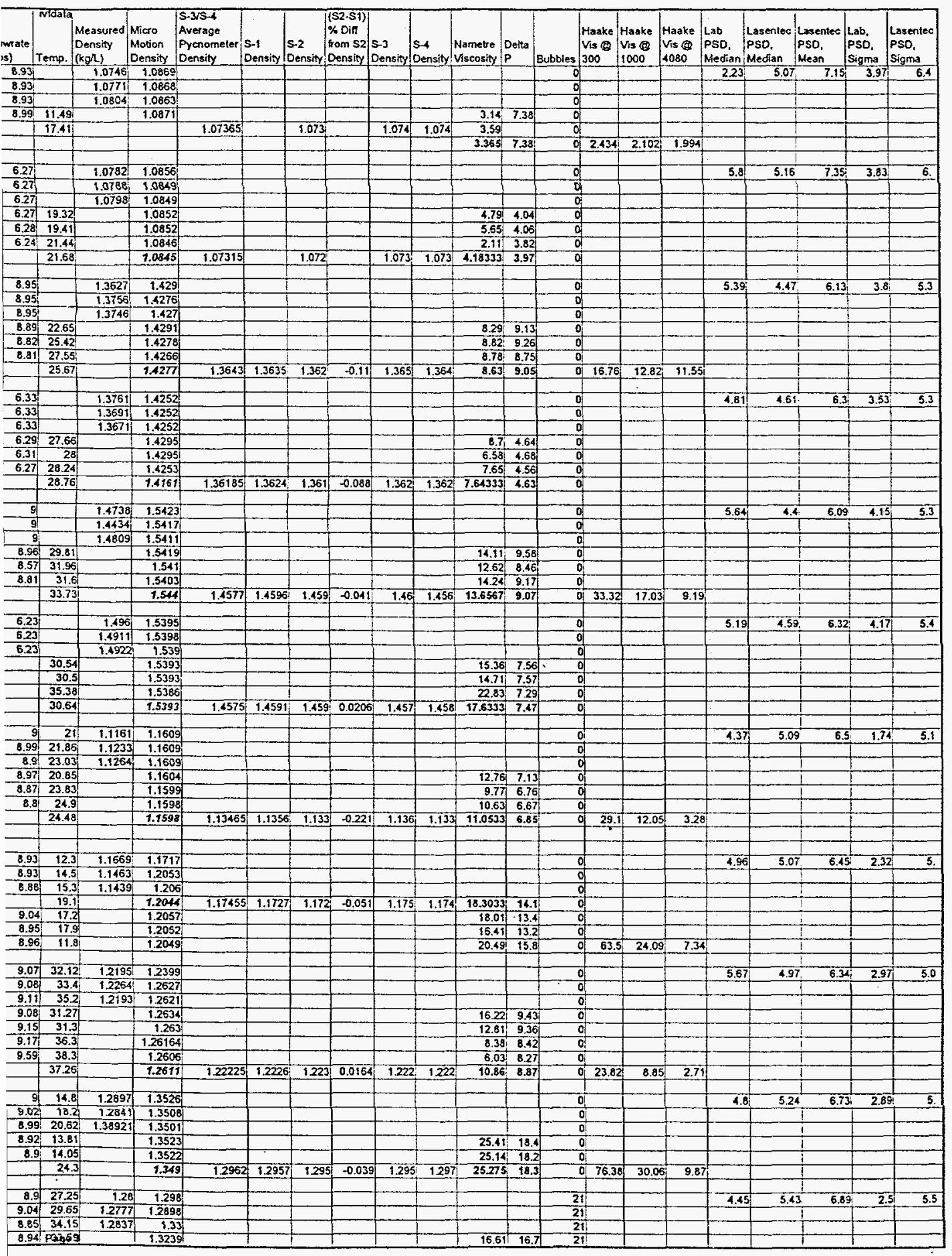


Table C.1. (cont

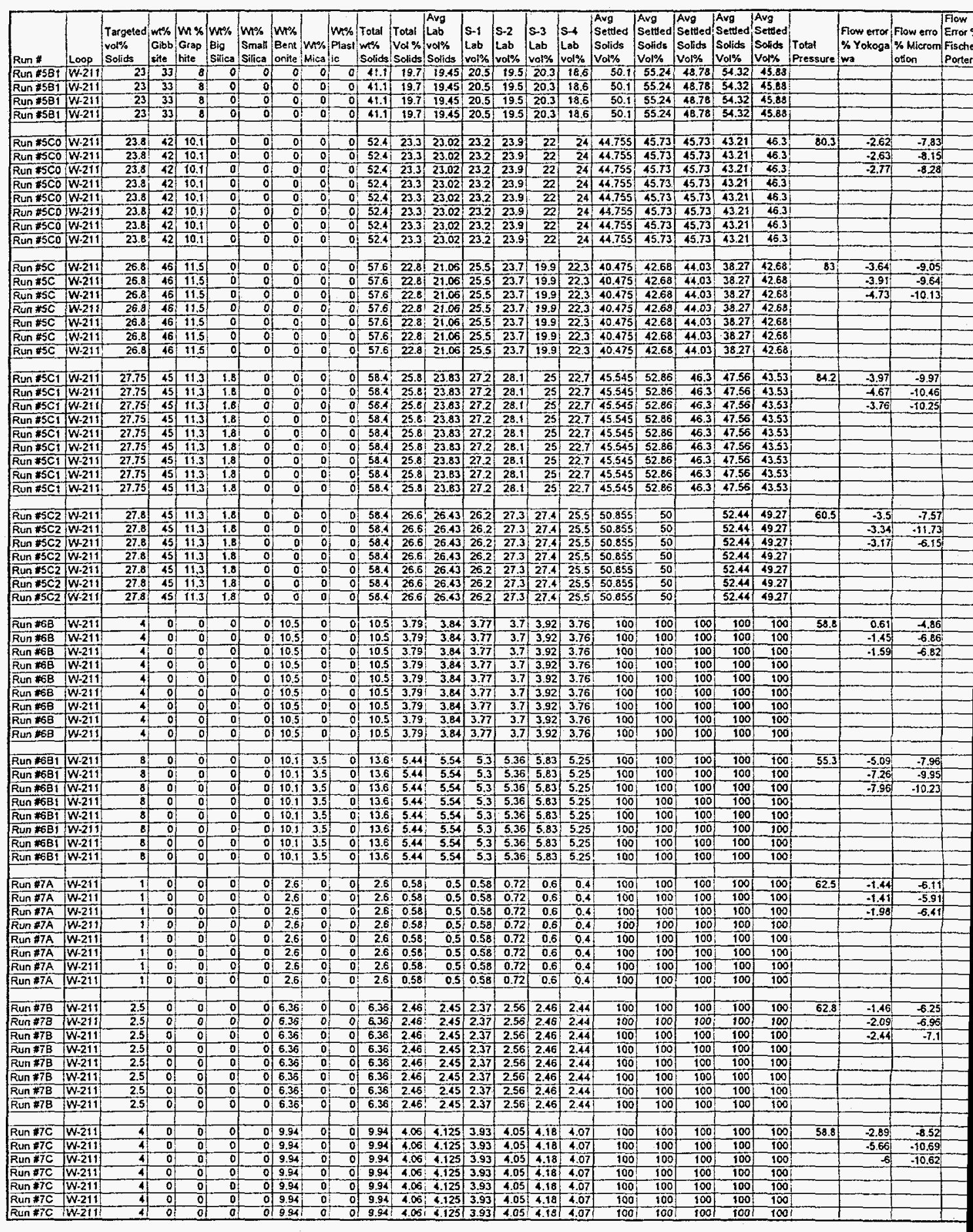




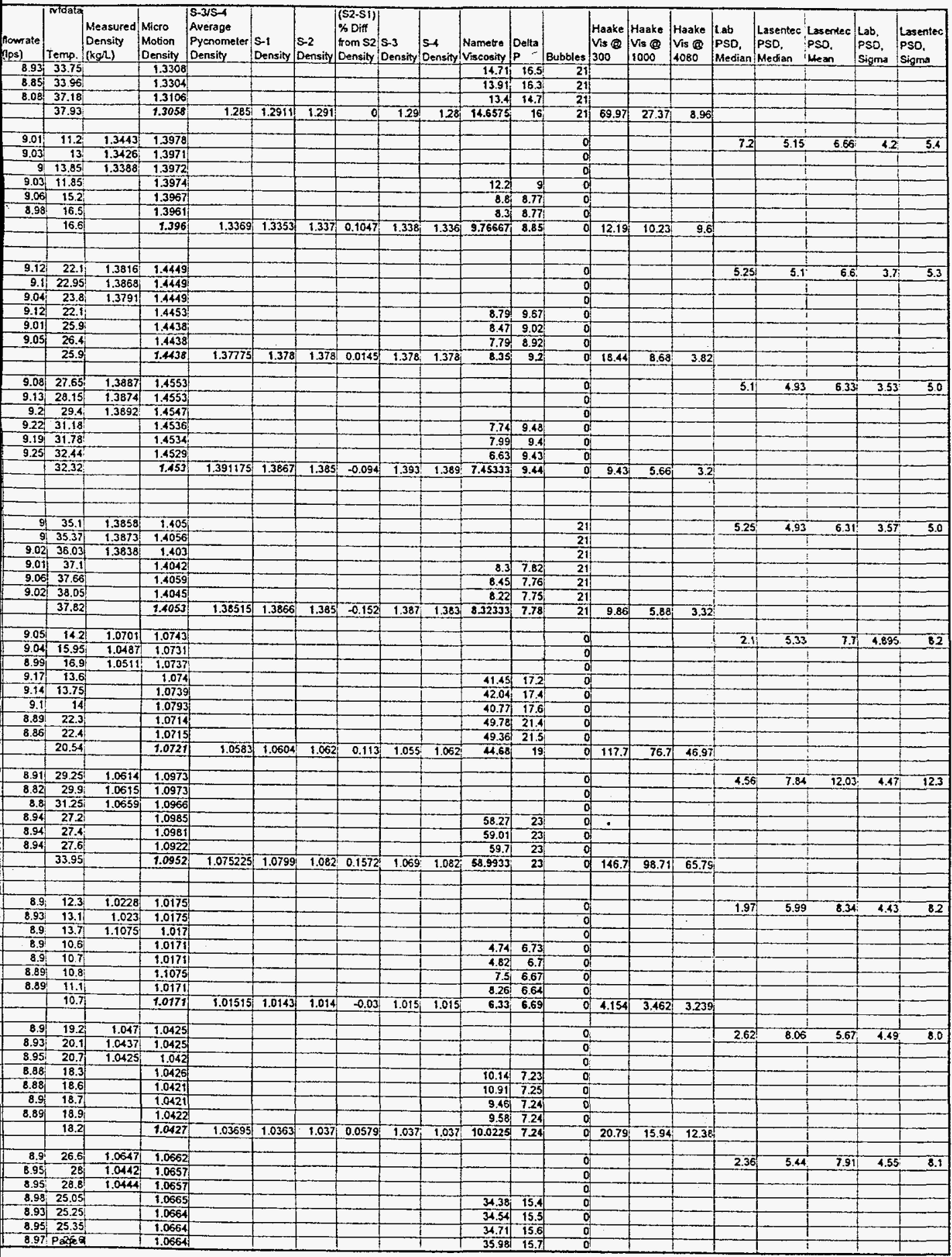


II

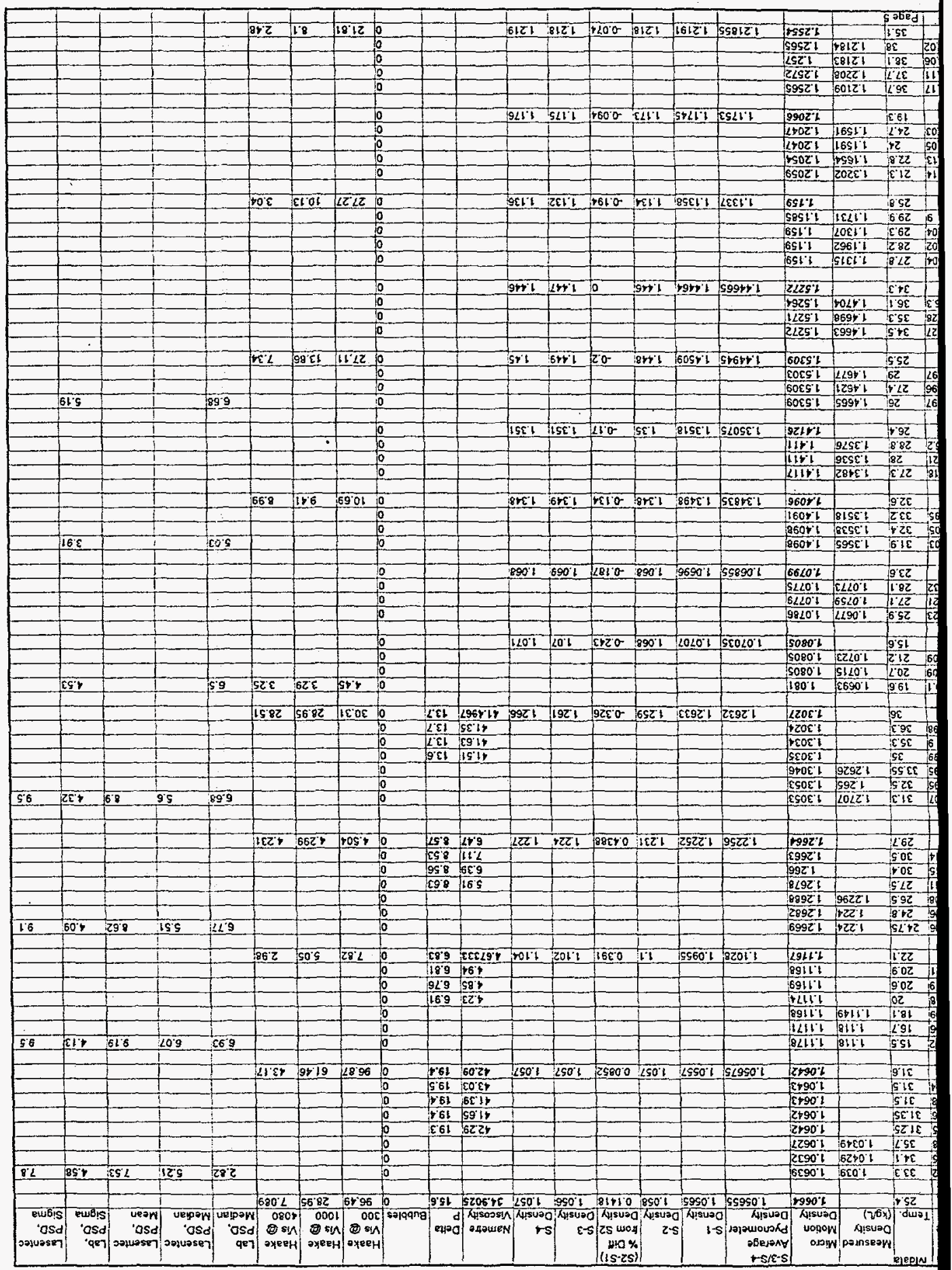


Table C.1. (contd)

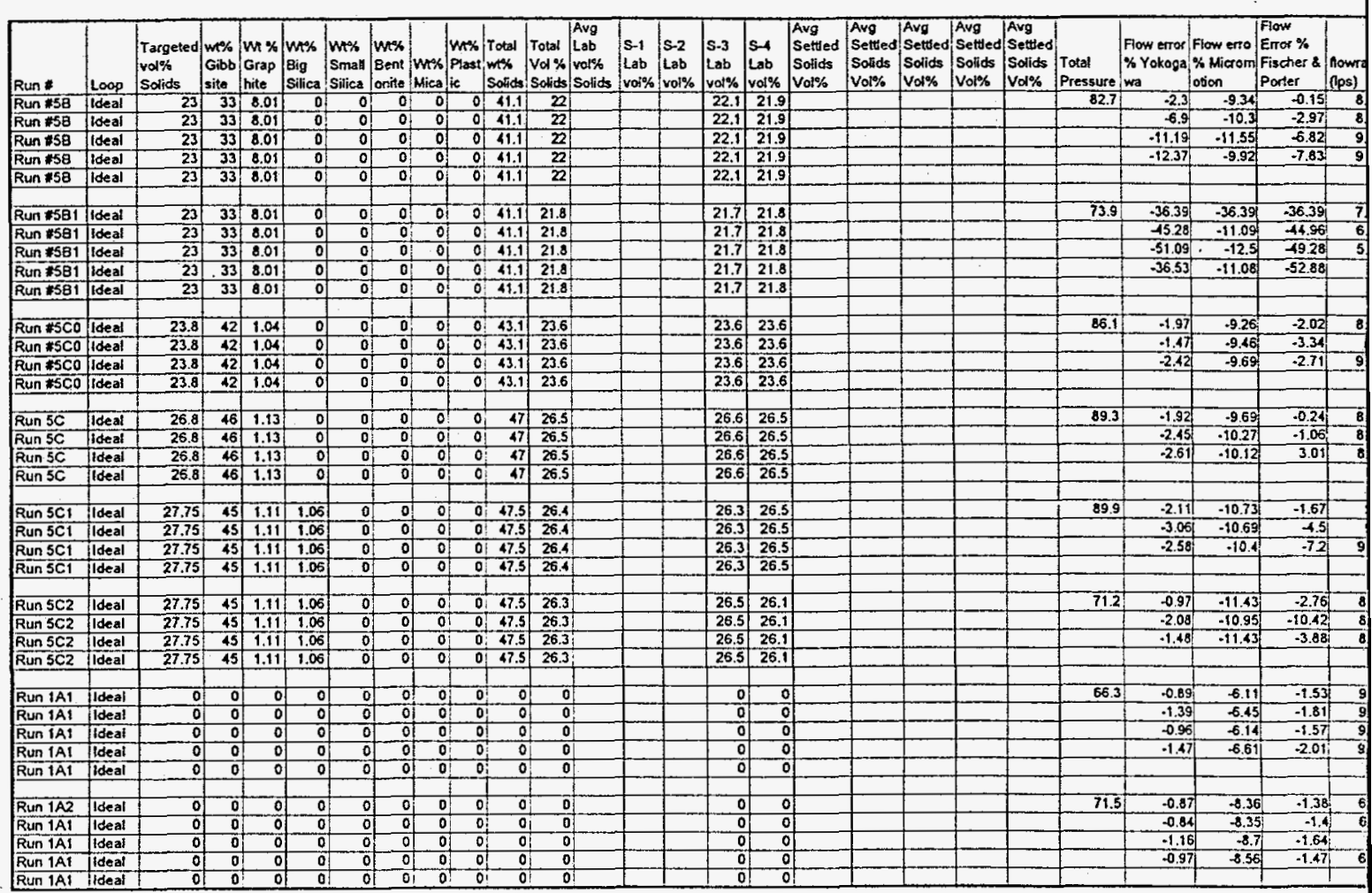




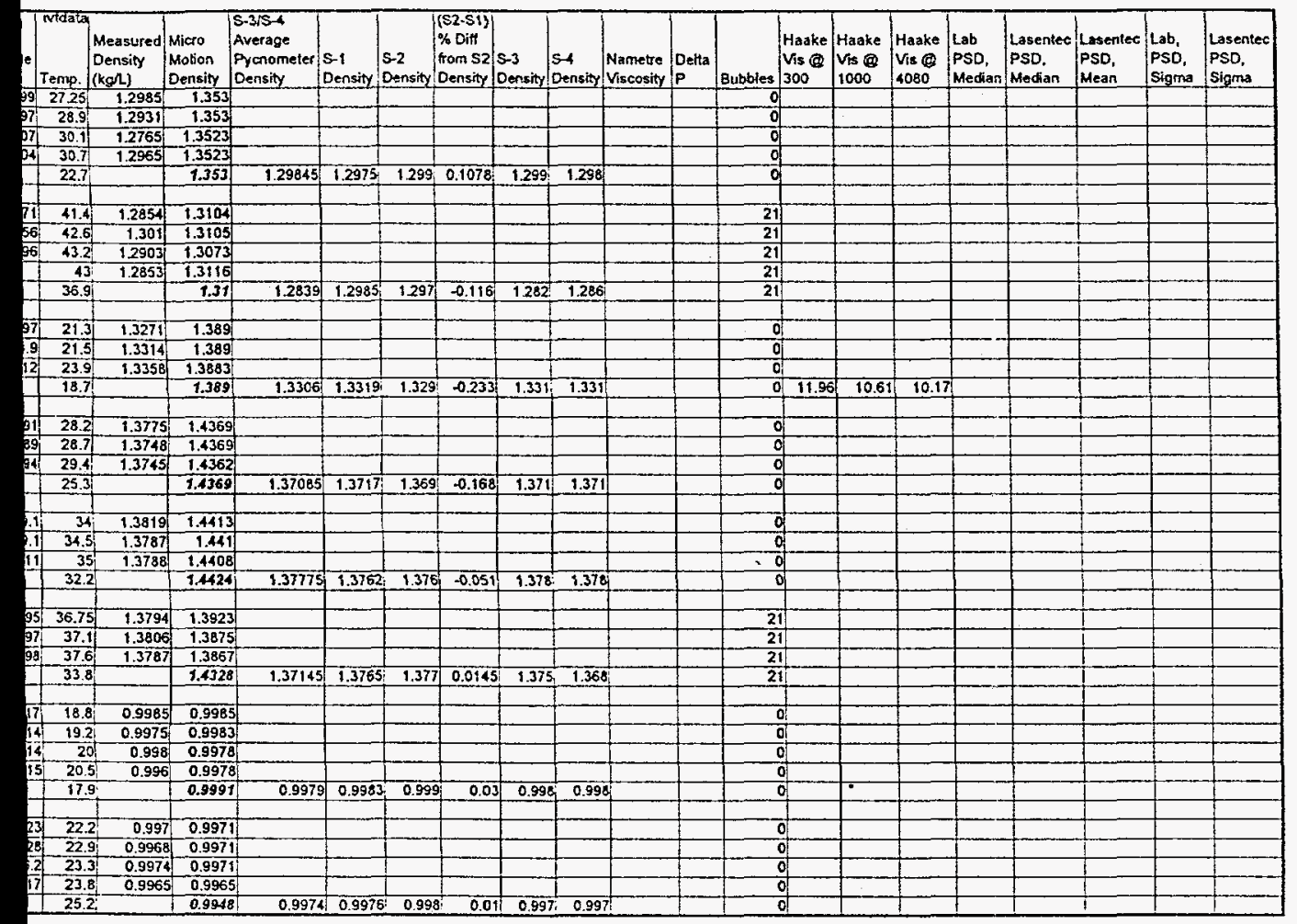


Appendix D

Statistical Analysis Results 
Appendix D-1, t-Test for S-1 vs. S-2 Density

D. 1 


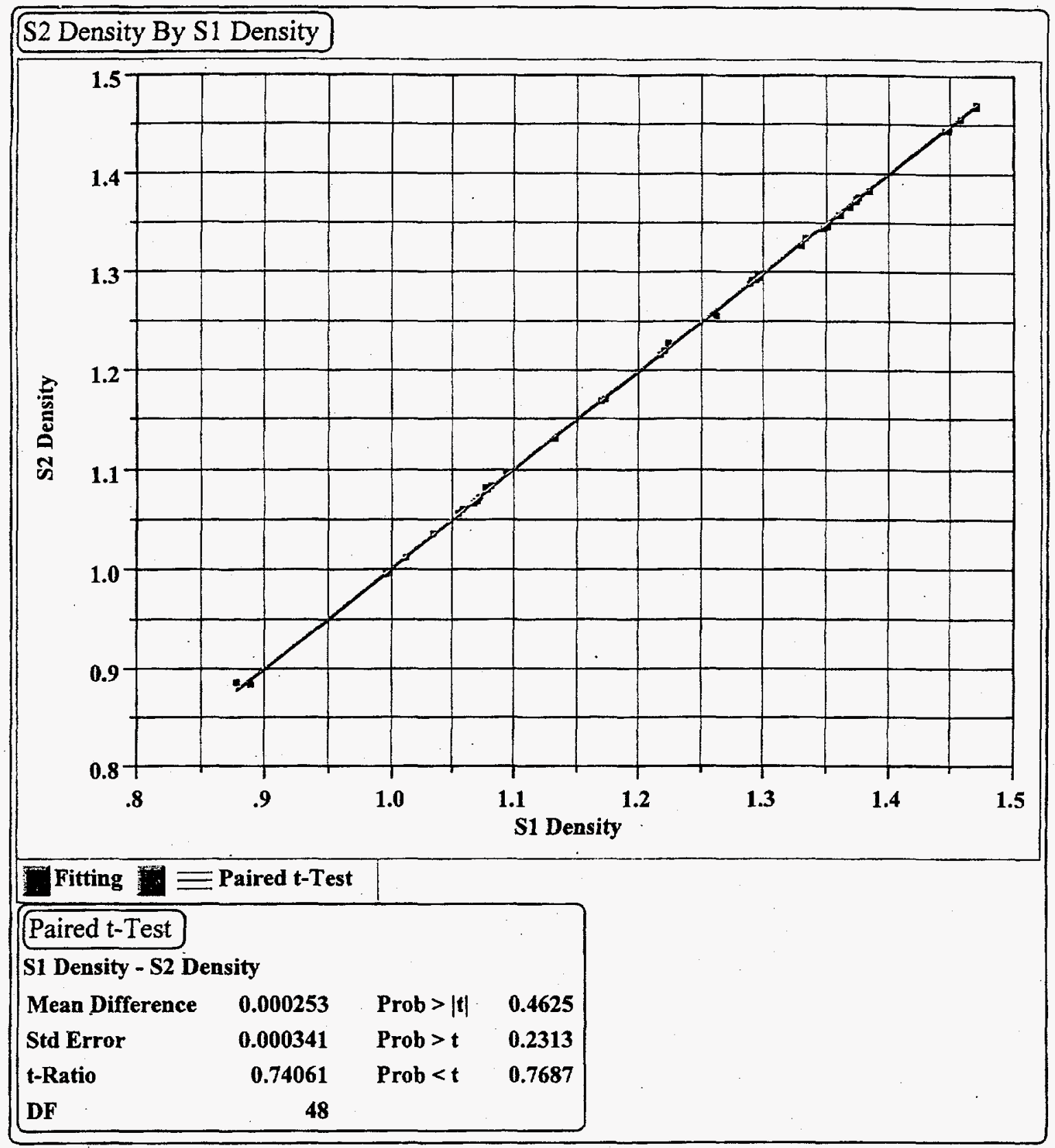

Figure D-1: t-Test for S1 vs S2 Density

Since the $\mathrm{Y}=\mathrm{X}$ line falls within the best fit upper and lower confidence limits, the difference between the $\mathrm{S} 1$ and $\mathrm{S} 2$ densities are not statistically significant. Therefore, no settling is observed.

D. 3 


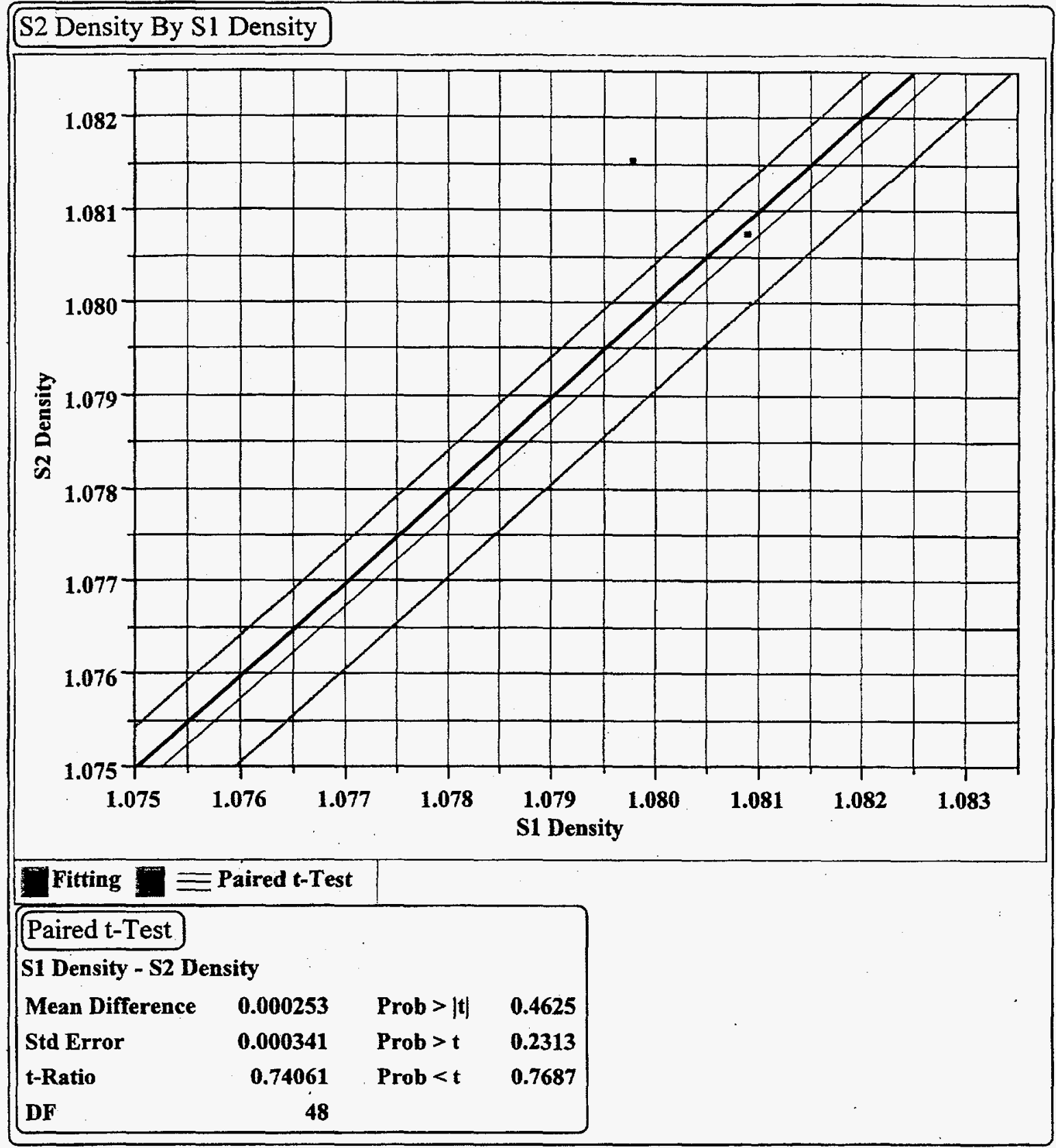

Figure D-1(Blow Up): t-Test for S1 vs S2 Density

Since the $Y=X$ line falls within the best fit upper and lower confidence limits, the difference between the S1 and S2 densities are not statistically significant. Therefore, no settling is observed.

D.4 
Appendix D-2; t-Test for S1 vs. S2 Volume \% Solids 


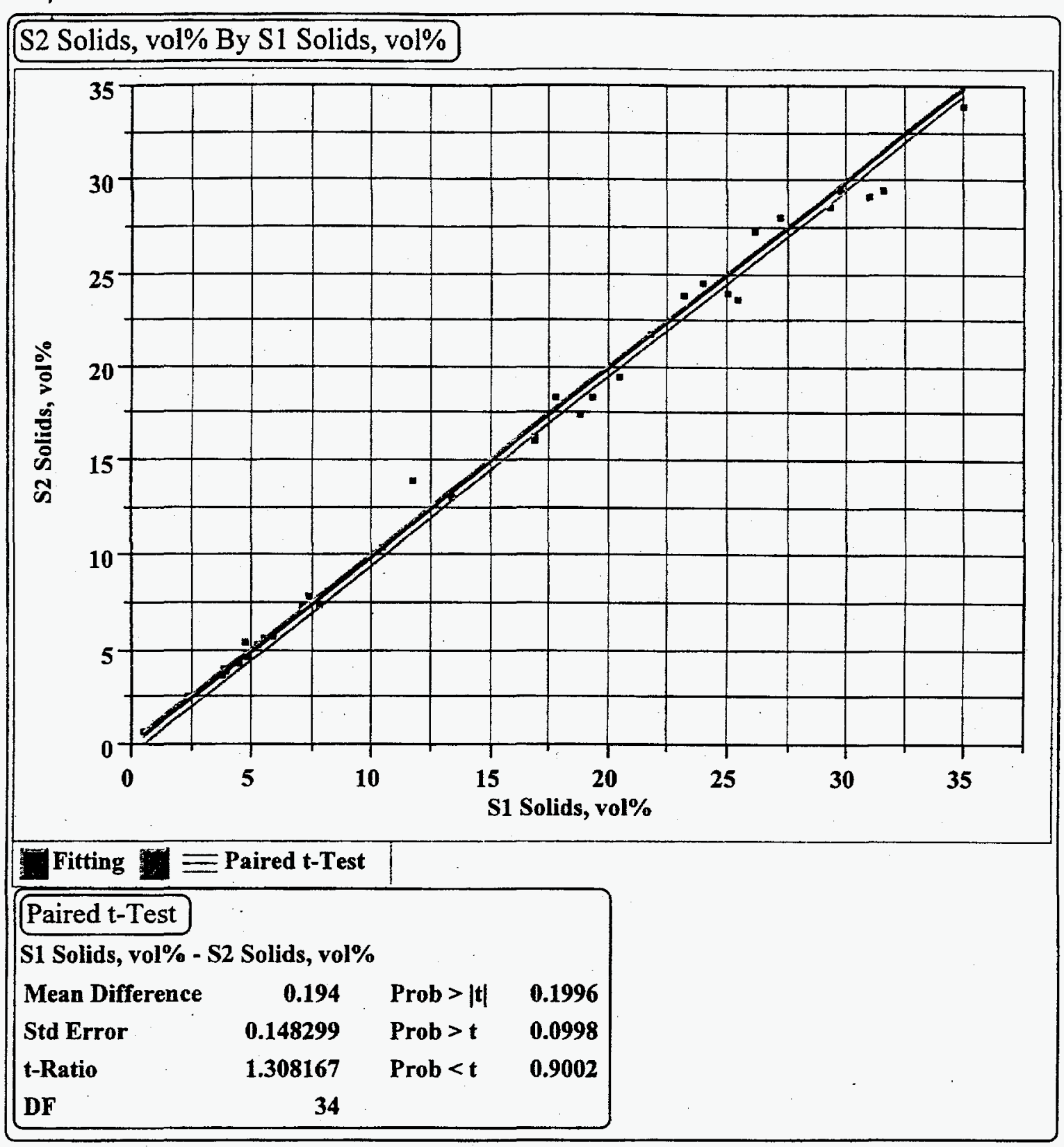

\section{Figure D-2; t-Test for S1 Volume \% Solids vs S2 Volume \% Solids}

Since the $Y=X$ line falls within the best fit upper and lower confidence limits, the difference between the $\mathbf{S 1}$ and $\mathbf{S} 2$ analytically measured solids loadings are not statistically significant. Therefore, no settling is observed. 


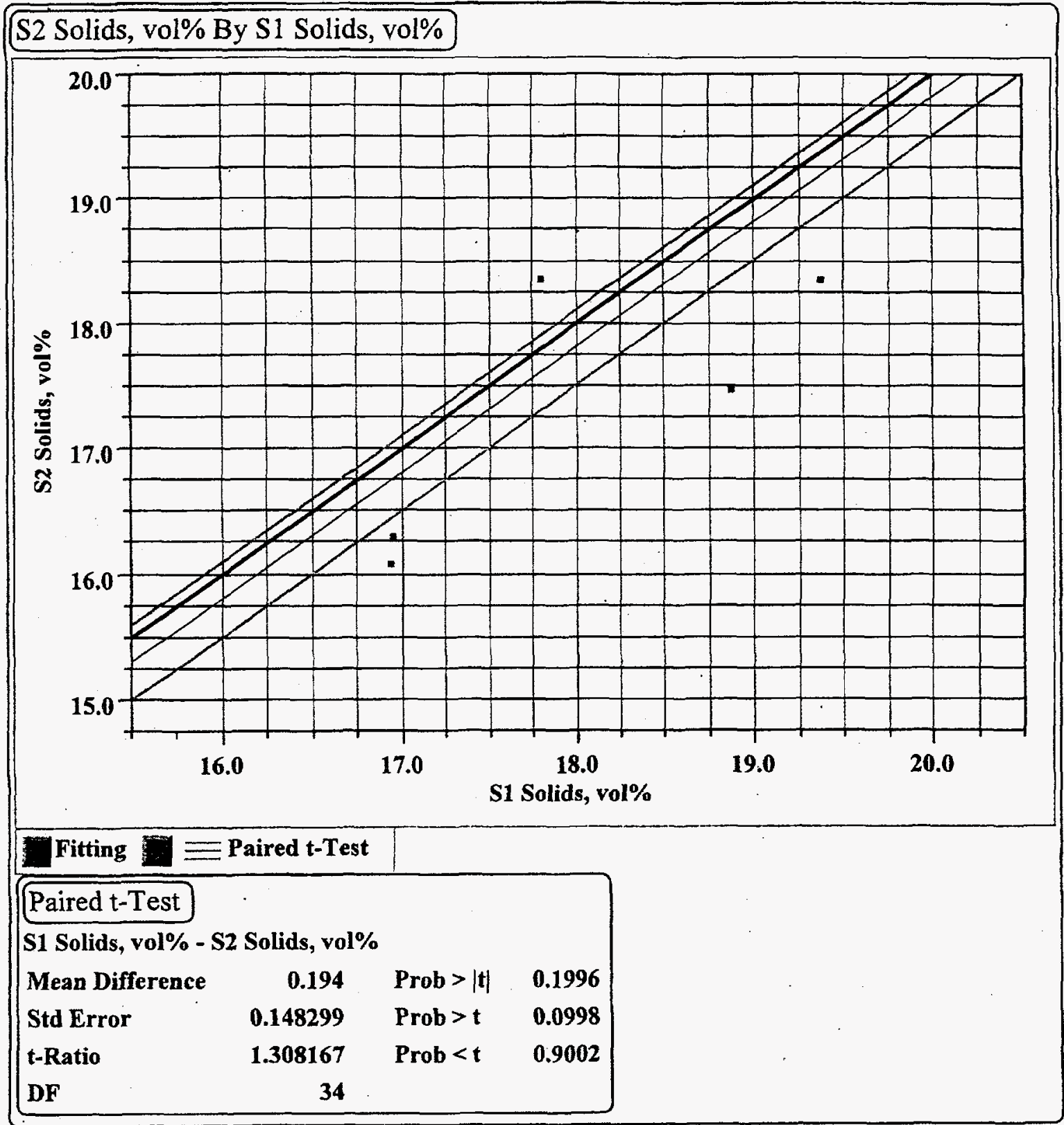

Figure D-2 (Blow Up); t-Test for S1 Volume \% Solids vs S2 Volume \% Solids

Since the $\mathrm{Y}=\mathrm{X}$ line falls within the best fit upper and lower confidence limits, the difference between the $S 1$ and $S 2$ analytically measured solids loadings are not statistically significant. Therefore, no settling is observed. 
Appendix D-3; t-Test for S1/S2 vs. S3/S4 Average Densities 


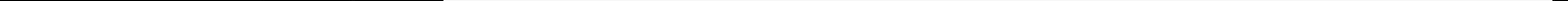




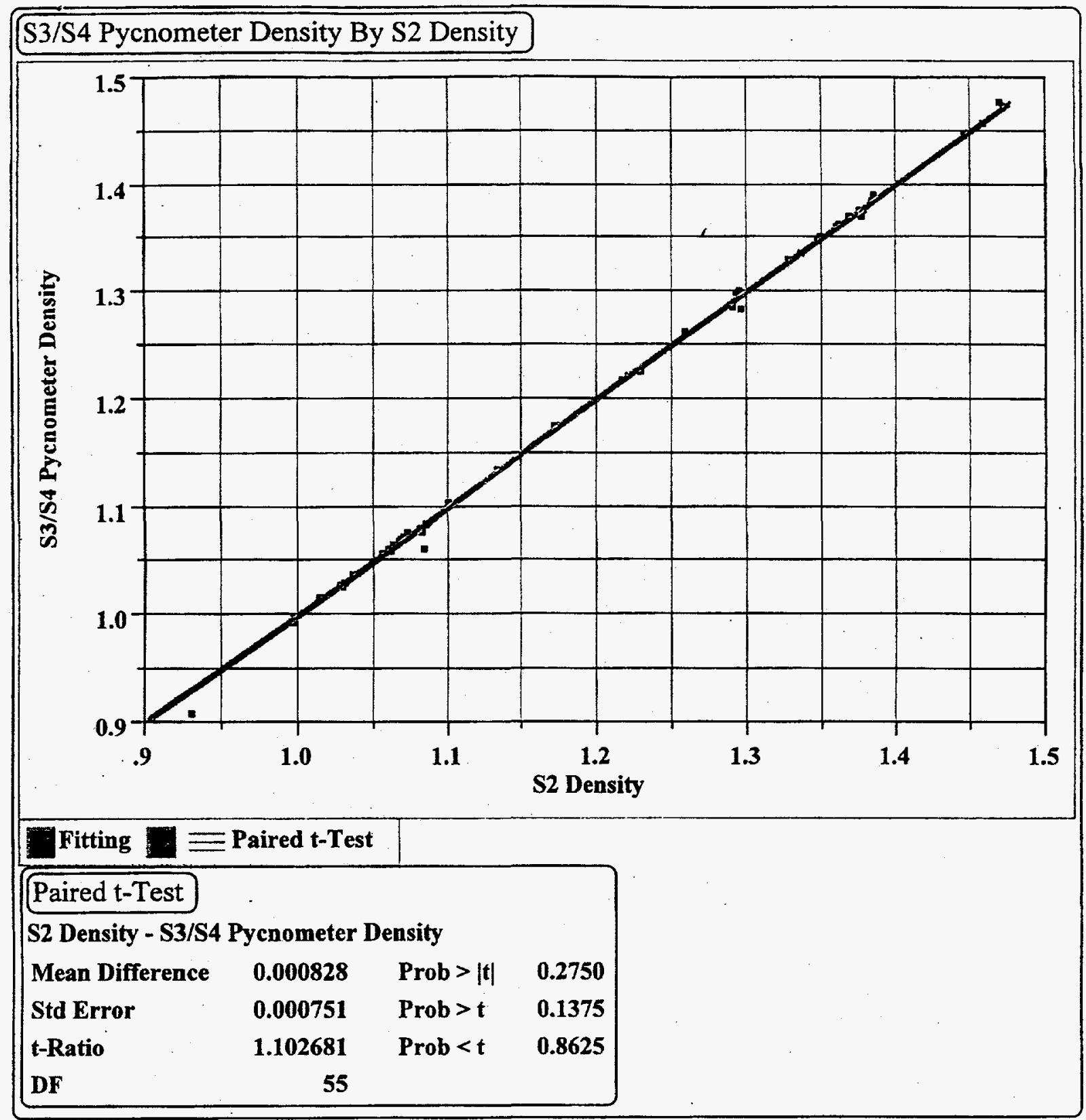

Figure D-3: t-Test for S3/S4 Density vs S2 Density

Since the $Y=X$ line falls within the best fit upper and lower confidence limits, the difference between the $\mathrm{S} 2$ and $\mathrm{S} 3 / \mathrm{S} 4$ densities are not statistically signficant. Therefore, no settling is observed.

D.11 


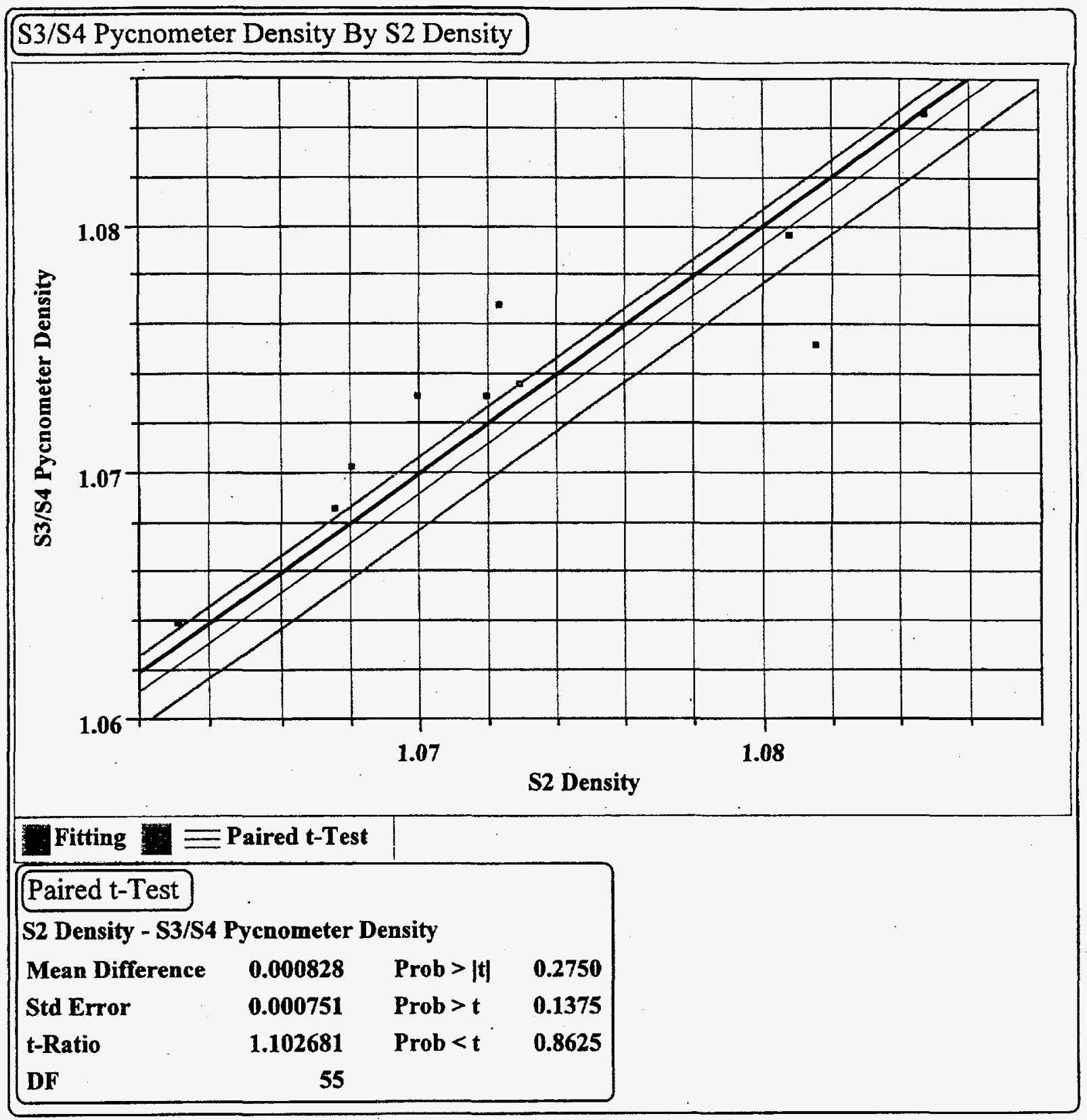

\section{Figure D-3 (Blow-Up): t-Test for S3/S4 Density vs S2 Density}

Since the $Y=X$ line falls within the best fit upper and lower confidence limits, the difference between the S2 and S3/S4 densities are not statistically signficant. Therefore, no settling is observed. 


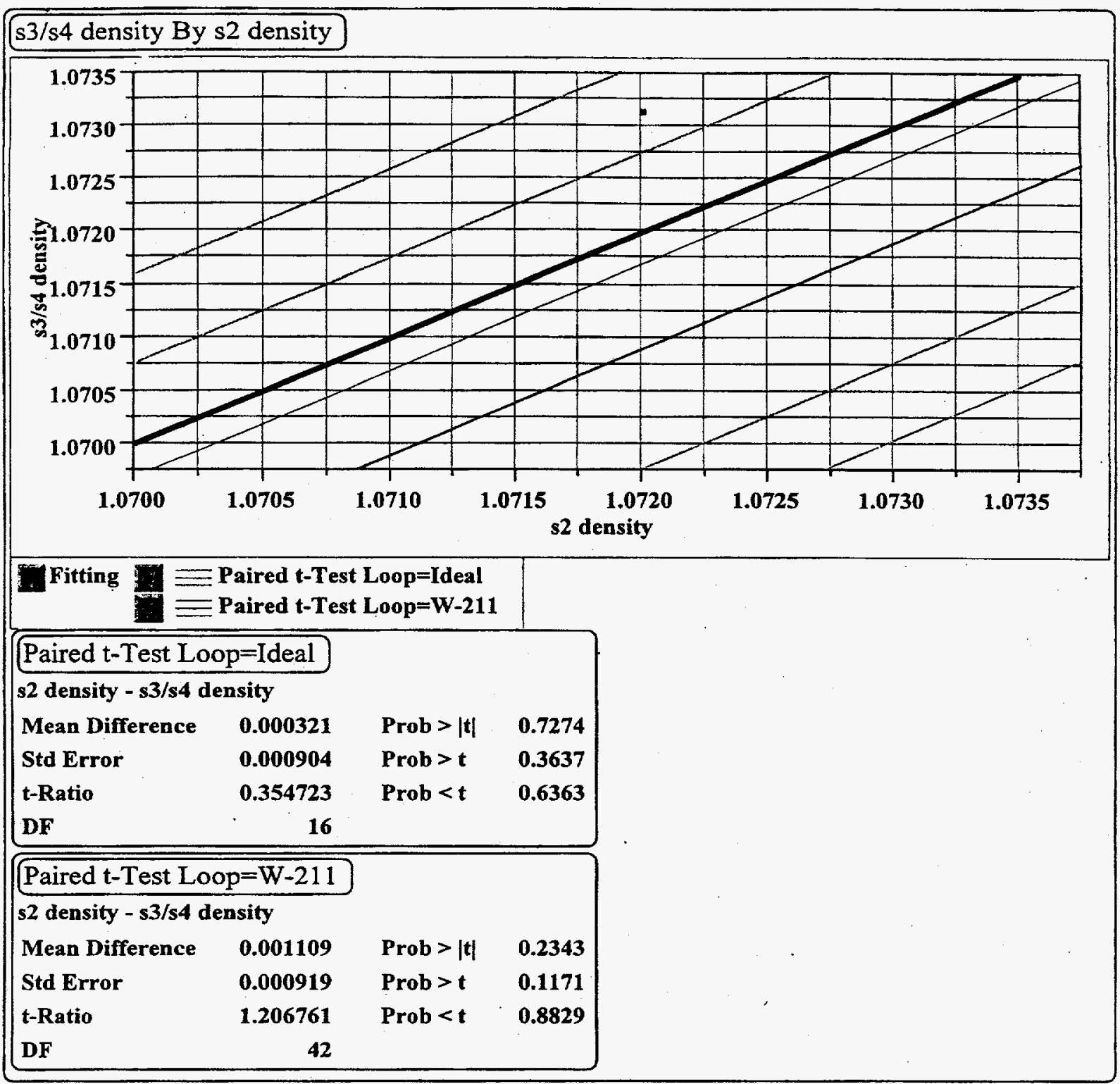

Figure D-3 (Blow-Up); Grouped t-Test for S3/S4 Density vs S2 Density

Since the best fit line of the two groups of data fall within the best upper and lower confidence limits of the two groups, the difference between the two groups is not statistically significant. Therefore, the S3/S4 average density is not affected by the design of the loop. 


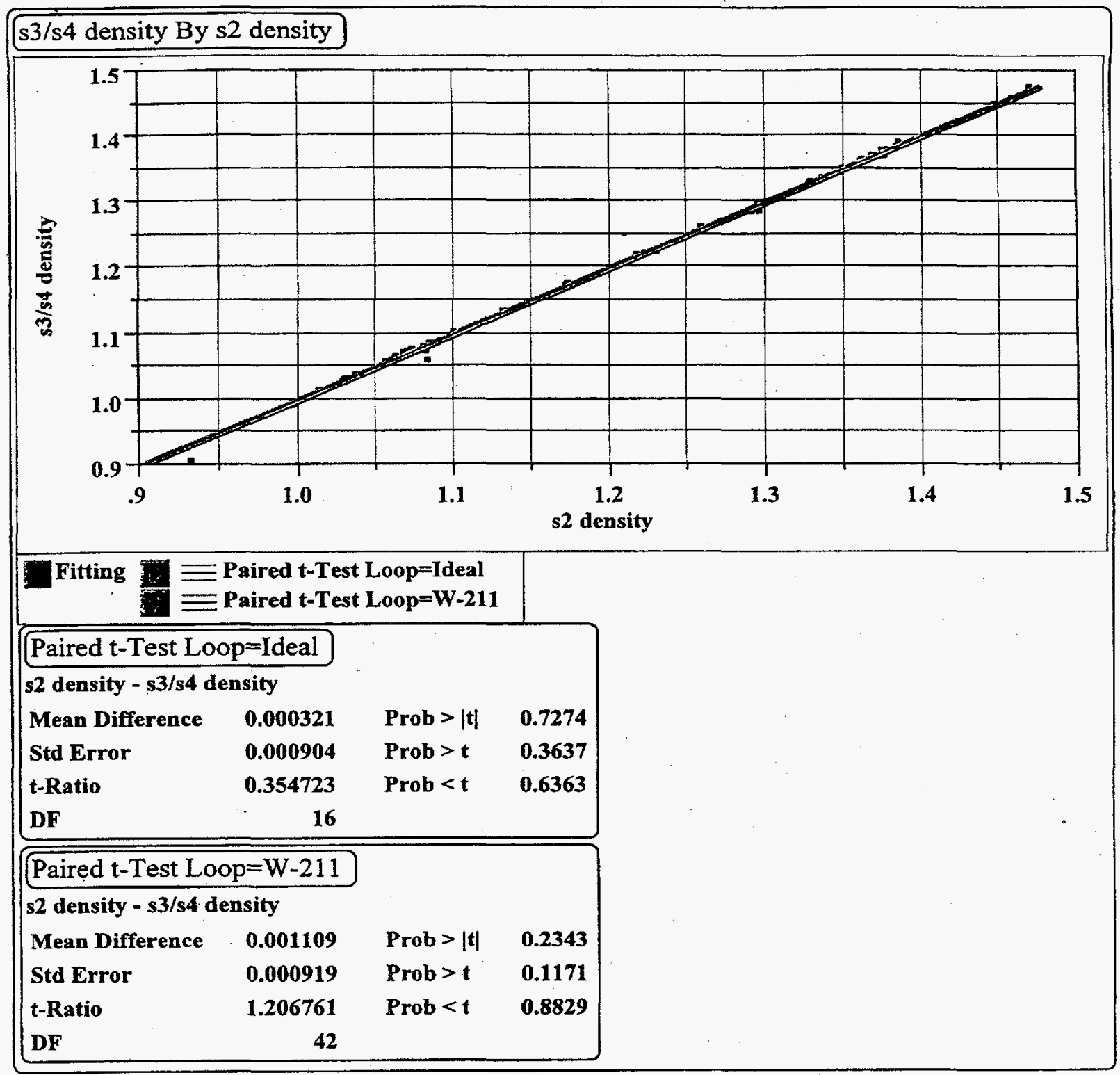

\section{Figure D-3; Grouped t-Test for S3/S4 Density vs S2 Density}

Since the best fit line of the two groups of data fall within the best upper and lower confidence limits of the two groups, the difference between the two groups is not statistically significant. Therefore, the S3/S4 average density is not affected by the design of the loop. 
Appendix D-4; t-Test for Micromotion vs. S3/S4 Average Densities 



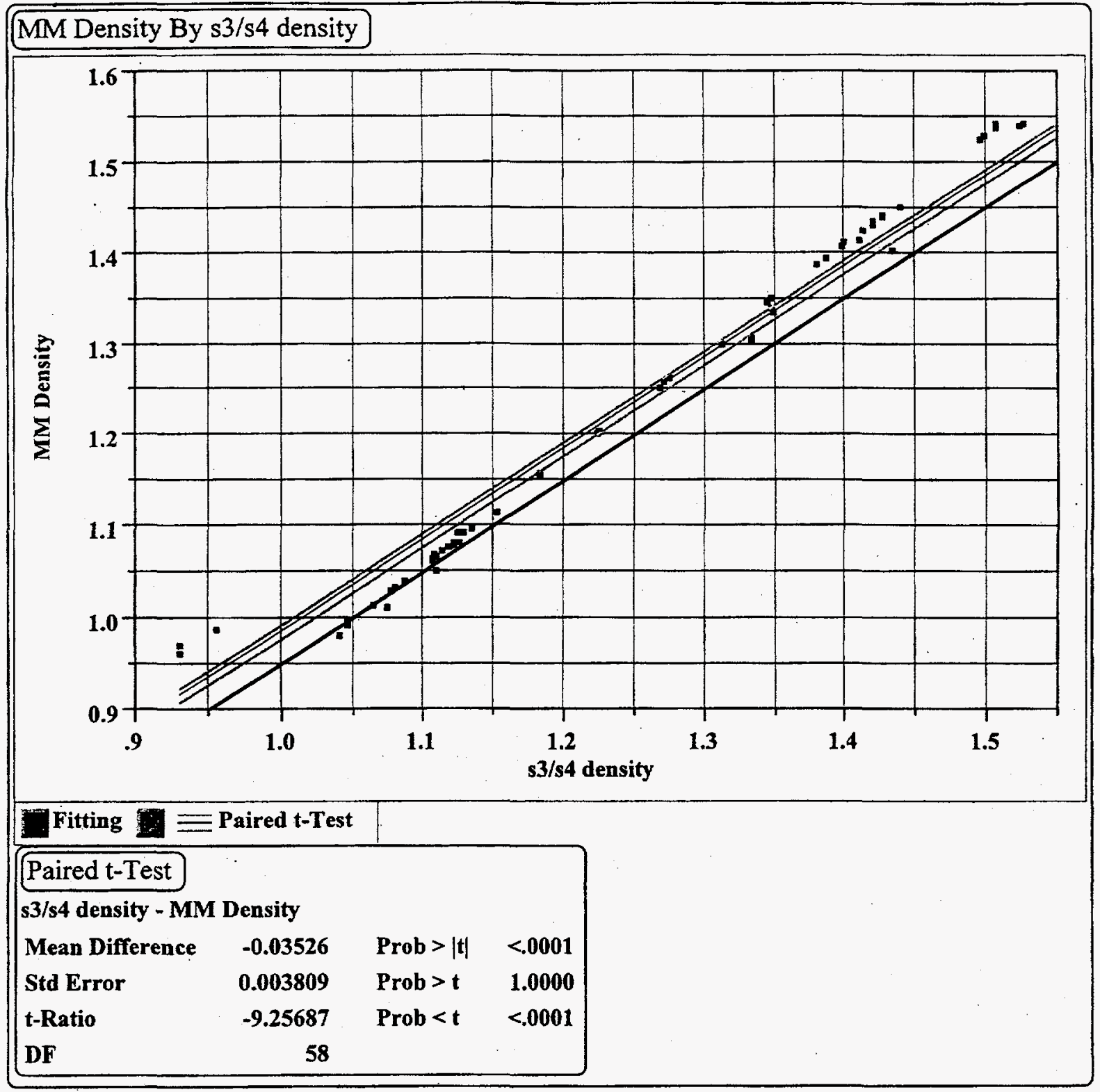

Figure D-4; t-Test for Micromotion Density vs S3/S4 Density

Since the $Y=X$ line does not fall within the best fit upper and lower confidence limits, the difference between the Micromotion density and the $\mathbf{S 3 / S 4}$ average density is statistically significant.

D.17 


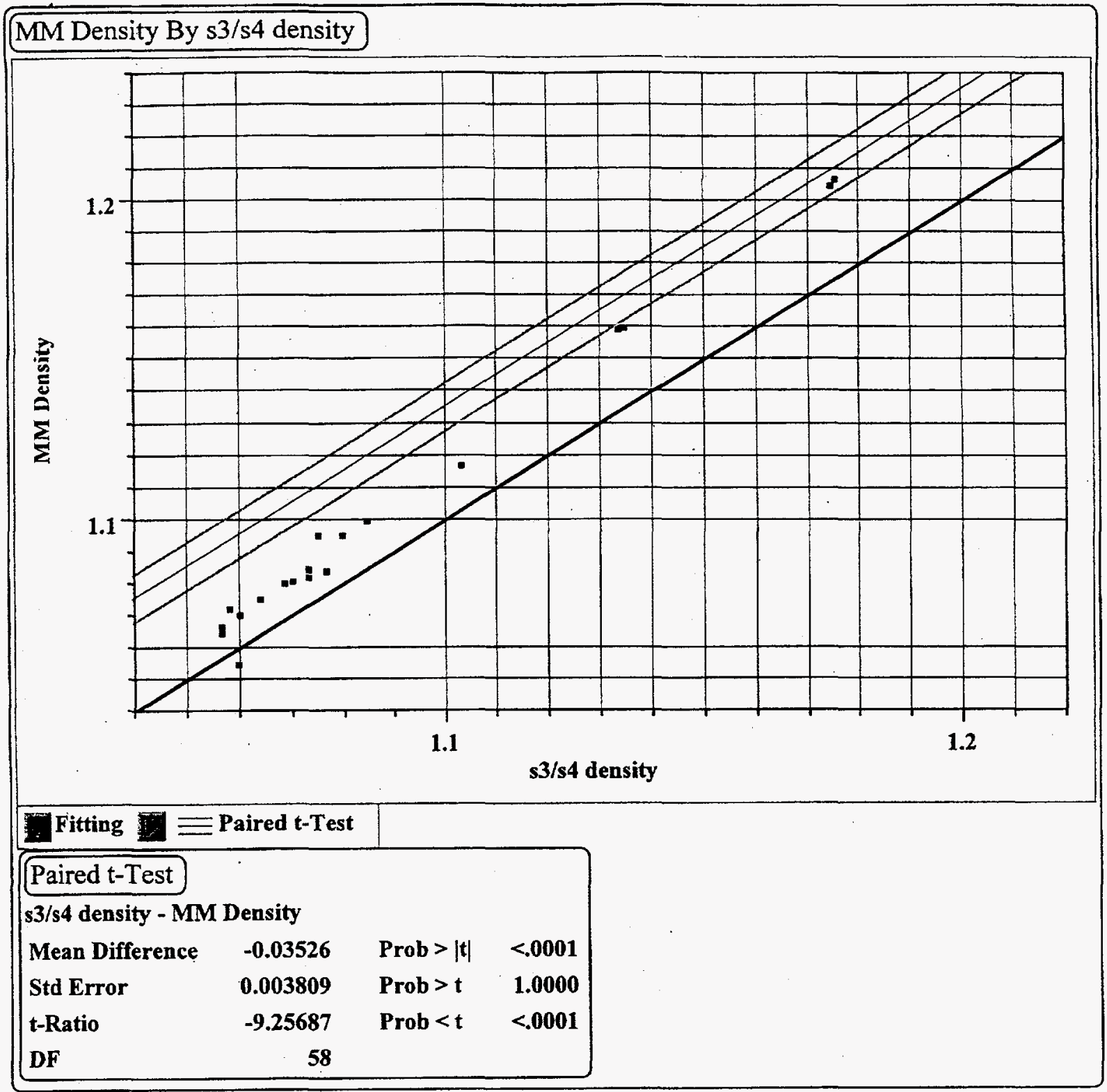

Figure D-4 (Blow-Up); t-Test for Micromotion Density vs S3/S4 Density

Since the $Y=X$ line does not fall within the best fit upper and lower confidence limits, the difference between the Micromotion density and the S3/S4 average density is statistically significant. 


\begin{tabular}{|l|l|l|l|l|l|l|l|l|l|l|l|}
\hline MM Density By s3/s4 density & \\
\hline
\end{tabular}

\section{Figure D-4; Grouped t-Test for Micromotion Density vs S3/S4 Density}

ince the best fit line of the two groups of data fall within the best fit upper and lower confidence limits of the two groups, the difference between the two groups is not statistically significant. Therefore, the Micromotion Densimeter works equally well in either loop. 


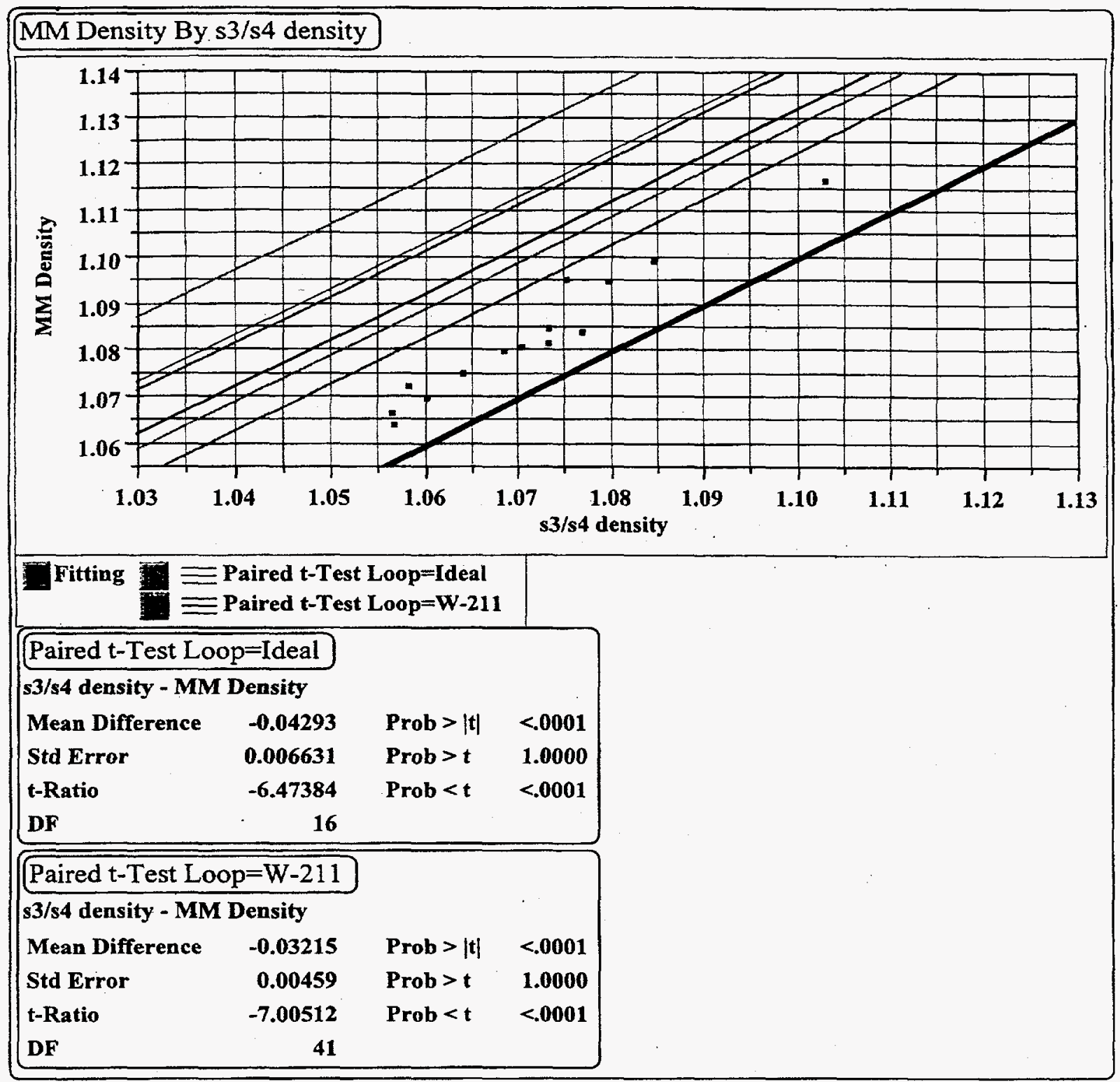

Figure D-4(Blow-Up); Grouped t-Test for Micromotion Density vs S3/S4 Density

ince the best fit line of the two groups of data fall within the best fit upper and lower confidence limits of the two groups, the difference between the two groups is not statistically significant. Therefore, the Micromotion Densimeter works equally well in either loop. 
Appendix D-5; t-Test for Micromotion vs. Calibration Tank Densities

D.21 



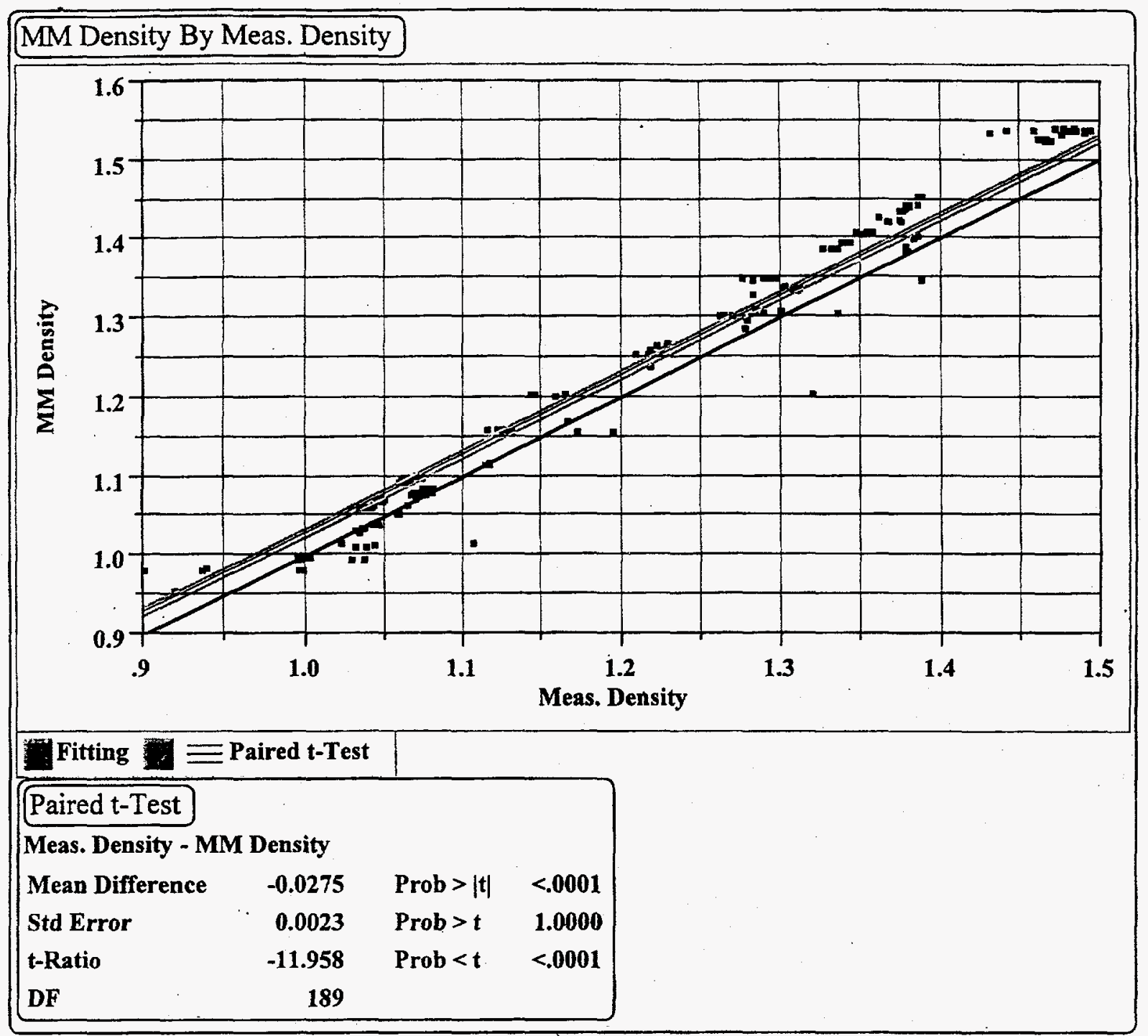

Figure D-5: t-Test for Micromotion Density vs Calibration Tank Measured Density

Since the $\mathrm{Y}=\mathrm{X}$ line does not fall within the best fit upper and lower confidence limits, the difference between the Micromotion density and the Denisty measured in the calibration feed tank is statistically significant. 


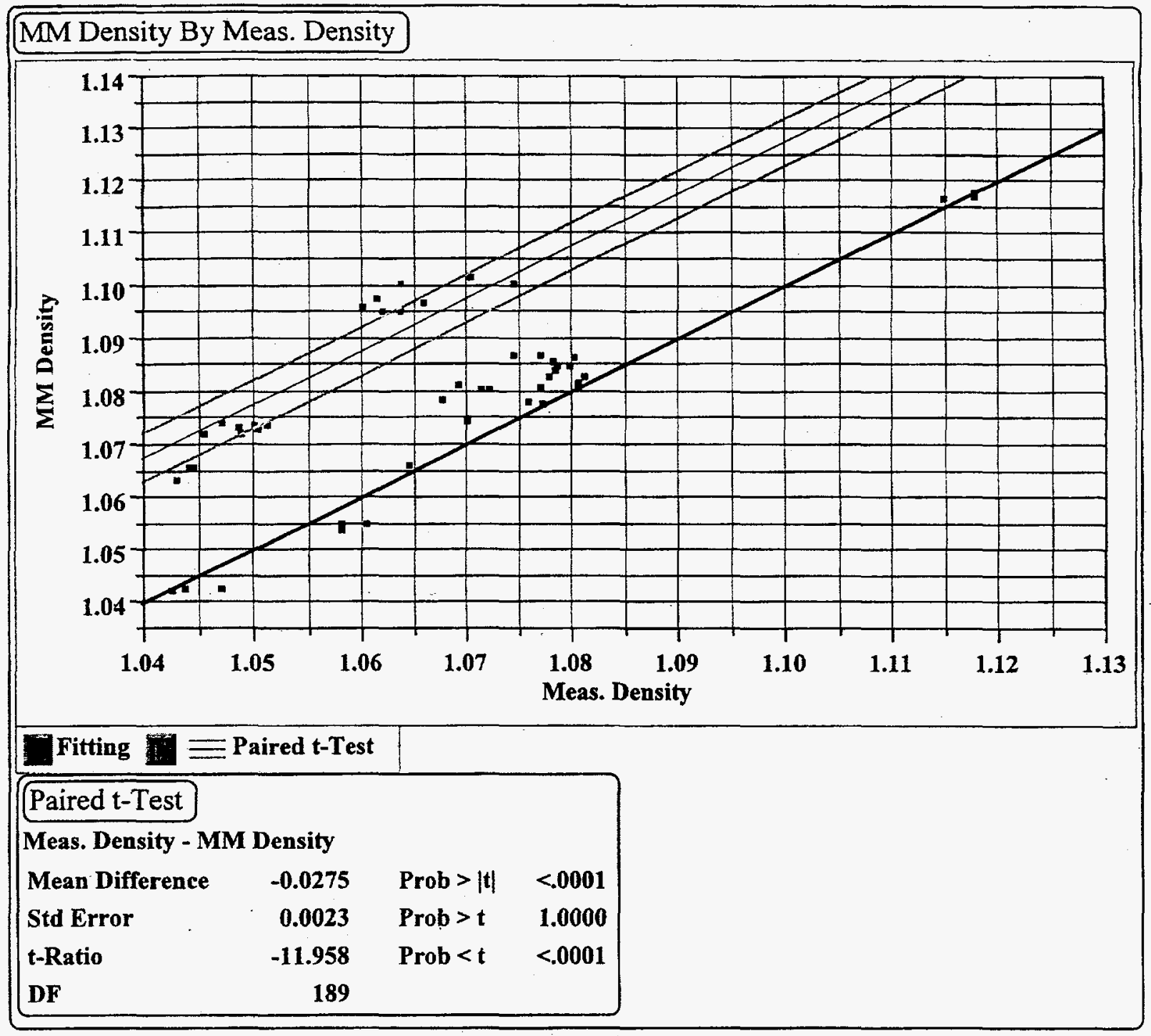

\section{Figure D-5 (Blow-Up): t-Test for Micromotion Density vs Calibration Tank Measured Density}

Since the $Y=X$ line does not fall within the best fit upper and lower confidence limits, the difference between the Micromotion density and the Denisty measured in the calibration feed tank is statistically significant. 


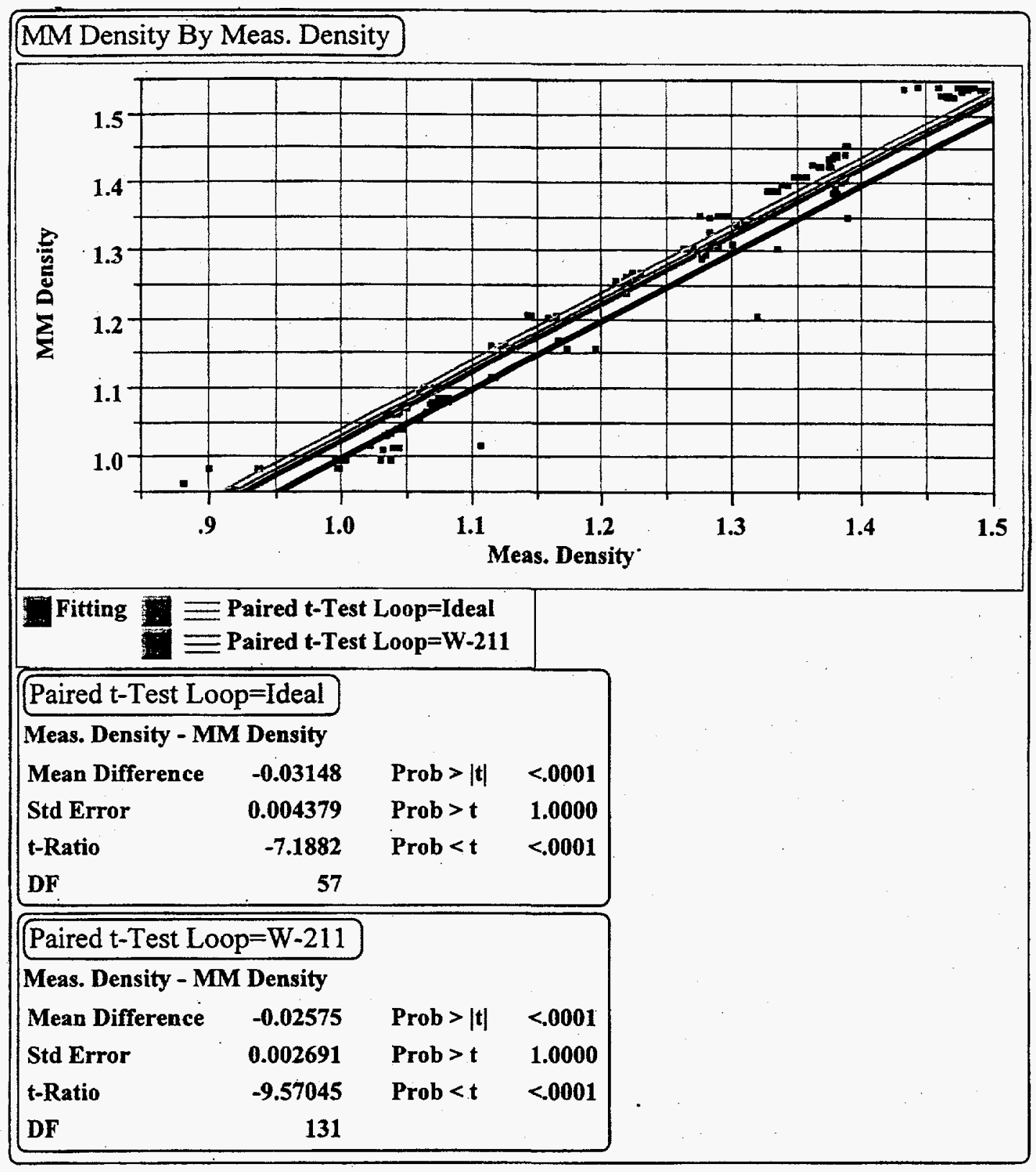

Figure D-5; Grouped t-Test for Micromotion Density vs Measured Density:

Since the best fit line of the two groups of data fall within the best fit upper and lower confidence limits of the two groups, the difference between the two groups is not statistically significant. Therefore, the Micromotion Densimeter works equally well in either loop. 


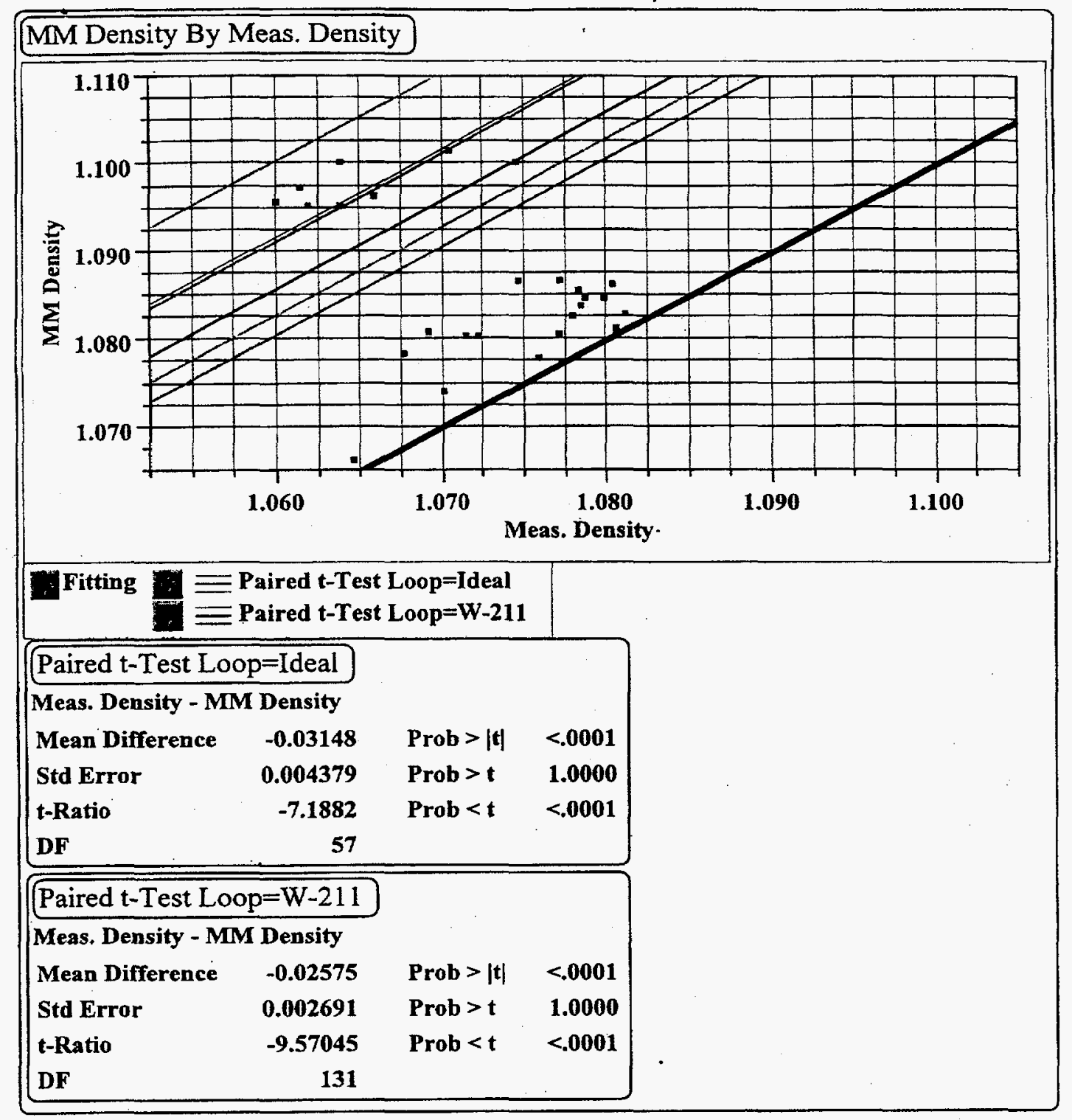

Figure D-5 (Blow-Up) ; Grouped t-Test for Micromotion Density vs Measured Density:

Since the best fit line of the two groups of data fall within the best fit upper and lower confidence limits of the two groups, the difference between the two groups is not statistically significant. Therefore, the Micromotion Densineter works equally well in either loop. 
Appendix D-6; t-Test for Yokagawa vs. Fisher \& Porter Flow Rates 


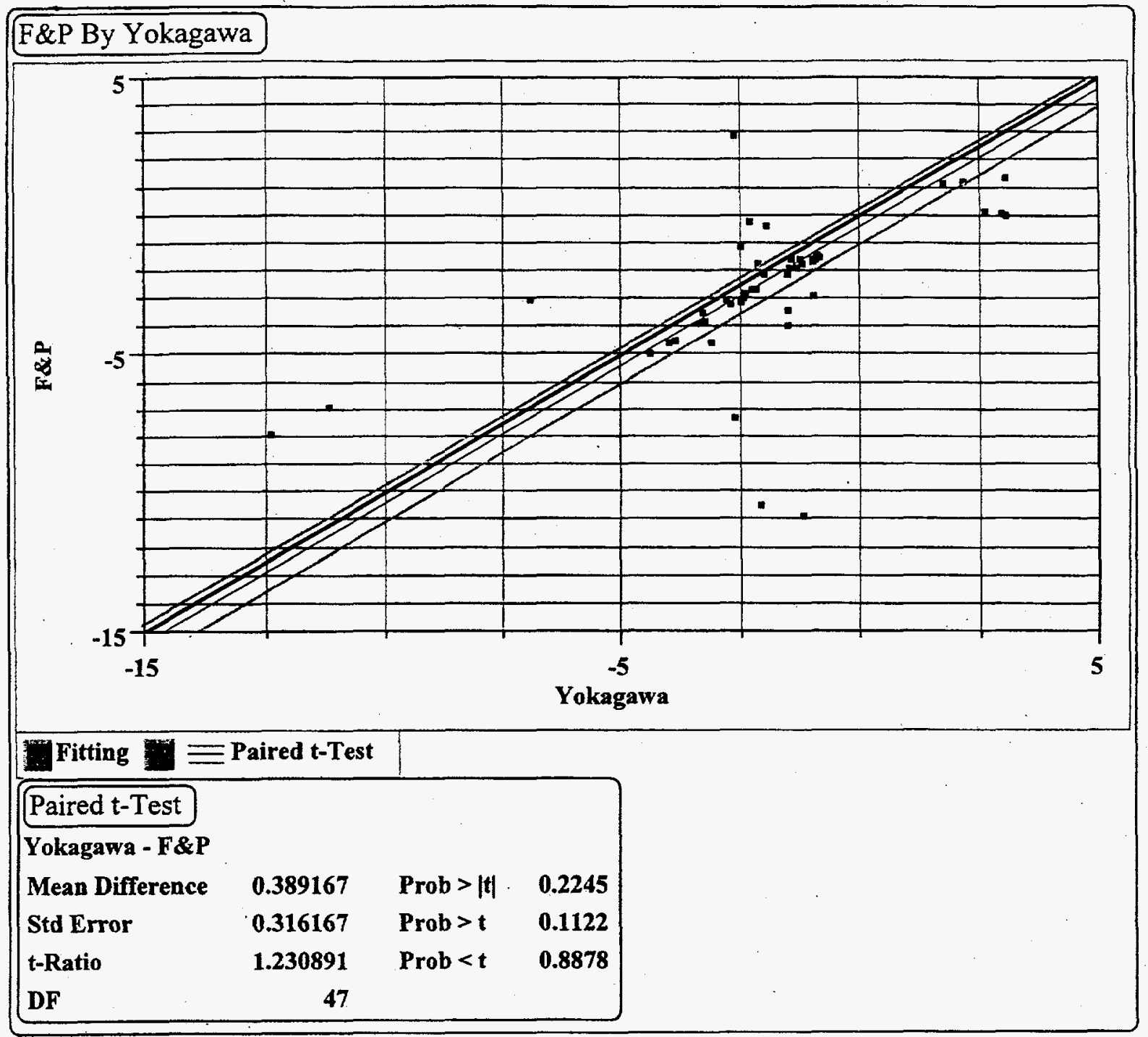

Figure D-6; t-Test for Yokagawa vs. Fischer \& Porter Flow Meter

Since the $Y=X$ line falls inside the best fit upper and lower cofidence limits, the difference between the two flow meters is not statistically significant. This analysis is with the data from runs $5 B 0$ and $5 B 1$ excluded due to the fouling of the electrodes and due to the exclusions of an outlier in run $5 \mathrm{AO}$ and $4 \mathrm{A3}$ 

Appendix D-7; t-Test for Micromotion vs. Yokagawa Flow Rates 



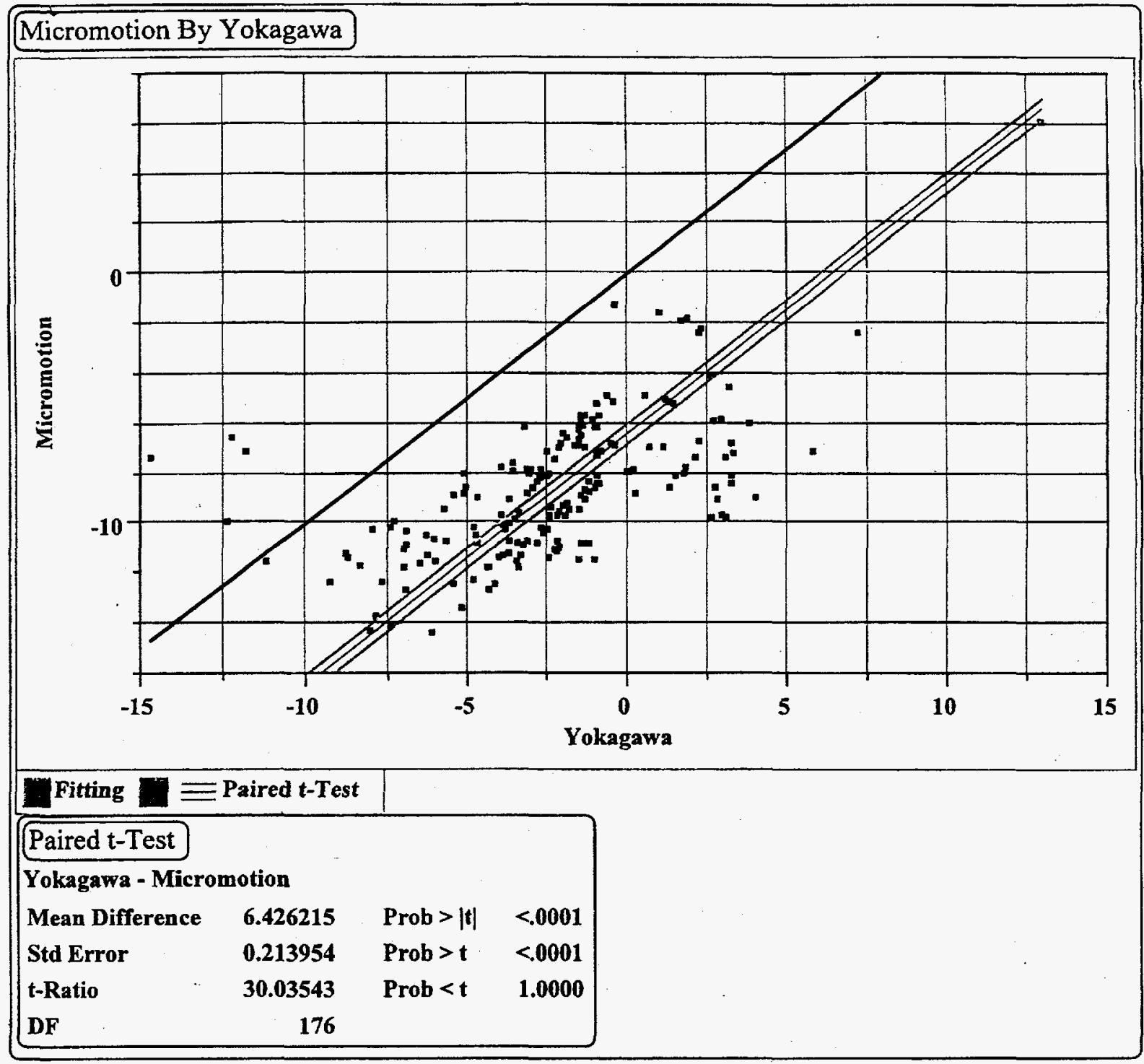

Figure D-7; t-Test for Micromotion Flow rate vs Yokagawa Flow Rate

Since the $Y=X$ line does not fit within the best fit upper and lower confidence limits, the difference between the two flow meters is statistically significant. This analysis was done with Run 5B1 from the W-211 loop testing, Runs 5B and 5B1 from the "Ideal" Loop testing and one outlier from 5A "Ideal" excluded.

D. 33 


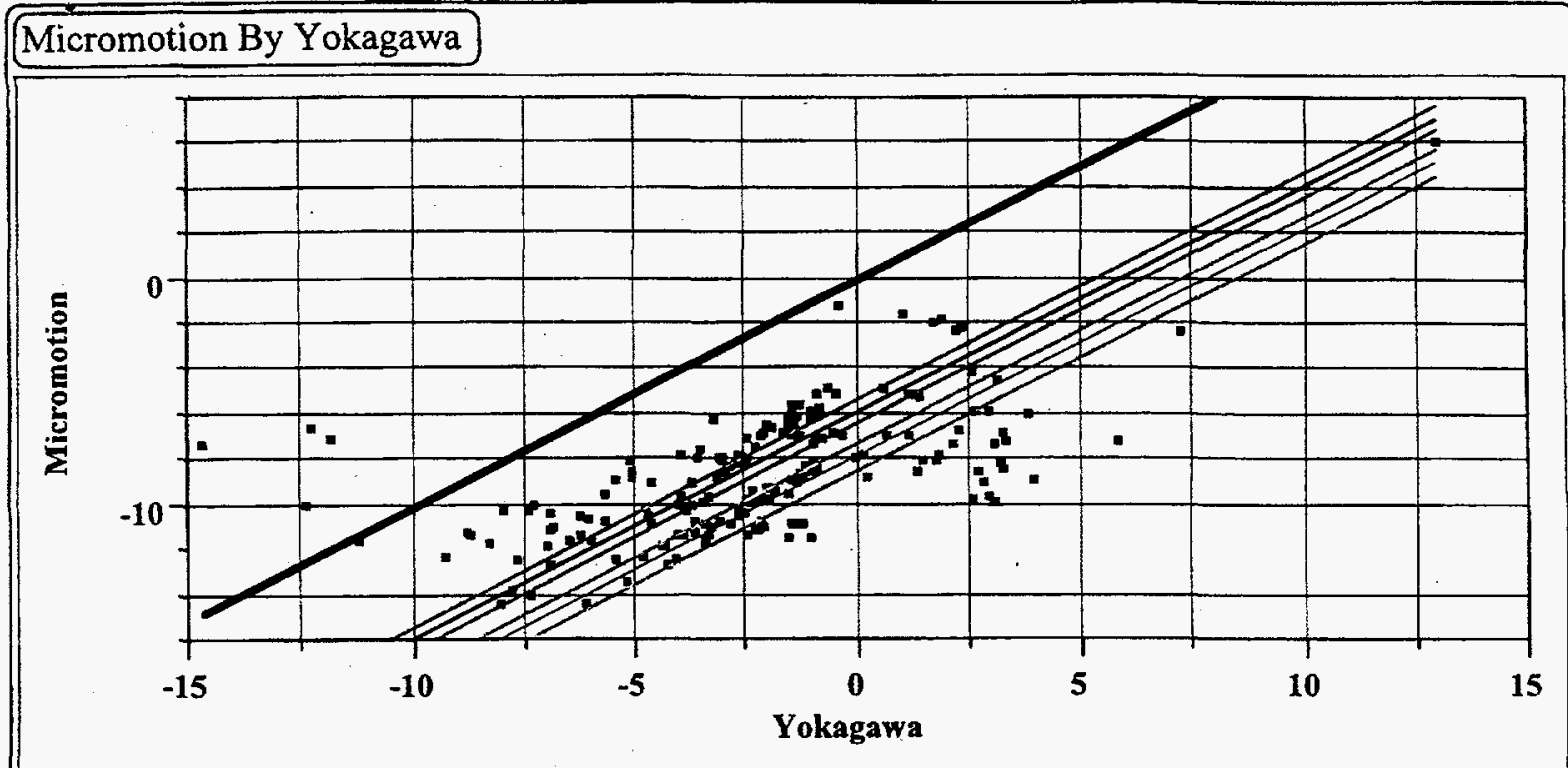

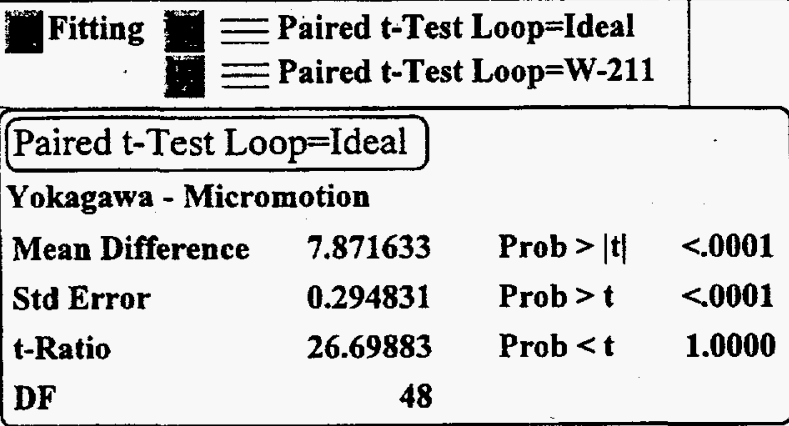

Paired t-Test Loop=W-211

Yokagawa - Micromotion

\begin{tabular}{|lrll} 
Mean Difference & 5.872891 & Prob $>|t|$ & $<.0001$ \\
Std Error & 0.257756 & Prob $>t$ & $<.0001$ \\
t-Ratio & 22.78467 & Prob $<t$ & 1.0000 \\
DF & 127 & & \\
\hline
\end{tabular}

\section{Figure D-7; Grouped t-Test for Micromotion vs Yokagawa Flow Rates}

Since the best fit line from the two groups do not fit within the upper and lower confidence limits of the ther group, the difference between thm is statistically significantly. This analysis was done with Run 5B1 from the W-211 loop testing, Runs 5B and 5B1 from the "Ideal" Loop testing and one outlier from 5A "Ideal" excluded. 
Appendix D-8; Yokagawa, Micromotion,

Fischer \& Porter Data Distributions

D. 35 



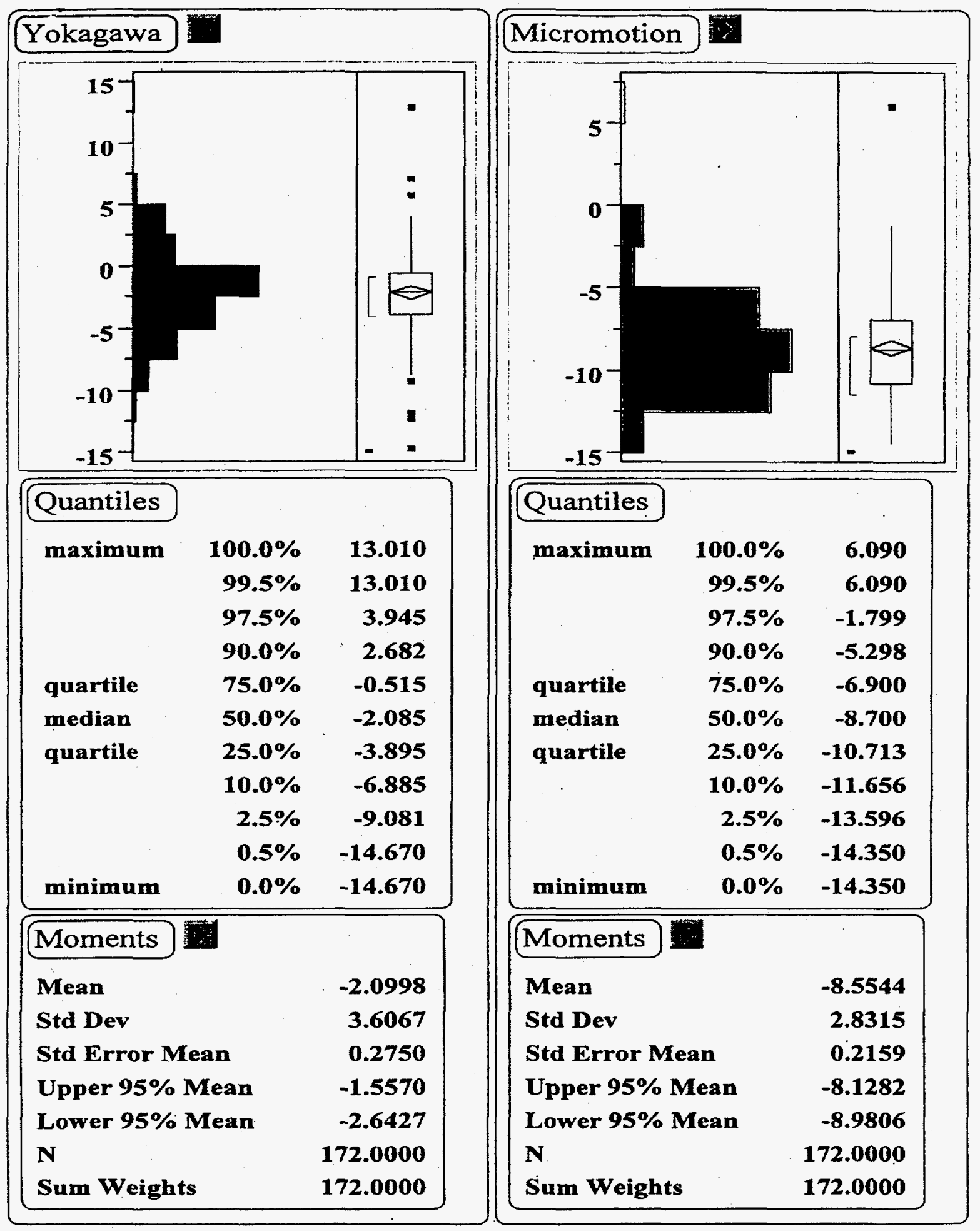



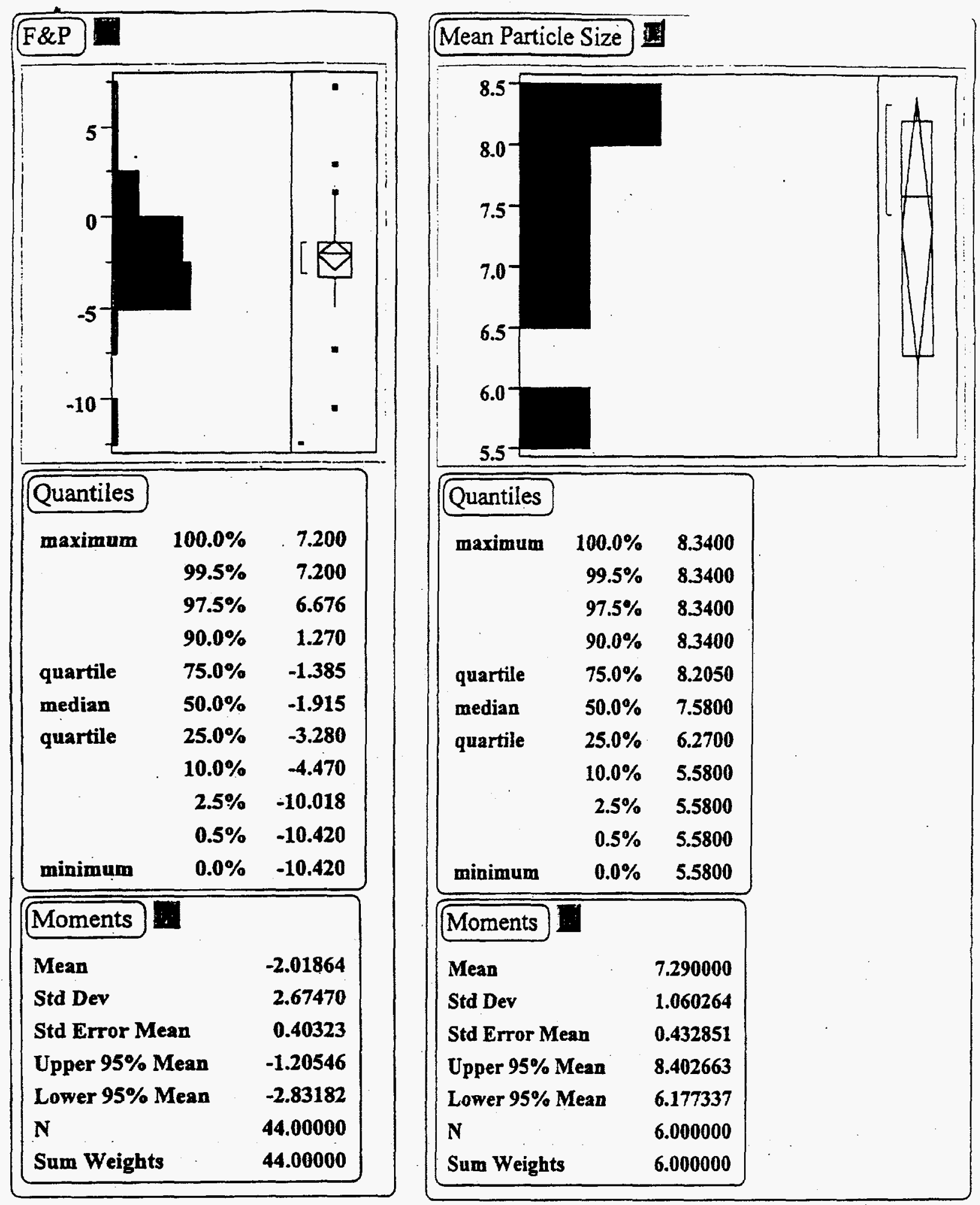

D. 38 
Appendix E

Lasentec Calibration 



\section{Appendix E}

\section{Lasentec Calibration}

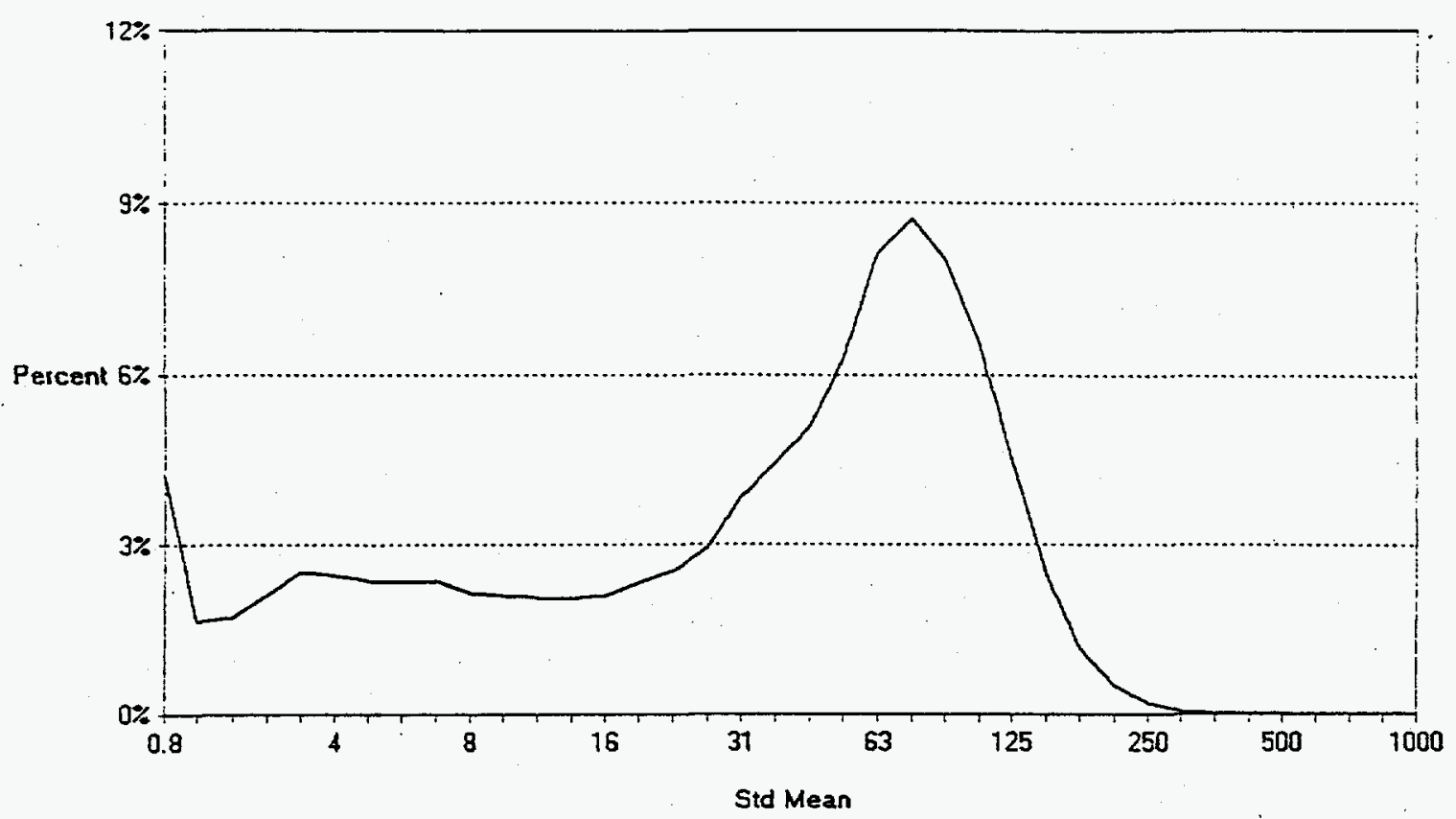

Figure E.1. LASENTEC Measurement Analysis

E. 1 


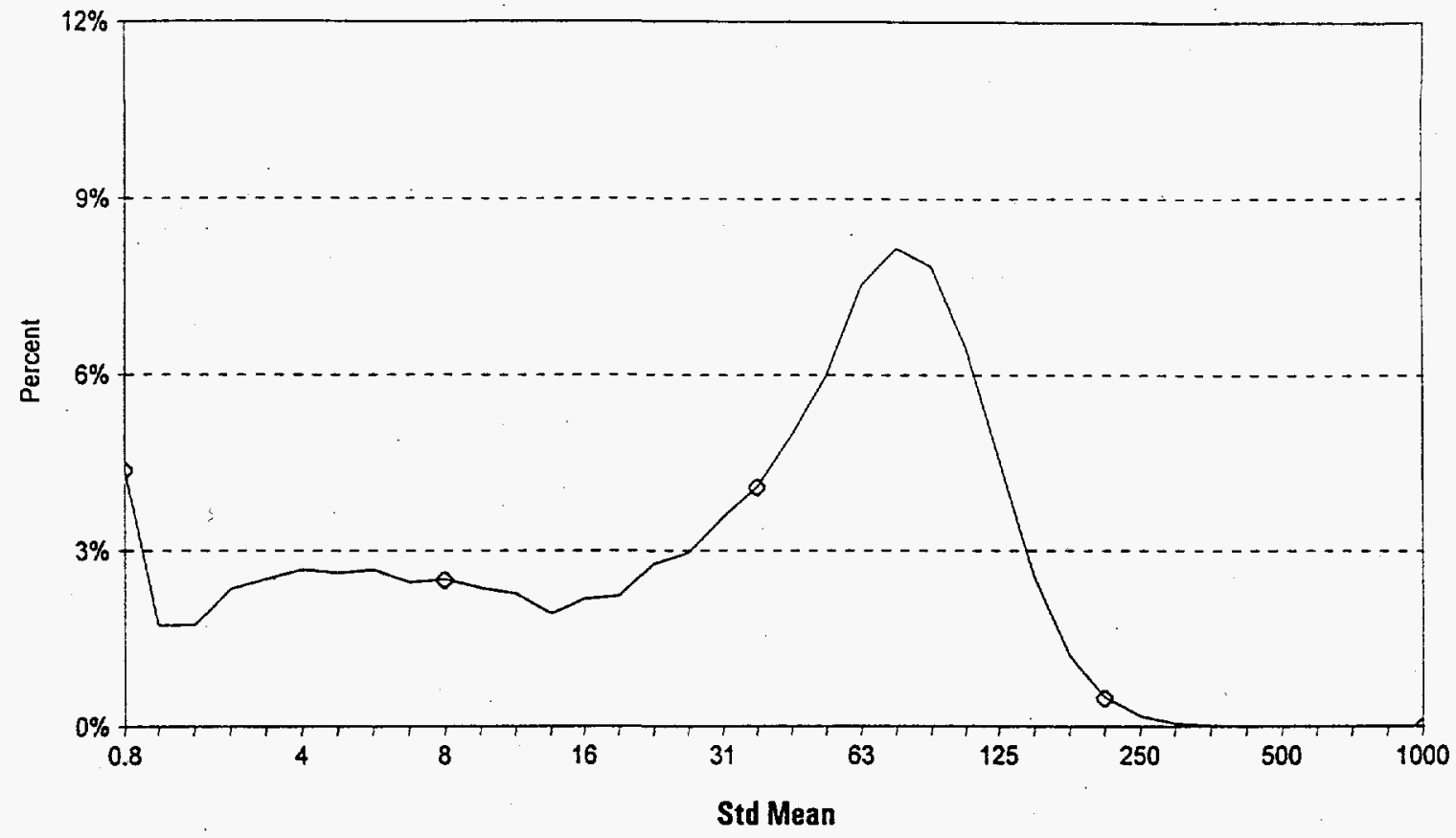

Figure E.2. LASENTC Compare Analysis 